\title{
AppRecommender: um recomendador de aplicativos GNU/Linux
}

\author{
Tássia Camões Araújo \\ DISSERTAÇÃO APRESENTADA \\ $\mathrm{AO}$ \\ Instituto De Matemática e Estatística \\ DA \\ Universidade De SÃo Paulo \\ PARA \\ OBTENÇÃO DO TÍTULO \\ $\mathrm{DE}$ \\ Mestre em CiênCIAS \\ Programa: Ciência da Computação \\ Orientador: Prof. Dr. Arnaldo Mandel
}

Durante o desenvolvimento deste trabalho a autora recebeu auxílio financeiro do $\mathrm{CNPq}$

São Paulo, novembro de 2011 



\section{AppRecommender: um recomendador de aplicativos GNU/Linux}

Esta dissertação contém as correções e alterações sugeridas pela Comissão Julgadora durante a defesa realizada por Tássia Camões Araújo em 30/09/2011.

O original encontra-se disponível no Instituto de Matemática e Estatística da Universidade de São Paulo.

Comissão Julgadora:

- Prof. Dr. Arnaldo Mandel (orientador) - IME-USP

- Prof. Dr. Marco Aurélio Gerosa - IME-USP

- Prof. Dr. Paulo Lício de Geus - UNICAMP 



\section{Agradecimentos}

Dedico este espaço a pessoas de extrema importância para a execução deste trabalho. Ao professor Imre Simon, por ter me convencido a me inscrever no mestrado. Ao professor Arnaldo Mandel por ter me recebido e orientado na medida certa. A Otávio Salvador, grande amigo e desenvolvedor Debian que cedeu uma robusta máquina virtual para realização dos experimentos. A Tiago Vaz, meu companheiro de todos os projetos e a minha querida família, que sempre me acompanha nas minhas andanças. Por fim, um super obrigada a todos que testaram o recomendador, participaram da consulta pública, assistiram ao ensaio da defesa, revisaram o texto ou colaboraram com o projeto de alguma outra forma. 



\section{Resumo}

A crescente oferta de programas de código aberto na rede mundial de computadores expõe potenciais usuários a muitas possibilidades de escolha. Em face da pluralidade de interesses desses indivíduos, mecanismos eficientes que os aproximem daquilo que buscam trazem benefícios para eles próprios, assim como para os desenvolvedores dos programas. Este trabalho apresenta o AppRecommender, um recomendador de aplicativos GNU/Linux que realiza uma filtragem no conjunto de programas disponíveis e oferece sugestões individualizadas para os usuários. Tal feito é alcançado por meio da análise de perfis e descoberta de padrões de comportamento na população estudada, de sorte que apenas os aplicativos considerados mais suscetíveis a aceitação sejam oferecidos aos usuários.

Palavras-chave: Sistemas de recomendação, aplicativos, pacotes Debian, filtragem colaborativa, distribuições GNU/Linux, Debian GNU/Linux. 



\begin{abstract}
The increasing availability of open source software on the World Wide Web exposes potential users to a wide range of choices. Given the individuals plurality of interests, mechanisms that get them close to what they are looking for would benefit users and software developers. This work presents AppRecommender, a recommender system for GNU/Linux applications which performs a filtering on the set of available software and individually offers suggestions to users. This is achieved by analyzing profiles and discovering patterns of behavior of the studied population, in a way that only those applications considered most prone to acceptance are presented to users.
\end{abstract}

Keywords: Recommender systems, applications, Debian packages, collaborative filtering, GNU/Linux distributions, Debian GNU/Linux. 



\section{Sumário}

Sumário $\quad$ xi

Lista de Figuras $\quad$ xiii

Lista de Tabelas $\quad$ xv

1 Introdução 1

2 Distribuições GNU/Linux 5

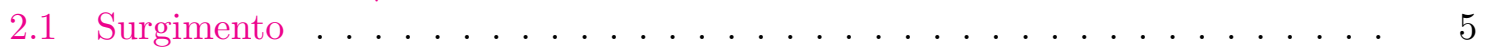

2.2 Empacotamento de programas . . . . . . . . . . . . 6

2.3 Relação entre pacotes . . . . . . . . . . . . . . . . . . 7

2.4 Sistemas gerenciadores de pacotes . . . . . . . . . . . . . 8

2.5 Seleção de programas . . . . . . . . . . . . . . . . . . . . 11

3 Sistemas de recomendação $\quad 13$

3.1 Contexto histórico . . . . . . . . . . . . . . . . . . . . . . 13

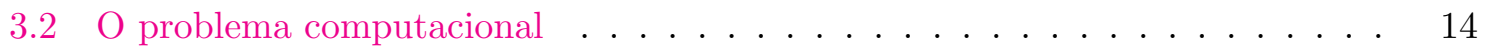

3.3 Ações e desafios . . . . . . . . . . . . . . . . . . . . . . . . . . 14

3.4 Seleção de atributos . . . . . . . . . . . . . . . . . . . . . 15

3.5 Estratégias de recomendação . . . . . . . . . . . . . . . . . . 16

3.6 Técnicas comumente utilizadas . . . . . . . . . . . . . . . . . 20

3.7 Avaliação de recomendadores . . . . . . . . . . . . . . . . . . . . 21

3.8 Segurança da informação . . . . . . . . . . . . . . . . . . 26

4 Trabalhos correlatos $\quad \mathbf{2 7}$

4.1 Anapop/Popsuggest . . . . . . . . . . . . . . . . . . 27

4.2 Debommender . . . . . . . . . . . . . . . . . . . . 27

4.3 Mineração de dados do Popcon . . . . . . . . . . . . . . . . . . . 28

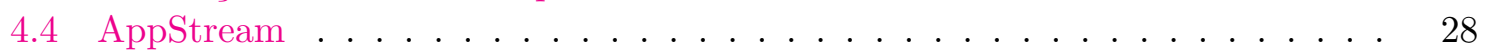

4.5 Armazenamento de avaliações e comentários . . . . . . . . . . . . . . . 29

4.6 Recomendadores para dispositivos móveis . . . . . . . . . . . . . . . 29

5 AppRecommender $\quad 31$

5.1 Caracterização do problema . . . . . . . . . . . . . . . . . . . . . . . . . . . .

5.2 Escolha da plataforma . . . . . . . . . . . . . . . . . . . 31

5.3 Fontes de dados . . . . . . . . . . . . . . . . . . . . . . . 33

5.4 Decisões de projeto . . . . . . . . . . . . . . . . . . . 38

5.5 Estratégias de recomendação . . . . . . . . . . . . . . 43 
5.6 Protótipo do AppRecommender . . . . . . . . . . . . . . . 45

6 Avaliação da proposta $\quad 49$

6.1 Fase 1: Experimentos offline . . . . . . . . . . . . . . . . 49

6.2 Fase 2: Consulta pública . . . . . . . . . . . . . . . . 59

7 Considerações finais $\quad 63$

$\begin{array}{lr}\text { Referências Bibliográficas } & 67\end{array}$

$\begin{array}{ll}\text { A Técnicas } & \mathbf{7 1}\end{array}$

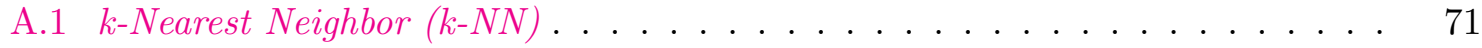

A.2 Agrupamento . . . . . . . . . . . . . . . . . . . 72

A.3 Classificador bayesiano . . . . . . . . . . . . . . . . . 72

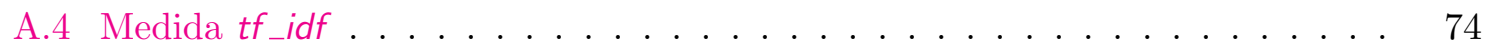

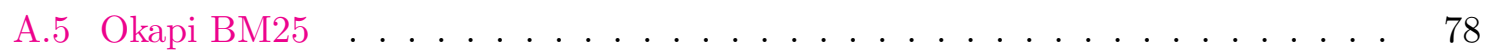

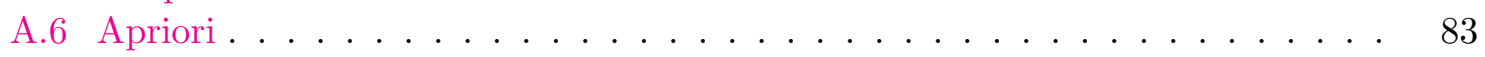

$\begin{array}{ll}\text { Índice Remissivo } & 87\end{array}$ 


\section{Lista de Figuras}

2.1 Extração do conteúdo de um pacote . . . . . . . . . . . . . . . . 7

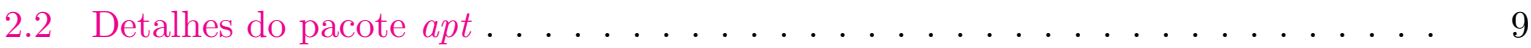

2.3 Captura de tela do Synaptic . . . . . . . . . . . . . . . . . . . . . . . 10

2.4 Captura de tela do Software Center . . . . . . . . . . . . . . . . . . . 10

3.1 Avaliação de usuário no IMDb . . . . . . . . . . . . . . . . . . . 16

3.2 Quadrinho sobre cálculo de média em avaliações . . . . . . . . . . . . . . . . . 17

3.3 Cenário de uma recomendação baseada em conteúdo . . . . . . . . . . . . . . . 18

3.4 Cenário da recomendação colaborativa . . . . . . . . . . . . . . . . . . 18

3.5 Recomendação por associação na Amazon . . . . . . . . . . . . . . . . . . 19

3.6 Ilustração do espaço ROC . . . . . . . . . . . . . . . . . . . . . . . . . . . 24

3.7 Exemplos de gráficos ROC $[$ Fawcett 2007] . . . . . . . . . . . . . . . . 24

5.1 Excerto da base do Debtags . . . . . . . . . . . . . . . . . . . . . 34

5.2 Lista de termos indexados para o pacote 2vcard . . . . . . . . . . . . . . 34

5.3 Exemplo de submissão do Popcon . . . . . . . . . . . . . . . . . 35

5.4 Fluxo de dados no UDD [Nussbaum and Zacchiroli 2010] . . . . . . . . . . . 37

5.5 Exemplo consulta ao plugin BTS . . . . . . . . . . . . . . . 38

5.6 Fluxo de dados no AppRecommender . . . . . . . . . . . . . . . . . . 39

5.7 Execução do recomendador para o sistema local . . . . . . . . . . . . . . 46

6.1 Distribuição de submissões do Popcon por tamanho de perfil . . . . . . . . . . 50

6.2 Aplicação de métricas para recomendação de 10 (esquerda) e 100 itens (direita) . 51

6.3 Registro de execução de experimento . . . . . . . . . . . . . . . . . 51

6.4 Cobertura como limitante ou indicador de melhor desempenho . . . . . . . . . 52

6.5 Cobertura em estratégias híbridas favorecida pela colaboração . . . . . . . . . . 54

6.6 Desempenho limitado pela cobertura em estratégias híbridas . . . . . . . . . 54

6.7 Resultados similares para estratégias cb e cbd . . . . . . . . . . . . 54

6.8 Resultados similares para estratégias cb_eset e cbd_eset . . . . . . . . 55

6.9 Desempenho insatisfatório de estratégias baseadas em conteúdo para limiar 100 . 55

6.10 Validação cruzada favorece vizinhanças pequenas . . . . . . . . . . . . . 56

6.11 Comportamento diferenciado para knn_eset com limiar $10 \ldots \ldots$. . . . . . . 56

6.12 Curva ROC média (esquerda) e com desvios (direita) de um recomendador cbt . $\quad 57$

6.13 Registro de desenho da curva ROC . . . . . . . . . . . . . . . . . 58

6.14 Curva ROC média (esquerda) e com desvios (direita) para estratégia knn . . . . 58

6.15 Curva ROC média (esquerda) e com desvios (direita) para estratégia knn_plus . 58

6.16 Curva ROC média (esquerda) e com desvios (direita) para estratégia knnco . . . 59

6.17 Descarte de modelo com comportamento inesperado . . . . . . . . . . . . . 60 
6.18 Interface da consulta pública . . . . . . . . . . . . . . 61

A.1 Eliminação de stop words e normalização do documento por stemming . . . . . . 74

A.2 Coleção de documentos . . . . . . . . . . . . . . . . . . 75

A.3 Conjunto das partes ilustrado por um diagrama de Hasse . . . . . . . . . . . . . . 84

A.4 Geração de conjuntos candidatos pelo algoritmo Apriori . . . . . . . . . . . . . 85 


\section{Lista de Tabelas}

2.1 Papéis exercidos por desenvolvedores no Debian . . . . . . . . . . . . . . 7

2.2 Descrição das relações entre pacotes Debian . . . . . . . . . . . . . . . . . 8

3.1 Métodos de hibridização . . . . . . . . . . . . . . . . . . . 20

3.2 Matriz de contingência de uma recomendação . . . . . . . . . . . . . . . . 22

3.3 Métricas de acurácia de sistemas preditivos . . . . . . . . . . . . . 25

5.1 Descrição do formato de uma submissão popcon . . . . . . . . . . . . . . . 35

5.2 Descrição das estratégias de recomendação implementadas . . . . . . . . . . . . . 45

5.3 Descrição dos parâmetros ajustáveis do AppRecommender . . . . . . . . . . . . 46

6.1 Melhores desempenhos para 10 sugestões . . . . . . . . . . . . . . . . 52

6.2 Melhores desempenhos para 100 sugestões . . . . . . . . . . . . . . . . . 53

6.3 Melhores desempenhos analisados por curvas ROC . . . . . . . . . . . . . 59

6.4 Desempenho das estratégias na consulta pública . . . . . . . . . . . . 62

A.1 Medidas de distância e similaridade entre objetos . . . . . . . . . . . . . . 71

A.2 Frequência dos termos nos documentos da coleção . . . . . . . . . . . . . 75

A.3 Valores de $i d f_{t}$ para termos do dicionário . . . . . . . . . . . 76

A.4 Ordenação dos documentos como resultado das consultas $q_{1}, q_{2}$ e $q_{3} \ldots \ldots$. . . 77

A.5 Representação da coleção no modelo de espaço vetorial . . . . . . . . . . . . . . . 77

A.6 Representação das queries no modelo de espaço vetorial . . . . . . . . . . . . . 78

A.7 Tabela de contingência da incidência dos termos . . . . . . . . . . . . . . 81 



\section{Capítulo 1}

\section{Introdução}

A facilidade de comunicação proporcionada pela Internet tem estimulado cada vez mais as formas de trabalho colaborativas. No âmbito do desenvolvimento de programas de computador, verificamos na prática o que muitos autores consideram como o maior exemplo deste fenômeno: o movimento do software livre; a construção coletiva de uma ampla gama de software de qualidade, em constante atualização e evolução [Simon and Vieira 2008]. Outro ponto defendido é que a qualidade do esforço coletivo aumentou ao longo do tempo devido à diversidade dos colaboradores envolvidos. Esta diversidade é refletida claramente na variedade de projetos disponíveis na grande rede, compondo um ecossistema que reúne os interessados por meio de fóruns na Web, listas de discussão, canais IRC, sistemas para notificação de falhas, conferências etc.

O SourceForge ${ }^{1}$, popular repositório de programas na Internet, possui atualmente mais de 300.000 projetos cadastrados ${ }^{2}$, superando a marca de 2 milhões de usuários registrados. Os benefícios desse fenômeno para o público são muitos, uma vez que, além de contar com programas de alta qualidade técnica, licenciamento livre e uso gratuito, os interessados podem também ter participação direta no processo de desenvolvimento.

Esta abundância de projetos, que por um lado oferece inúmeros benefícios, pode também implicar num fator complicador para os próprios usuários. O excessivo montante de informação pode prejudicar o processo de escolha, enredando o usuário num labirinto de resultados inesperados, possivelmente distantes do que seria sua real preferência. É comum referir-se a esse fenômeno (p. ex., [Iyengar 2010]) como "mais é menos", no sentido de que o aumento da disponibilidade de escolhas pode confundir o usuário e diminuir sua satisfação.

A título de exemplo, uma pesquisa pelo termo webserver no SourceForge retorna 620 projetos cadastrados. O usuário então define seus critérios para continuar uma análise mais apurada, eliminando nesta etapa o que certamente não é adequado para o seu ambiente. Um administrador de um sistema crítico, por exemplo, investigaria o histórico de falhas de segurança do software; para um hardware modesto, a exemplo de netbooks e smartphones, dá-se preferência a aplicativos de baixo custo computacional; já um usuário de desktop usualmente tem interesse por aplicativos atualizados, o que demanda uma comunidade de desenvolvimento ativa; uma empresa necessita de programas com termos de licenciamento claros, de modo a evitar eventuais conflitos jurídicos; programas com alto índice de popularidade - tipicamente mensurados pela quantidade de downloads - destacam-se na preferência dos usuários de maneira geral.

Notamos portanto uma infinita gama de possibilidades no que diz respeito aos critérios

\footnotetext{
${ }^{1}$ http: //www. sourceforge.net

${ }^{2}$ Em 2 de setembro de 2011 o SourceForge registra 308.307 projetos, sendo que 180.127 estão sob licenciamento aprovado pela Open Source Initiave, que tratam das licenças de software livre e código aberto mais populares.
} 
para seleção de um software. Há também uma variedade de fontes a se consultar com o objetivo de colocar lado a lado aqueles requisitos e o que o programa de fato oferece, com o objetivo de continuar o processo de filtragem. Pode-se consultar estatísticas de commits de código, atividades em listas de e-mail, bugs não resolvidos nos sistemas de notificação de falhas (bug tracking systems), histórico de falhas nos boletins de segurança, últimas novidades nos blogs dos projetos etc. Algumas dessas informações são apresentadas como opções de filtragem nos próprios repositórios, como ocorre no SourceForge. No entanto, após uma série de filtragens de caráter manual, como a leitura das descrições daquilo que ainda não foi filtrado, comumente o usuário ainda encara uma quantidade razoável de opções, das quais muitas são inadequadas para suas necessidades e demandam análises ainda mais minuciosas.

Até este ponto relatamos o que tipicamente ocorre com usuários dotados de certa habilidade, que sabem onde e como realizar as buscas, além de serem capazes de definir seus critérios embasados em conhecimento de caráter técnico. Temos por outro lado o usuário regular de desktop, que utiliza programas de computador como meio para outras atividades, não tem conhecimentos técnicos aprofundados e muitas vezes é limitado pela barreira do idioma. Nesse contexto, repositórios como o SourceForge não são de grande utilidade. Estes usuários requerem um sistema simples, no seu idioma e de preferência presente no seu ambiente doméstico de trabalho, que os auxiliem a fazer escolhas acerca de quais aplicativos instalar.

A inexistência de um sistema livre capaz de oferecer tais recomendações motivou a concepção e desenvolvimento do AppRecommender. Um recomendador de aplicativos exerceria papel relevante em ambos os contextos ilustrados, pois independentemente da habilidade ou conhecimento do usuário, o excesso de possibilidades traz dificuldades ao processo de escolha. Ao recorrer a tal sistema os usuários poupariam tempo e recursos antes dedicados a buscas e filtragens manuais para encontrar os aplicativos mais adequados a seu ambiente de trabalho. Em contrapartida, a comunidade de desenvolvedores tiraria proveito de um consequente aumento na utilização de seus programas que, por serem experimentados por mais usuários, certamente receberiam mais relatórios de erro, sugestões e contribuições diversas.

No caso de uso típico do AppRecommender, o usuário submete a lista de aplicativos instalados em seu sistema e o recomendador lhe sugere outros programas que ele não possui, mas provavelmente seriam de seu interesse. No âmbito deste trabalho foram desenvolvidas uma interface em modo texto e um serviço $\mathrm{Web}^{3}$ para este fim. O recomendador pode ainda ser facilmente integrado a outros sistemas, como os gerenciadores de aplicativos.

A recomendação oferecida é personalizada, fundamentada nas características específicas do usuário, em alternativa a recomendações generalistas, como as baseadas em popularidade dos aplicativos. Sugestões individualizadas requerem a identificação de atributos que diferenciem o usuário do restante da população. Este é um dos grandes desafios do recomendador, que utiliza conceitos específicos do domínio de aplicação na extração de atributos para composição de um perfil, como as relações de dependência entre os programas.

A filtragem do repositório de aplicativos para um determinado usuário ocorre por meio de buscas, fundamentando-se em técnicas de recuperação da informação. Os parâmetros das consultas variam de acordo com a estratégia escolhida, podendo considerar as escolhas prévias do próprio usuário, caracterizando desta forma um perfil de atributos de aplicativos; as escolhas de usuários com características similares às dele, referenciados como vizinhos nesse contexto; ou uma abordagem mista. Diferentes estratégias para composição de recomendações foram implementadas, visando uma posterior análise de desempenho, que nos auxiliaria a escolher a estratégia a ser adotada pelo serviço.

O presente texto relata as decisões de projeto que embasaram o desenvolvimento do protótipo disponível atualmente, além dos procedimentos realizados para avaliar o sistema. Foram realizados experimentos preliminares automatizados e uma consulta pública para coletar avaliações de usuários reais sobre as recomendações produzidas.

${ }^{3}$ http://recommender.debian.net 
Este trabalho foi realizado em colaboração com desenvolvedores e usuários da comunidade Debian. Diversos serviços já providos pela distribuição foram integrados na solução, que apresentou-se portanto como uma vitrine para tais iniciativas - algumas das quais desconhecidas pelo público.

Esta dissertação está organizada da seguinte forma: os Capítulos 2 e 3 trazem uma breve introdução sobre distribuições GNU/Linux e sistemas de recomendação; no Capítulo 4 trabalhos correlatos são apresentados, enquanto o 5 propõe o AppRecommender como uma solução para o problema exposto. Os experimentos realizados para avaliar a proposta são analisados no Capítulo 6. Por fim, no Capítulo 7 relatamos algumas considerações que julgamos relevantes em respeito aos resultados obtidos e às perspectivas de trabalhos futuros. 



\section{Distribuições GNU/Linux}

O contexto histórico no qual emergiu o que se conhece hoje por distribuições GNU/Linux é abordado a seguir. Especial atenção é dedicada aos princípios de "empacotamento" de software e seus sistemas de gerenciamento, conceitos que ganharam destaque no processo de consolidação das principais distribuições - e que guardam estreita relação com o presente trabalho.

\subsection{Surgimento}

Distribuições GNU/Linux, popularmente conhecidas como distros, são variações do sistema operacional composto pelo núcleo Linux (kernel) e milhares de aplicativos, cuja base foi desenvolvida pelo projeto GNU. As primeiras iniciativas nesse domínio surgiram em circunstâncias que favoreciam o desenvolvimento colaborativo, abertura de código e comunicação predominantemente por meio da Internet.

O projeto GNU ${ }^{1}$ foi criado em 1983 por Richard Stallman com o objetivo principal de desenvolver um sistema operacional livre em alternativa ao UNIX $^{2}$ — solução comercial amplamente difundida na indústria - e que fosse compatível com os padrões POSIX ${ }^{3}$. Nos anos 90 o projeto GNU já havia atraído muitos colaboradores, que num curto espaço de tempo desenvolveram inúmeros aplicativos para compor o sistema operacional. No entanto, o desenvolvimento do núcleo do sistema (GNU Hurd) não acompanhou o ritmo dos demais aplicativos.

Em outubro de 1991 o estudante finlandês Linus Torvalds, na tentativa de atrair colaboradores, publicou código do Freax, o núcleo de um sistema operacional desenvolvido por ele na universidade. Anos mais tarde Torvalds declara que não imaginava que aquele projeto desenvolvido sem grandes pretensões teria a dimensão do que hoje se conhece como Linux [Torvalds and Diamond 2001].

Com o anúncio de Torvalds, Stallman vislumbrou a possibilidade de acelerar o lançamento do sistema operacional livre se os aplicativos GNU que já estavam prontos fossem combinados com o núcleo recém-lançado - de fato, a primeira versão estável do GNU Hurd foi lançada apenas em 2001. Em 1992 o Linux foi licenciado sob a GNU GPL ${ }^{4}$ e as equipes dos dois projetos começaram a trabalhar na adaptação do kernel Linux para o ambiente GNU. Este esforço conjunto desencadeou o surgimento das primeiras distribuições GNU/Linux.

\footnotetext{
${ }^{1}$ hhtp://www.gnu.org

${ }^{2}$ http://www . unix.org/

${ }^{3}$ Acrônimo para Portable Operating System Interface. Família de normas definidas pelo IEEE com foco na portabilidade entre sistemas operacionais. http://standards. ieee.org/develop/wg/POSIX.html

${ }^{4}$ Acrônimo para General Public License, é um suporte legal para a distribuição livre de software.
} 
As distros oferecem diferentes "sabores" do sistema operacional, a exemplo do Debian, Fedora, Mandriva e Ubuntu, que são constituídos por aplicativos criteriosamente selecionados por seus desenvolvedores. Tais iniciativas tendem a reduzir a complexidade de instalação e atualização do sistema para usuários finais [Cosmo et al. 2008]. Os desenvolvedores das distribuições atuam como intermediários entre os usuários e os autores dos aplicativos, por meio do encapsulamento de componentes de software em abstrações denominadas pacotes.

\subsection{Empacotamento de programas}

O termo empacotamento refere-se ao ato de reunir num único arquivo (o pacote), um conjunto de programas executáveis, bibliotecas, arquivos de configuração, documentação, e qualquer outro dado necessário para a utilização de um programa no sistema operacional.

As distribuições que optam por disponibilizar pacotes mantêm uma infraestrutura de servidores como fonte de distribuição de programas. Tais servidores, denominados "repositórios", podem ser mantidos oficialmente pela distribuição ou oferecidos por terceiros, considerados portanto "não oficiais". Os sistemas gerenciadores de pacotes, responsáveis por manter uma base consistente de programas no sistema, são configurados para buscar os pacotes a serem instalados em um determinado conjunto de repositórios.

\subsubsection{Pacotes Debian}

Debian GNU/Linux e distribuições derivadas, entre elas a $U b u n t u^{5}$, utilizam o formato de pacote binário deb, composto por arquivos executáveis, bibliotecas e documentação associados a um programa ou conjunto de programas relacionados. Idealmente, todos os dados e procedimentos necessários para instalar, configurar e remover os aplicativos de um sistema estão contidos em seu pacote.

A estrutura dos pacotes e repositórios, bem como os requisitos que um pacote deve atender para que seja distribuído oficialmente estão especificados no Manual de Políticas Debian $^{6}$. Uma das exigências deste documento é que os pacotes estejam em conformidade com padrões que visam a interoperabilidade com outros sistemas GNU/Linux, como o Filesystem Hierarchy Standard (FHS), referente à localização de arquivos no sistema, e recomendações para aplicativos gráficos estabelecidos pelo FreeDesktop.org ${ }^{7}$.

A estrutura de um pacote Debian pode ser observada na Figura 2.1, que exibe o conteúdo do pacote cups extraído pela ferramenta ar. O arquivo debian-binary contém a versão da especificação de empacotamento implementada no pacote (linhas 4 e 5). control.tar.gz contém scripts e arquivos de controle utilizados principalmente pelo gerenciador de pacotes no momento de instalação, configuração e remoção do pacote (linhas 8 a 16). data.tar.gz contém todos os binários e demais arquivos que devem ser copiados para os devidos diretórios do sistema de arquivos (linhas 19 a 21).

Para cada pacote no repositório oficial existe um desenvolvedor ou equipe responsável por sua manutenção. O mantenedor acompanha o desenvolvimento do software original que nesse contexto é denominado upstream - e incorpora as correções e atualizações dos aplicativos ao contexto do Debian. Espera-se ainda que ele interaja com o desenvolvedor principal e retribua aos projetos originais as melhorias implementadas no âmbito do Debian. A tabela 2.1 sumariza os principais papéis exercidos por desenvolvedores de software no ecossistema de programas empacotados para o Debian.

O acesso de escrita aos repositórios do Debian é controlado por uma rede de confiança com base em assinatura de chaves criptográficas assimétricas. Para fazer parte da rede, um

\footnotetext{
${ }^{5}$ http: //www. ubuntu.com

${ }^{6}$ http://www.debian.org/doc/debian-policy/

${ }^{7}$ http://www.freedesktop.org/
} 


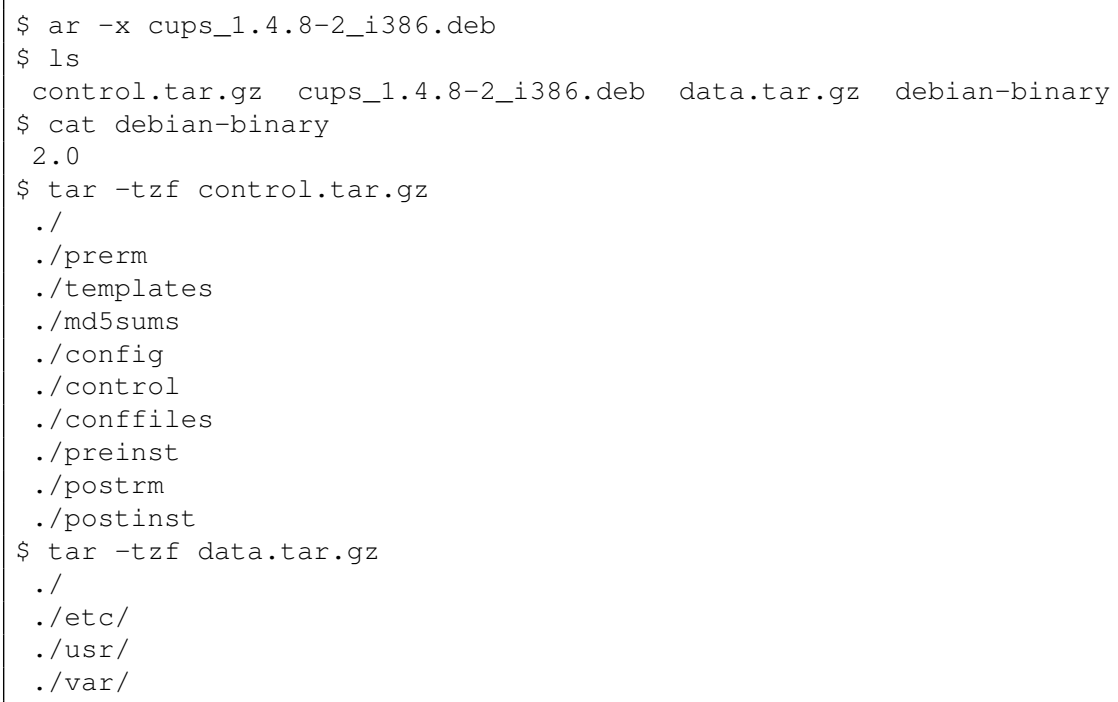

Figura 2.1: Extração do conteúdo de um pacote

\begin{tabular}{|l|l|}
\hline Papel & Descrição \\
\hline Mentor & Pessoa experiente que orienta mantenedores novatos nas atividades de empacotamento. \\
\hline Maintainer & Pessoa ou equipe que mantém o pacote Debian. \\
\hline Sponsor & $\begin{array}{l}\text { Desenvolvedor com acesso de escrita ao repositório oficial que revisa e envia aos servidores } \\
\text { pacotes de outros mantenedores que não possuem tal permissão. }\end{array}$ \\
\hline Upstream & Autor ou mantenedor responsável pelo desenvolvimento do software original. \\
\hline
\end{tabular}

Tabela 2.1: Papéis exercidos por desenvolvedores no Debian

colaborador precisa ter a sua chave assinada por pelo menos um membro do projeto e a troca de chaves deve necessariamente acontecer pessoalmente, mediante a conferência de um documento de identificação do proponente.

O envio de um novo pacote ao repositório oficial deve obrigatoriamente ser realizado por um desenvolvedor membro oficial do projeto (Debian Developer $(D D)$ ). As atualizações subsequentes podem também ser realizadas por um mantenedor oficial (Debian Maintainer $(D M)$ ), que não passou pelo processo de se tornar DD, mas faz parte da rede de confiança e mantém pacotes oficialmente. Colaboradores que não são DD ou DM podem igualmente exercer a função de mantenedor, porém, precisam do intermédio de um sponsor para enviar seus pacotes ao servidor.

A título de curiosidade, em outubro de 2010 foi aprovado em votação ${ }^{8}$ que o Debian passaria a acolher membros não empacotadores. Em reconhecimento à importância de atividades não-técnicas para o projeto, a partir desta data, podem ser admitidos como membros oficiais (DDs) colaboradores engajados em atividades como tradução, publicidade, design gráfico, entre outras. A admissão desses membros não atesta seu conhecimento técnico, e portanto eles não têm acesso de escrita aos repositórios.

\subsection{Relação entre pacotes}

Segundo [Abate et al. 2009], as relações entre pacotes podem ser caracterizadas como requisitos positivos, quando representam uma dependência, ou requisitos negativos, quando indicam um conflito. A tabela 2.2 traz a descrição de relações possíveis entre os pacotes fictícios $a, b$ e $c$, que seriam declaradas no conteúdo do pacote $a$, em seu arquivo control (linha 12 da Figura

\footnotetext{
${ }^{8}$ http://www.debian.org/vote/2010/vote_002
} 
2.1). Existem ainda relações entre pacotes fontes ${ }^{9}$ que deliberadamente não foram listadas por estarem fora do escopo deste trabalho.

\begin{tabular}{|l|l|}
\hline Relação & Descrição \\
\hline$a$ Depends $b$ & $\begin{array}{l}\text { Dependência absoluta: } a \text { não será configurado pelo gerenciador de pacotes a menos } \\
\text { que } b \text { tenha sido previamente configurado. }\end{array}$ \\
\hline$a$ Pre-Depends $b$ & $\begin{array}{l}\text { Pré-dependência absoluta: a instalação completa de } b \text { deve ser realizada antes que a } \\
\text { instalação de } a \text { seja iniciada. }\end{array}$ \\
\hline$a$ Recommends $b$ & $\begin{array}{l}\text { Recomendação: dependência forte, mas não absoluta; } a \text { e } b \text { são comumente utilizados } \\
\text { em conjunto, apesar de não haver obrigatoriedade para tal; em geral os gerenciadores } \\
\text { de pacotes instalam recomendações por padrão. }\end{array}$ \\
\hline$a$ Suggests $b$ & $\begin{array}{l}\text { Sugestão: a utilização de } a \text { está relacionada com o uso de } b \text {, que pode aumentar a } \\
\text { utilidade de } a \text {, no entanto, a não instalação de } b \text { é perfeitamente aceitável. }\end{array}$ \\
\hline$a$ Enhances $c$ & $\begin{array}{l}\text { Melhoria: } a \text { aumenta a funcionalidade de } c \text {; significado equivalente a suggests, porém } \\
\text { declarado no pacote que aumenta a funcionalidade do outro. }\end{array}$ \\
\hline$a$ Breaks $b$ & $\begin{array}{l}\text { Quebra: o gerenciador não prossegue com a instalação de } a \text { sem que } b \text { seja previamente } \\
\text { desconfigurado. }\end{array}$ \\
\hline$a$ Conflicts $b$ & $\begin{array}{l}\text { Conflito: restrição maior do que a quebra, pois impede que a instalação do pacote } \\
\text { tenha início antes da completa remoção dos indicados como conflito. }\end{array}$ \\
\hline$a$ Provides $b$ & $\begin{array}{l}\text { Fornecimento: o pacote provê a funcionalidade } b, \text { representada por um pacote virtual } \\
(b \text { não existe de fato no repositório). }\end{array}$ \\
\hline$a$ Replaces $b$ & $\begin{array}{l}\text { Substituição: } a \text { substitui } b \text {, portanto na instalação de } a \text { os arquivos de } b \text { podem ser } \\
\text { sobrescritos. }\end{array}$ \\
\hline
\end{tabular}

Tabela 2.2: Descrição das relações entre pacotes Debian

O conceito de pacotes virtuais foi criado especialmente para situações em que diversos pacotes diferentes oferecem um conjunto de funcionalidades semelhantes. Pacotes virtuais não existem fisicamente no repositório, são apenas mencionados na definição de outros pacotes ("concretos"). Por exemplo, os pacotes ssmtp e postfix oferecem a funcionalidade de um agente de transporte de mensagem (servidor de e-mail), portanto o arquivo control de ambos os pacotes conterá a informação "Provides: mail-transport-agent". Quando uma dependência se refere a um pacote virtual, ela pode ser satisfeita com a instalação de qualquer pacote que provê o mesmo.

Informações sobre o relacionamento de um determinado pacote com outros do repositório podem ser obtidas por meio da ferramenta apt-cache. A Figura 2.2 apresenta detalhes do pacote apt, com declarações de dependências entre as linhas 10 e 15. Em cada linha, o identificador da relação é seguido por uma lista de nomes de pacotes separados por vírgulas. Quando há uma lista de pacotes alternativos que satisfazem uma relação, eles aparecem separados por uma barra vertical. No exemplo dado, se ao menos um entre os pacotes aptitude, synaptic e wajig estiver presente no sistema, o termo Suggests: aptitude|synaptic|wajig é considerado satisfeito (linha 14).

Todos os campos, com exceção de Provides, podem restringir sua aplicabilidade a versões particulares indicadas em parênteses juntamente com uma das relações $<<,<=,=,>=\mathrm{e}$ $>>$, para estritamente menor, menor ou igual, igual, maior ou igual e estritamente maior, respectivamente.

\subsection{Sistemas gerenciadores de pacotes}

Os gerenciadores de pacotes são sistemas projetados para coordenar as ações de aquisição, instalação, atualização e remoção de pacotes no sistema operacional, mantendo o estado do sistema consistente. Em sua estrutura os pacotes declaram dependências e conflitos com outros pacotes, procedimentos que devem ser executados antes ou depois da instalação ou

\footnotetext{
${ }^{9}$ http://www.debian.org/doc/debian-policy/ch-relationships.html
} 


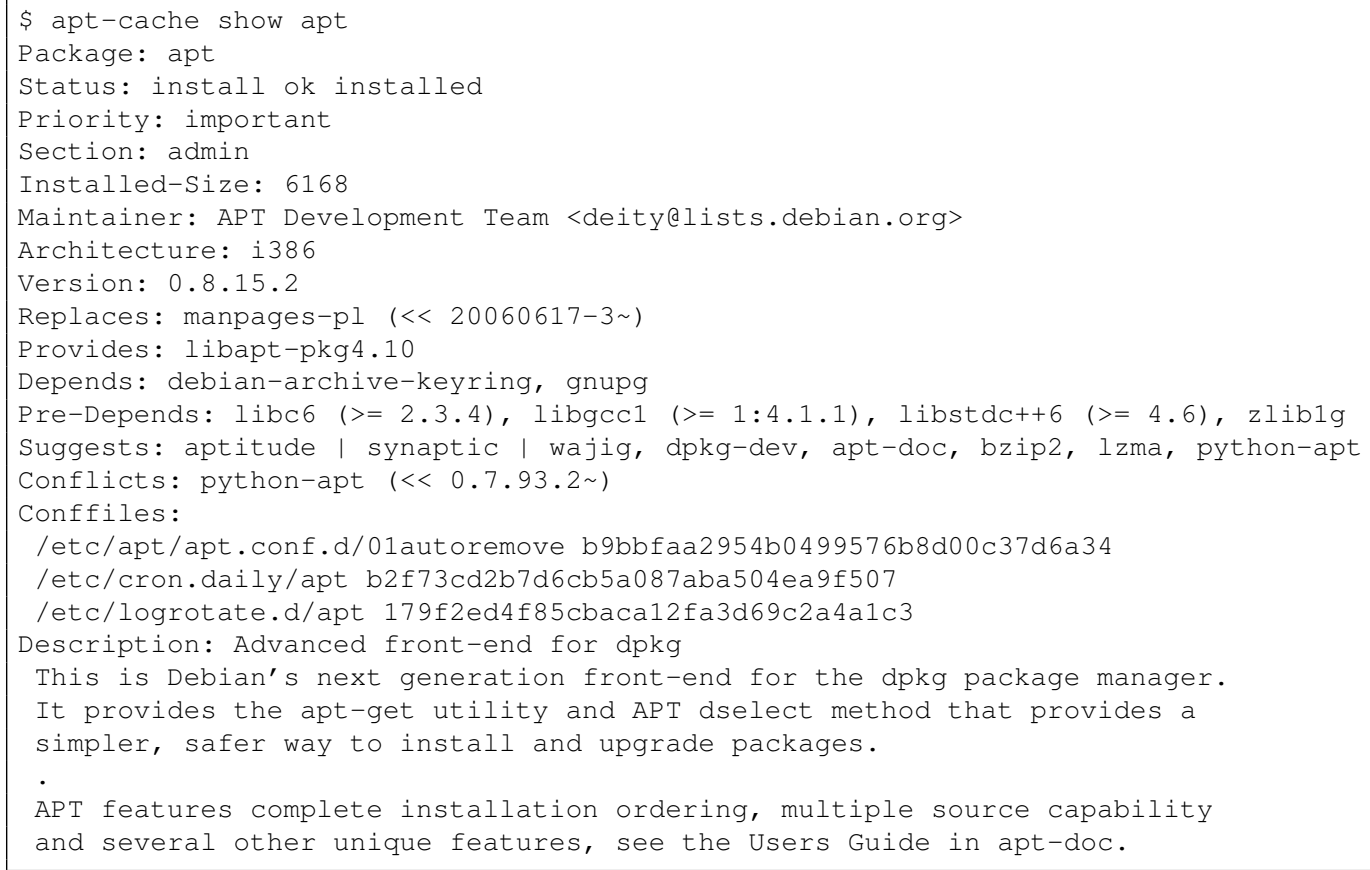

Figura 2.2: Detalhes do pacote apt

remoção (postinst, postrm, etc), diretórios onde os executáveis, configurações e documentações devem ser posicionados, entre outras informações.

O tratamento de dependências e conflitos é uma das mais importantes e críticas funções de um sistema gerenciador. Ao receber uma requisição - instalação de um novo aplicativo, por exemplo - o gerenciador tenta modificar o estado do sistema satisfazendo todas as restrições indicadas pelo pacote. Promove a instalação de todas as dependências antes de instalá-lo, ao passo que não permite a instalação de pacotes que conflitam com outros já instalados no sistema. Alguns são capazes de oferecer diferentes soluções para problemas de dependências não satisfeitas ou conflitos, e cabe ao usuário escolher a que melhor lhe convier.

Atualizações parciais dos sistemas e o lançamento incessante de novas versões dos pacotes nos repositórios por vezes provocam situações de inconsistência indesejável, que o gerenciador não é capaz de resolver sem intervenção humana. A dificuldade em lidar de forma automatizada com tal questão é uma das motivações para o surgimento de esquemas de instalação independentes de pacotes e sistemas gerenciadores, a exemplo do projeto Gentoo ${ }^{10}$.

A seguir são listados alguns exemplos de sistemas de gerenciamento de pacotes.

\subsubsection{Advanced Packaging Tool (APT)}

O gerenciamento de pacotes em sistemas Debian GNU/Linux e derivados é realizado pelo $A P T^{11}$, considerado um gerenciador de alto nível. Por meio do $A P T$ são realizadas ações como busca, obtenção, instalação, atualização e remoção de pacotes. Após o tratamento de dependências e definição da ordem de instalação dos pacotes, o $A P T$ aciona o $d p k g^{12}$ (nível médio) que apenas checa a satisfação de dependências e por fim aciona o $d p k g$-deb para de fato ler os arquivos de controle e extrair os demais arquivos, instalando-os nos diretórios indicados.

O Synaptic é um gerenciador de pacotes gráfico desenvolvido em GTK+ como uma interface amigável para o APT (Figura 2.3).

\footnotetext{
${ }^{10}$ http://www.gentoo.org/main/pt_br/philosophy.xml

${ }^{11}$ http://wiki.debian.org/Apt

${ }^{12}$ http://wiki.debian.org/dpkg
} 


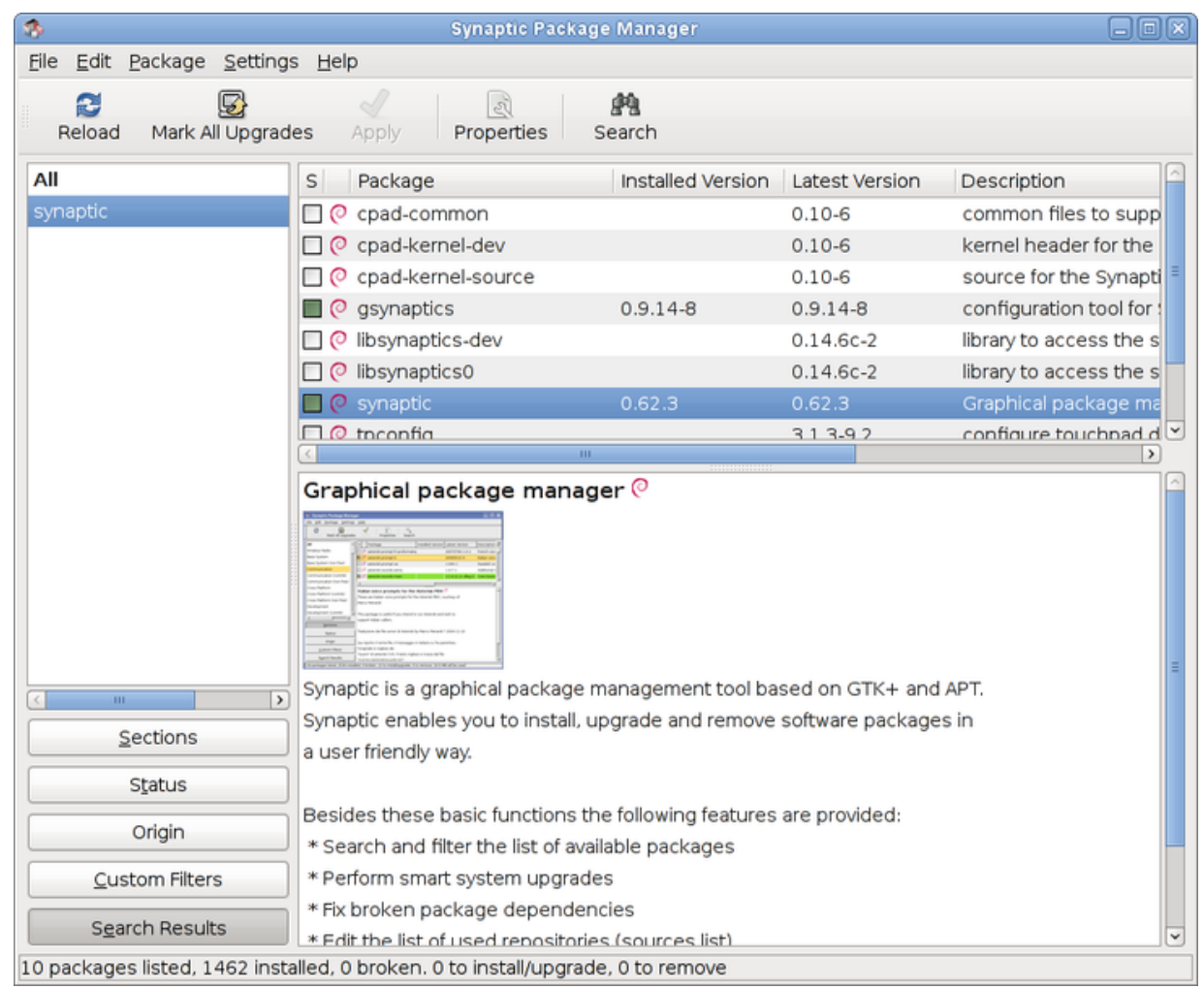

Figura 2.3: Captura de tela do Synaptic

Em sistemas Ubuntu, as atividades relativas à instalação de aplicativos (navegação pelo repositório, instalação e remoção de pacotes) são centralizadas pelo Ubuntu Software Center. Esta ferramenta, inicialmente denominada AppCenter, foi desenvolvida com base no gnomeapp-install, sendo escrita em Python e GTK+ como biblioteca gráfica. Serve como interface para o $A P T$, dado que o sistema de empacotamento daquela distribuição é herdado do Debian.

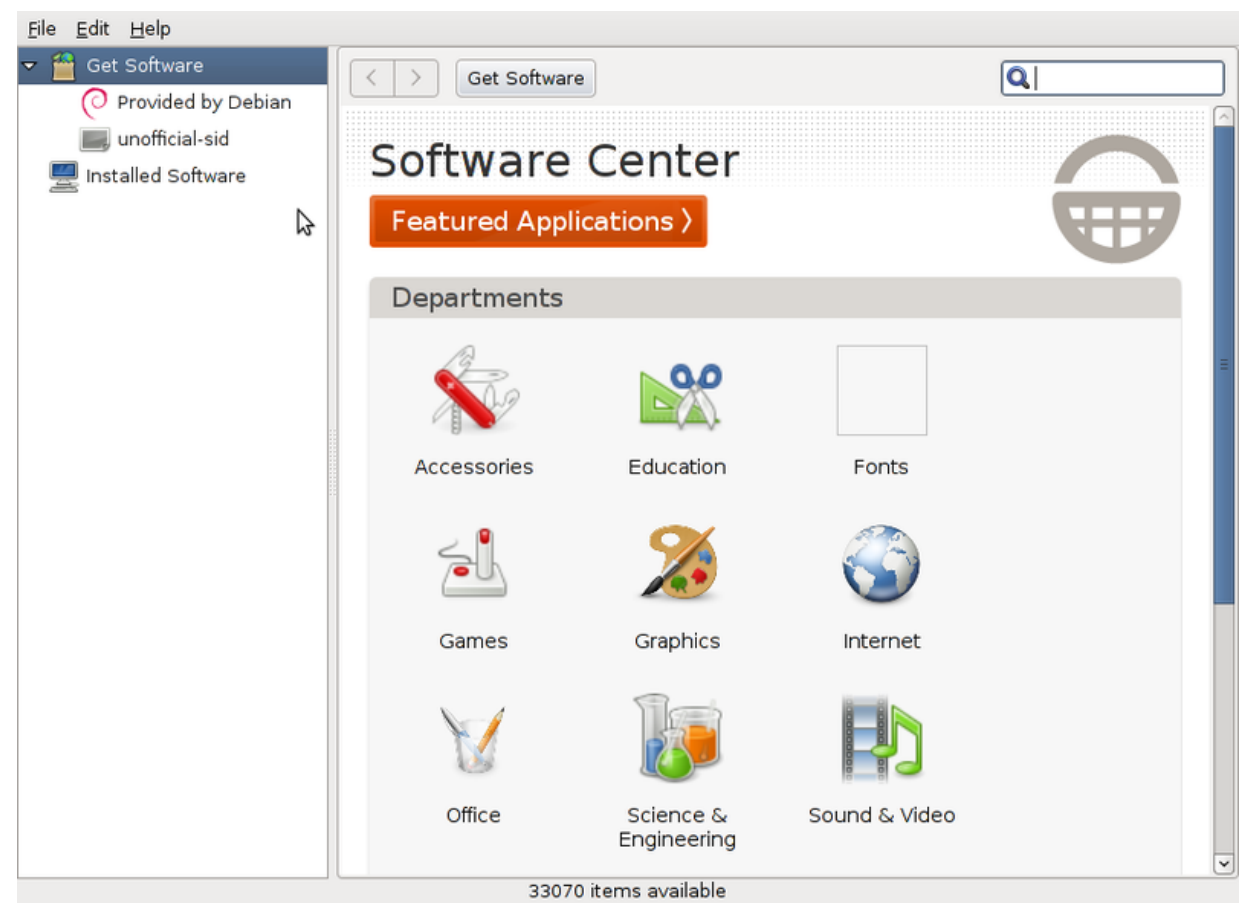

Figura 2.4: Captura de tela do Software Center 


\subsection{Seleção de programas}

O conjunto de programas instalados num determinado sistema é tipicamente resultado de dois processos de seleção: o primeiro é realizado no âmbito do desenvolvimento da distribuição e o segundo faz parte da manutenção cotidiana do sistema, realizado pelo usuário e/ou administrador da máquina.

A seleção e configuração dos aplicativos básicos de uma distribuição (instalados por padrão) são de responsabilidade da equipe que a desenvolve, com diferentes níveis de interferência da comunidade. Este é um ponto bastante sensível nos projetos, dado que é um dos fatores que influenciam a escolha dos usuários finais por qual distribuição adotar, e pode revelar eventuais conflitos de interesses. Por exemplo, a decisão da Canonical que determinou, sem debates públicos, a substituição do popular gerenciador de janelas GNOME por um outro menos maduro, expôs um modelo em que a comunidade e mesmo os desenvolvedores envolvidos exercem papel limitado nos rumos do projeto [Paul 2010].

Por outro lado, a configuração de um sistema básico é geralmente seguida por uma personalização que visa atender às demandas específicas dos usuários finais, por meio da instalação de programas adicionais. Ainda que a infraestrutura de instalação de software provida pelas distribuições (geralmente baseada em pacotes) simplifique a manutenção de sistemas [Cosmo et al. 2008], a seleção dos programas inevitavelmente dependerá de uma ação humana. Com o desenvolvimento deste trabalho pretende-se auxiliar o indivíduo nessa tarefa, especialmente no cenário em que o usuário não é dotado de experiência pessoal e habilidade suficientes para decidir qual aplicativo instalar. 



\section{Capítulo 3}

\section{Sistemas de recomendação}

Este capítulo apresenta uma breve introdução ao domínio de sistemas de recomendação. Circunstâncias que motivaram o surgimento de tais sistemas, objetivos e desafios comuns no desenvolvimento, técnicas que apoiam a composição das recomendações e métricas de avaliação são alguns dos tópicos abordados a seguir.

\subsection{Contexto histórico}

A popularização de recursos computacionais e do acesso à Internet nas últimas décadas contribuiu para o aumento expressivo na quantidade e diversidade de conteúdo e serviços à disposição dos usuários. Um dos fatores para esse aumento é que indivíduos que anteriormente limitavam-se ao papel de consumidores de conteúdo, hoje colocam-se numa posição de produtores. Surgem inúmeros casos de sucesso de serviços criados e/ou mantidos por internautas independentes, a exemplo de blogs, enciclopédias colaborativas como a Wikipedia ${ }^{1}$, repositórios para compartilhamento de fotografia e vídeo, como Flickr ${ }^{2}$ e Youtube ${ }^{3}$, entre outros. [Castells 2006] analisa tal fenômeno, comumente referenciado como Web 2.0, afirmando que a maioria da população acredita que pode influenciar outras pessoas atuando no mundo por meio da sua força de vontade e utilizando seus próprios meios.

Recomendações, sugestões ou simples indicações do que se julga mais ou menos adequado numa determinada situação são fenômenos bastante comuns nas relações sociais. Um exemplo de recomendação tradicional são as avaliações de livros e filmes produzidas por críticos de arte e publicadas nos principais jornais e revistas especializadas. A empresa Netflix ${ }^{4}$, locadora de filmes norte-americana, tornou-se referência na década de 90 ao utilizar preferências de usuários e histórico de compras dos usuários para produção de recomendações automatizadas.

$\mathrm{Na}$ Internet, que é também uma rede de interação social, refletem-se esses mesmos comportamentos. Expandem-se entretanto no mundo digital a um montante de atores e informação disponível muito mais elevados que no plano do tangível. Diante de tal peculiaridade da grande rede, é natural que os processos de indicação sejam também mais sofisticados território dos sistemas especializados em recomendação, que fundamentam-se na opinião e comportamento de usuários não especializados.

\footnotetext{
${ }^{1}$ http://wikipedia.org

${ }^{2}$ http://flickr.com

${ }^{3}$ http://youtube.com

${ }^{4}$ http://www.netflix.com
} 


\subsection{O problema computacional}

O problema da recomendação é comumente formalizado por meio de uma estrutura de pontuação como representação computacional da utilidade dos itens para os usuários ou clientes. A partir de avaliações feitas pelos próprios usuários do sistema, tenta-se estimar pontuações para os itens que ainda não foram avaliados pelos mesmos. Uma vez que as estimativas tenham sido feitas, pode-se recomendar os itens com maior pontuação estimada.

Todavia, a utilidade é um conceito subjetivo e difícil de mensurar, principalmente porque, em diversos contextos, a identificação dos fatores que a determinam não é uma tarefa trivial. Portanto, com a ressalva de que essas medidas não representam necessariamente a realidade, as pontuações são usadas como aproximações, pois têm como base as avaliações registradas pelos próprios usuários.

\subsection{Ações e desafios}

Sistemas recomendadores são implementados nos mais diversos contextos e podem ser desenvolvidos para propósitos distintos, referenciados na literatura como ações de sistemas de recomendação. Por exemplo, a recomendação pode se limitar a encontrar os itens mais relevantes, porém, em alguns casos, é interessante que sejam retornados todos os itens relevantes; outra possibilidade é recomendar uma sequência de itens, quando não somente os itens recomendados importam mas também a ordem em que eles são apresentados; a navegação num extenso repositório de itens também pode ser beneficiada por um recomendador que apresenta primeiramente os itens que o usuário deve se interessar [Herlocker et al. 2004].

Ações distintas não representam necessariamente a necessidade de aplicação de técnicas distintas, visto que é basicamente a apresentação dos resultados que vai ser diferenciada e não o cálculo da recomendação em si. No entanto, a avaliação de eficácia de um recomendador está diretamente relacionada com sua ação principal. Por exemplo, se apenas os mais relevantes serão apresentados ao usuário, é de extrema importância que os primeiros itens recomendados sejam acertados, enquanto que no caso de retorno de todos os relevantes o ponto chave é que nenhum item relevante seja desconsiderado, mesmo que os primeiros apresentados sejam irrelevantes.

Os desafios do desenvolvimento de tais sistemas estão relacionados a questões inerentes ao problema e sua representação computacional. As estratégias e técnicas propostas devem levar em conta tais questões, algumas das quais foram apontadas por [Vozalis and Margaritis 2003] e são citadas a seguir.

\section{Qualidade das recomendações}

Usuários esperam recomendações nas quais eles possam confiar. Essa confiabilidade é alcançada na medida em que se diminui a incidência de falsos positivos. Em outras palavras, deve-se evitar recomendações que não interessam ao usuário.

\section{Esparsidade}

A existência de poucas relações usuário-item resulta numa matriz de relacionamentos esparsa, o que dificulta a localização de usuários com preferências semelhantes (relações de vizinhança) e resulta em recomendações fracas.

\section{Escalabilidade}

A complexidade do cálculo de recomendações cresce tanto com o número de clientes quanto com a quantidade de itens, portanto a escalabilidade dos algoritmos é um ponto importante a ser considerado. 


\section{Transitividade de vizinhança}

Usuários que têm comportamento semelhante a um determinado usuário não necessariamente têm comportamento semelhante entre si. A captura desse tipo de relação pode ser desejável mas em geral essa informação não é resguardada, exigindo a aplicação de métodos específicos para tal.

\section{Sinônimos}

Quando o universo de itens possibilita a existência de sinônimos, a solução deve considerar essa informação a fim de prover melhores resultados.

\section{Primeira avaliação}

Um item só pode ser recomendado se ele tiver sido escolhido por um usuário anteriormente. Portanto, novos itens precisam ter um tratamento especial até que sua presença seja notada.

\section{Usuário incomum}

Indivíduos com opiniões que fogem do usual, que não concordam nem discordam consistentemente com nenhum grupo, normalmente não se beneficiam de sistemas de recomendações.

\subsection{Seleção de atributos}

Uma grande quantidade de atributos a ser considerada resulta em alta complexidade computacional, além de geralmente mascarar a presença de ruídos. A fim de amenizar este problema, comumente realiza-se um processo de seleção de atributos, que consiste na escolha de algumas características dos dados a utilizar como conjunto de treinamento para a classificação, evitando assim o super-ajuste (overfitting). Essa seleção equivale à substituição de um classificador complexo por um mais simples. [Manning et al. 2009] defende que, especialmente quando a quantidade de dados de treinamento é limitada, modelos mais fracos são preferíveis.

A seleção de atributos geralmente é realizada para cada classe em separado, seguida pela combinação dos diversos conjuntos. Abaixo são apresentados alguns métodos de escolha.

Informação mútua. Análise de quanto a presença ou ausência de um atributo contribui para a tomada de decisão correta por uma determinada classe. Informação mútua máxima significa que o atributo é um indicador perfeito para pertencimento a uma classe. Isso acontece quando um objeto apresenta o atributo se e somente se o objeto pertence à classe.

Independência de eventos. Aplicação do teste estatístico $\chi^{2}$ para avaliar a independência de dois eventos - neste caso, um atributo e uma classe. Se os dois eventos são dependentes, então a ocorrência do atributo torna a ocorrência da classe mais provável.

Baseado em frequência. Seleção dos atributos mais comuns para uma classe.

Os métodos apresentados acima são "gulosos", ou seja, assumem escolhas ótimas locais na esperança de serem ótimas globais. Como resultado, podem selecionar atributos que não acrescentam nenhuma informação para a classificação quando considerados outros previamente escolhidos. Apesar disto, algoritmos não gulosos são raramente utilizados em virtude do seu alto custo computacional [Manning et al. 2009]. 


\subsection{Estratégias de recomendação}

O presente trabalho considera uma classificação de estratégias de recomendação baseada em taxonomias propostas por diferentes autores. A peculiaridade de cada abordagem está relacionada com a fonte de dados utilizada para produzir o conhecimento do recomendador e o tipo de técnica aplicada para extrair as recomendações.

\subsubsection{Reputação dos itens}

Popular entre serviços de venda como livrarias, sites de leilão e lojas em geral, esta estratégia consiste no registro de avaliações dos produtos produzidas por usuários, bem como na apresentação das mesmas no momento e local apropriado [Cazella et al. 2010].

Atualmente existem serviços especializados em reputação de produtos que apenas disponibilizam as avaliações, sem que haja venda alguma associada. Alguns exemplos são o Trip Advisor ${ }^{5}$, que oferece avaliações sobre hotéis, restaurantes e recomendações em geral para viagens, e o Internet Movie Database ${ }^{6}$, que armazena uma vasta coleção de informações sobre cinema (Figura 3.1).

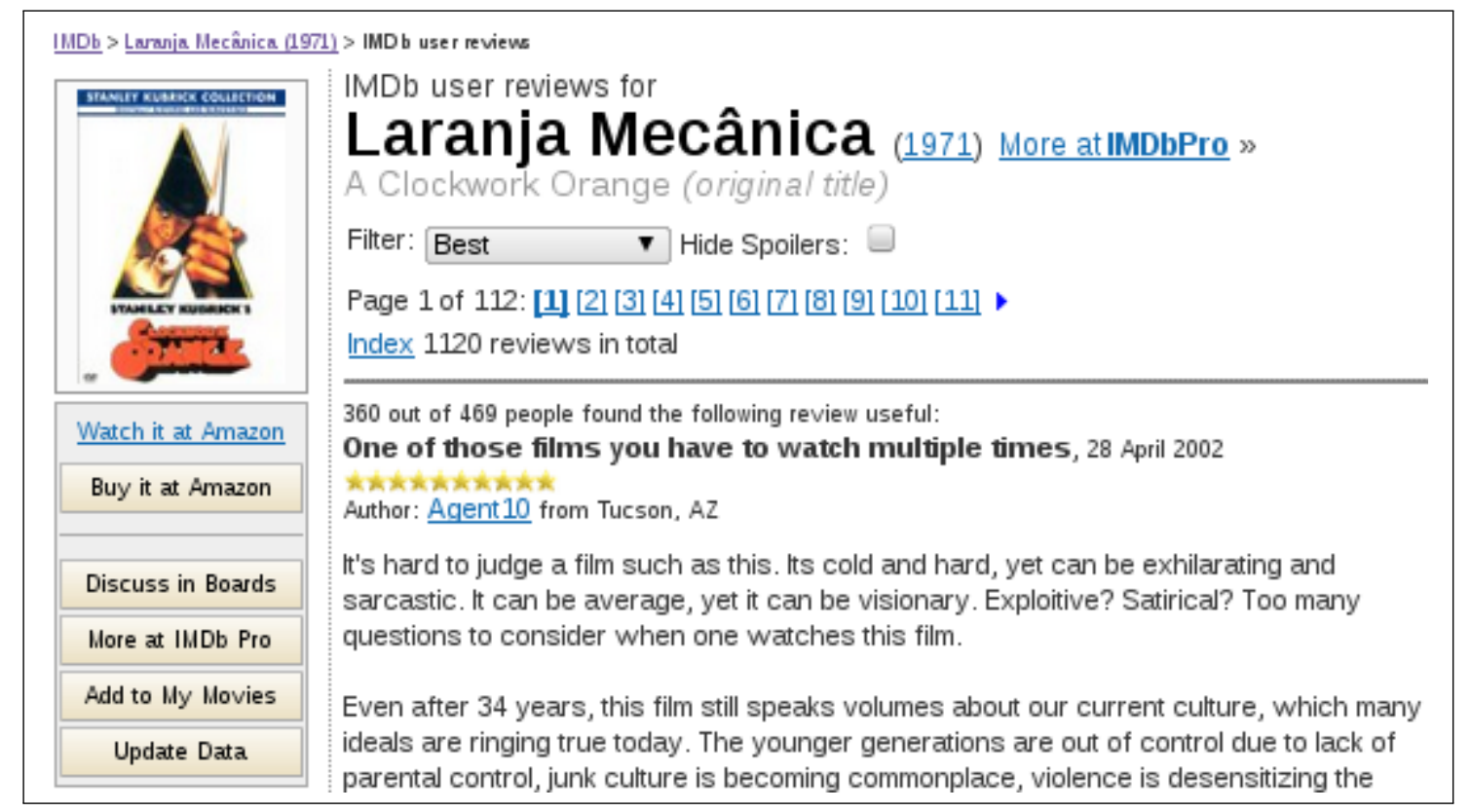

Figura 3.1: Avaliação de usuário no IMDb

A eficácia desse tipo de recomendação está diretamente relacionada com a qualidade das avaliações produzidas pelos usuários. A depender da expertise do indivíduo sobre determinado tema, ele pode se mostrar rigoroso ou permissivo demais em suas avaliações. Por este motivo, não é raro a ocorrência de avaliações conflitantes para um mesmo item. Outra dificuldade é lidar com a parcialidade dos usuários em suas opiniões, que geralmente não pode ser atestada, principalmente quando tratam de questões subjetivas ou percepções pessoais.

Uma maneira de lidar com essas questões é atrelar o conceito de reputação também para avaliadores ou para as próprias avaliações. Nesse caso, o fato de uma avaliação ter sido bem avaliada por outros usuários tende a aumentar sua confiança. A Figura 3.2 ilustra como a qualidade das avaliações produzidas por usuários pode comprometer a reputação de um item (fonte: $\mathrm{xkcd}^{7}$ ).

\footnotetext{
${ }^{5}$ http: //www.tripadvisor.com/

${ }^{6}$ http://www. imdb.com/

${ }^{7}$ http://xkcd.com/937/
} 


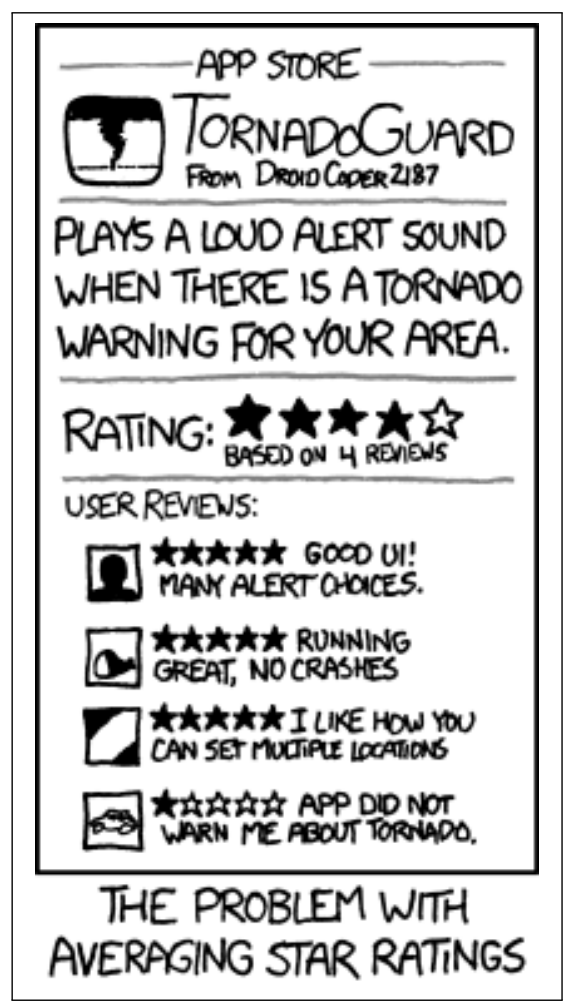

Figura 3.2: Quadrinho sobre cálculo de média em avaliações

Esta é uma abordagem de simples implementação, visto que geralmente depende apenas da manutenção dos dados originais. Os desafios surgem quando se tenta quantificar automaticamente as avaliações, seja pelo processamento do texto e classificação entre avaliação boa ou ruim, ou ainda, quando a reputação é composta por meio de outros parâmetros, por exemplo, a quantidade de vendas, reclamações ou devoluções de um produto.

\subsubsection{Recomendação baseada em conteúdo}

Esta abordagem parte do princípio de que os usuários tendem a se interessar por itens semelhantes aos que eles já se interessaram no passado [Herlocker 2000]. Em uma livraria, por exemplo, sugerir ao cliente outros livros do mesmo autor ou tema dos previamente selecionados é uma estratégia amplamente adotada.

O ponto chave desta estratégia é a representação dos itens por meio de suas características, por exemplo, a descrição de um livro pelo conjunto \{título, autor, editora, tema\}. A partir da identificação de atributos, aplica-se técnicas de recuperação da informação com o intuito de encontrar itens semelhantes ou de classificação para encontrar itens relevantes. Algumas técnicas aplicáveis nesse contexto são descritas na Seção 3.6. A Figura 3.3 ilustra um exemplo em que o cliente escolhe uma guitarra e o sistema de recomendação lhe sugere outros instrumentos musicais e artigos relacionados.

Pelo fato de se apoiar na classificação dos itens, os resultados da recomendação são prejudicados nos casos em que os atributos não podem ser identificados de forma automatizada. Outro problema é a superespecialização, ou seja, a abrangência das recomendações fica limitada a itens similares aos já escolhidos pelos usuários [Adomavicius and Tuzhilin 2005].

\subsubsection{Recomendação colaborativa}

A recomendação colaborativa é fundamentada na troca de experiências entre indivíduos que possuem interesses em comum, portanto não exige o reconhecimento semântico do conteúdo 


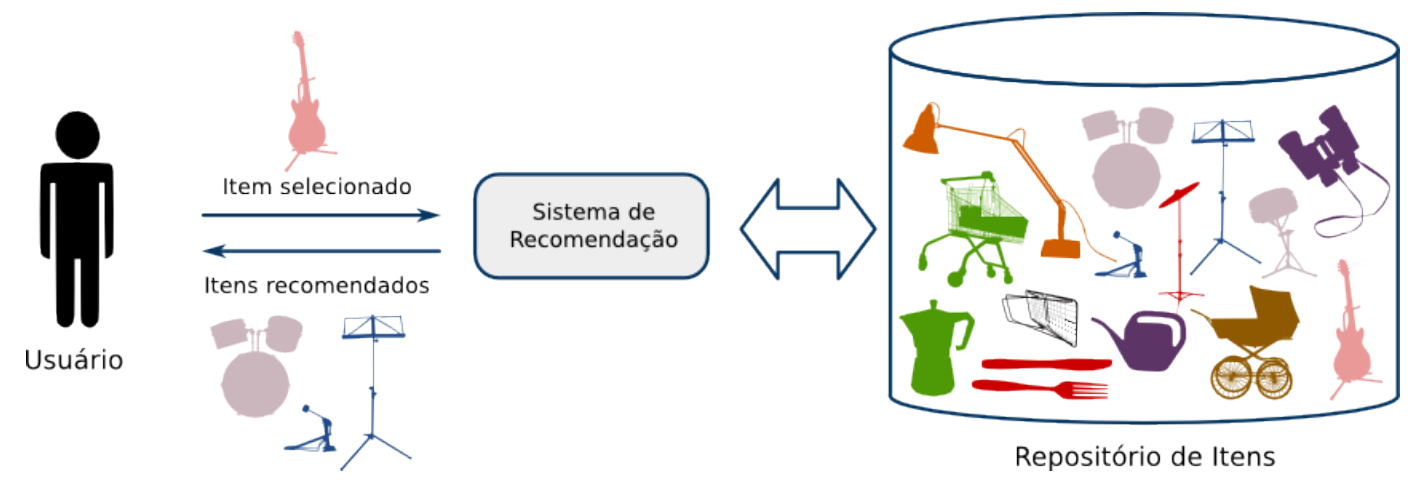

Figura 3.3: Cenário de uma recomendação baseada em conteúdo

dos itens. Esta estratégia é inspirada na técnica de classificação $k$-Nearest Neighbors ( $k$ - $N N)$, apresentada na Seção A.1.

A vizinhança de um determinado usuário é composta pelos usuários que estiverem mais próximos a ele. O ponto chave desta abordagem é a definição da função que quantifica a proximidade entre os usuários, que também pode ser herdada de soluções em classificação e recuperação da informação. A recomendação é então produzida a partir da análise dos itens que os seus vizinhos consideram relevantes. Geralmente os itens que ocorrem com maior frequência na vizinhança compõem a recomendação. A Figura 3.4 ilustra o cenário de uma recomendação colaborativa na qual um artigo comum a todos os usuários da vizinhança é sugerido.

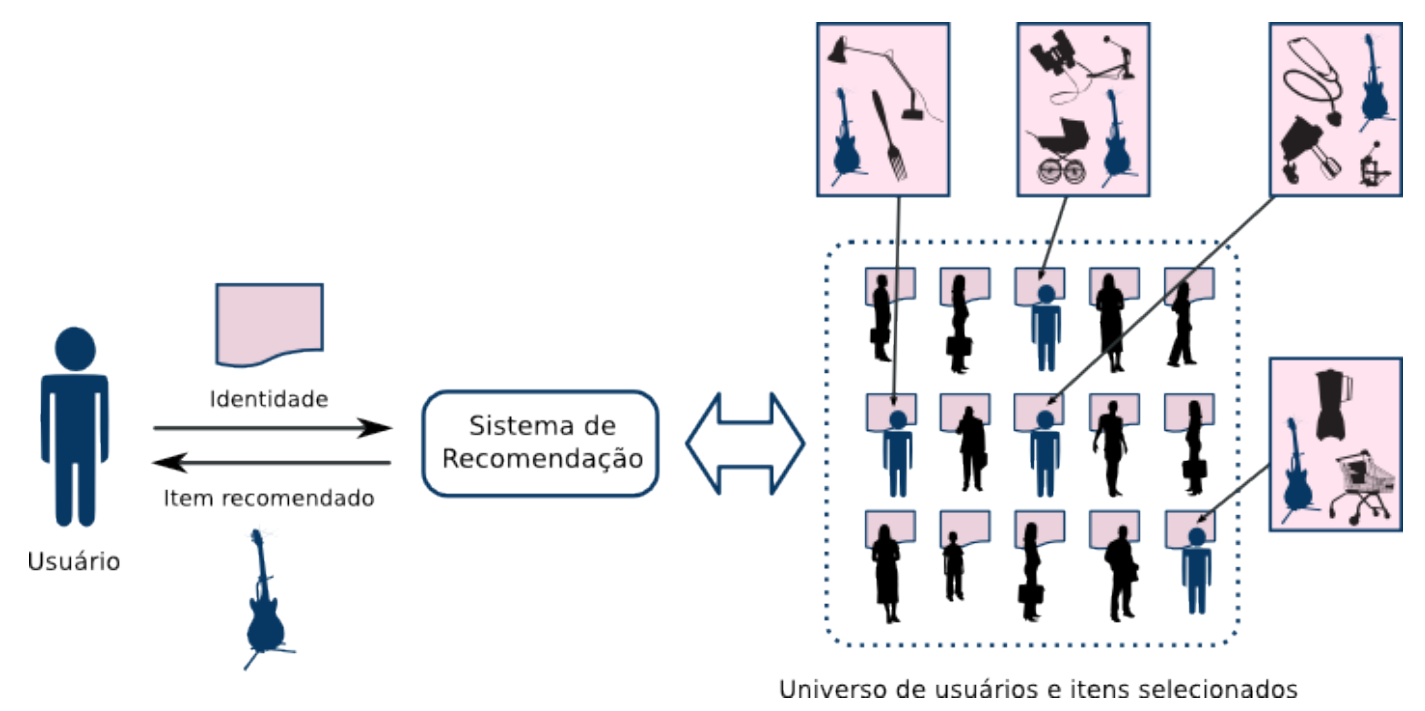

Figura 3.4: Cenário da recomendação colaborativa

Nesta abordagem o problema da superespecialização é superado, visto que a recomendação não se baseia no histórico do próprio usuário. Consequentemente itens totalmente inesperados podem fazer parte da sugestão. Outro ponto positivo é a possibilidade de formação de comunidades de usuários pela identificação de interesses semelhantes entre os mesmos [Cazella et al. 2010].

\subsubsection{Recomendação baseada em conhecimento}

Esta estratégia tem como princípio a produção de recomendações a partir de um conhecimento previamente adquirido sobre o domínio da aplicação, em vez de avaliações prévias produzidas 
por usuários. A grande vantagem desta abordagem é que ela não depende de preferências individuais dos usuários, já que não usa a base de dados de avaliação usuário-item.

No entanto, a descoberta de conhecimento é o principal gargalo desta categoria de soluções, e por isso é mais utilizada nos casos em que já existe uma base de conhecimento disponível, por exemplo, na forma de uma ontologia [Adomavicius and Tuzhilin 2005]. Quando não é esse o caso, técnicas de aprendizado de máquina e mineração de dados podem ser utilizadas para extrair correlações e padrões frequentes no comportamento dos usuários, por meio da análise de suas escolhas ao longo do tempo.

Regras de associação são outro tipo de conhecimento formalizado, representado por regras de inferência que indicam a presença simultânea de conjuntos de itens numa determinada porcentagem dos casos conhecidos. As técnicas mais utilizadas para descoberta de tais regras são variações do algoritmo Apriori, apresentado na Seção A.6 [Kotsiantis and Kanellopoulos 2006]. Dado um conjunto de associações, a recomendação para determinado usuário é produzida de acordo com as regras satisfeitas pelo conjunto de itens que ele já tenha selecionado. Por exemplo, a regra $A, B, C \Rightarrow D$ seria satisfeita por usuários que possuem os itens $A, B$ e $C$, resultando na indicação do item $D$ : "Clientes que compraram os itens $A, B$ e $C$ também compraram o item D".

Segundo [Hegland 2003], recomendação baseada em conhecimento é frequentemente utilizada para sugestões implícitas, por exemplo, na definição do posicionamento de produtos numa prateleira ou a realização de propagandas dirigidas. Um caso popular desta estratégia é encontrado na loja virtual da empresa Amazon $^{8}$ (Figura 3.5).

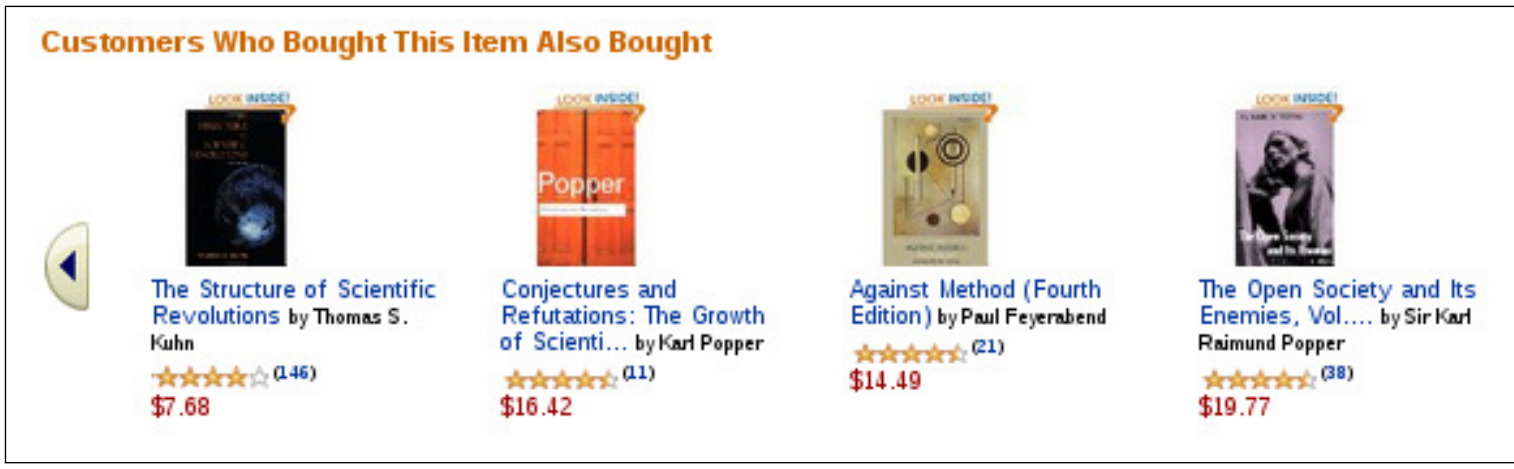

Figura 3.5: Recomendação por associação na Amazon

\subsubsection{Baseada em dados demográficos}

A estratégia demográfica fundamenta-se na composição de perfis de usuários e identificação de nichos demográficos para produção de recomendações. Os dados pessoais geralmente são coletados de forma explícita, por meio de um cadastro do usuário, e podem englobar informações como idade, sexo, profissão e áreas de interesse. Dados demográficos, no entanto, são tipicamente utilizados em combinação com outras fontes de dados e técnicas diversas, como parte de uma estratégia de recomendação híbrida.

\subsubsection{Estratégias híbridas}

Sistemas de recomendação híbridos combinam duas ou mais estratégias, buscando obter melhor performance do que a que as estratégias oferecem individualmente. A tabela 3.1 apresenta as principais técnicas de hibridização segundo [Burke 2002].

\footnotetext{
${ }^{8}$ http://www. amazon.com/
} 


\begin{tabular}{|l|l|}
\hline Método & Descrição \\
\hline Ponderação & $\begin{array}{l}\text { Pontuações de relevância oriundas de diversas técnicas de recomendação são } \\
\text { combinadas para compor uma única recomendação. }\end{array}$ \\
\hline Revezamento & $\begin{array}{l}\text { O sistema reveza entre técnicas de recomendação diversas, de acordo com a } \\
\text { situação do momento. }\end{array}$ \\
\hline Combinação & $\begin{array}{l}\text { Recomendações oriundas de diversos recomendadores diferentes são apresentadas } \\
\text { de uma só vez. }\end{array}$ \\
\hline Combinação de atributo & $\begin{array}{l}\text { Um algoritmo de recomendação único coleta atributos de diferentes bases de } \\
\text { dados para recomendação. }\end{array}$ \\
\hline Cascata & Um recomendador refina a recomendação produzida por outro. \\
\hline Acréscimo de atributo & O resultado de uma técnica é usado como atributo de entrada para outra. \\
\hline Meta-nível & O modelo que um recomendador "aprendeu" é usado como entrada para o outro. \\
\hline
\end{tabular}

Tabela 3.1: Métodos de hibridização

\subsection{Técnicas comumente utilizadas}

As estratégias apresentadas na Seção 3.5 são fundamentadas em técnicas provenientes de áreas distintas, algumas das quais apresentadas com mais detalhes no apêndice A deste documento. O problema computacional a ser tratado está fortemente relacionado com outros problemas clássicos, como classificação e recuperação de informação em documentos de texto.

A fim de obter a informação desejada, o usuário de uma ferramenta de busca deve traduzir suas necessidades de informação para uma consulta (query), que geralmente é representada por um conjunto de palavras-chave. O desafio do buscador é recuperar os documentos da coleção que são relevantes para a consulta, baseando-se nos termos que a constituem. Ademais, visto que a busca pode retornar um número excessivo de documentos, é desejável que o resultado seja apresentado ao usuário em ordem decrescente de relevância, aumentando assim as chances de a informação desejada ser encontrada com rapidez. Para tanto, cada documento da coleção deve ter uma pontuação (peso) que indique seu grau de importância para a referida query. Entre os esquemas de pesos mais populares estão o tf_idf(Term Frequency - Inverse Document Frequency) e o BM25 (Best Match 25) (Seções A.4 e A.5).

Traçando um paralelo com o problema de recomendação, a identidade e/ou o comportamento de um determinado usuário representaria uma consulta ao sistema de busca, que provocaria o retorno dos itens de maior peso, ou seja, com maior potencial de aceitação pelo usuário.

Na busca por informação, assume-se que as necessidades do usuário são particulares e passageiras, e por isso a reincidência de queries não é muito frequente [Manning et al. 2009]. Porém, em situações onde se observa que as mesmas consultas são aplicadas com uma certa frequência, é interessante que o sistema suporte consultas permanentes. Sendo assim, a computação necessária pode ser realizada previamente e apresentada sempre que a consulta for requisitada. Se a classe de documentos que satisfazem a uma dessas queries permanentes é tida como uma categoria, o processo de realização das consultas prévias pode ser caracterizado como uma classificação. O problema da classificação diz respeito à determinação de relacionamentos entre um dado objeto e um conjunto de classes pré-definidas.

A recomendação pode ser vista como uma classificação, na qual os itens são categorizados entre relevantes e irrelevantes - os relevantes seriam recomendados. No entanto, a definição de consultas ou regras fixas para uma busca não é uma estratégia eficiente nesse caso, porque a consulta estaria diretamente relacionada com a identidade do usuário e portanto deveria ser escrita especialmente para ele. A disciplina de inteligência artificial aborda esse problema por meio de estratégias que não se baseiam em busca. Algoritmos de aprendizado de máquina são utilizados para a construção de modelos de classificação ditos inteligentes, que "aprendem" por meio da análise de exemplos.

Métodos de aprendizado supervisionados fundamentam-se na construção de um classificador 
que aprende na medida em que lhe são apontados exemplos de objetos classificados. São caracterizados como supervisionados porque as classes atribuídas aos objetos de treinamento são determinadas por um ser humano, que atua como um supervisor orientando o processo de aprendizado [Manning et al. 2009]. O algoritmo $k$-NN ( $k$-Nearest-Neighbors) é um exemplo deste tipo de solução, que classifica um objeto de acordo com a classe mais frequente entre os objetos mais próximos ou vizinhos (Seção A.1). Outro exemplo é o classificador bayesiano, método que se apoia na teoria de Bayes para inferir qual a classe mais provável de um objeto (Seção A.3).

Por outro lado, algoritmos não supervisionados procuram identificar padrões de organização nos dados sem que haja uma classificação prévia dos exemplos. Técnicas de agrupamento se encaixam nesta categoria de soluções, onde grupos são extraídos dos dados sem que haja uma atribuição explícita de classes aos objetos (Seção A.2).

\subsection{Avaliação de recomendadores}

A avaliação de sistemas de recomendação não é uma tarefa trivial, principalmente porque não há consenso sobre quais atributos devem ser observados e quais métricas devem ser adotadas para cada atributo [Herlocker et al. 2004]. Ademais, diferentes estratégias podem funcionar melhor ou pior, de acordo com o domínio da aplicação e as propriedades dos dados. Por exemplo, algoritmos projetados especificamente para conjuntos de dados com um número muito maior de usuários do que de itens podem se mostrar inapropriados em domínios onde há muito mais itens do que usuários.

A compreensão das ações para as quais o sistema foi projetado (Seção 3.3) é de fundamental importância para o planejamento dos testes e deve fundamentar as decisões metodológicas ao longo dos experimentos. Por exemplo, se a principal ação do recomendador é sugerir os $n$ itens mais relevantes, deve-se priorizar modelos que tenham uma baixa taxa de erro entre os $n$ primeiros itens; por outro lado, se todos os itens relevantes devem ser necessariamente retornados, o modelo ideal é o que maximiza a recuperação dos itens relevantes, independente da posição em que aparecem.

\subsubsection{Seleção dos dados}

[Herlocker et al. 2004] classifica procedimentos de avaliação quanto ao conjunto de dados utilizados como (a) análises offline, que utilizam bases de dados previamente coletadas e (b) experimentos "ao vivo", realizados diretamente com usuários, seja num ambiente controlado (laboratório) ou em campo.

Análises offline geralmente são objetivas, com foco na acurácia das predições e performance das soluções [Vozalis and Margaritis 2003]. Inicialmente os dados são particionados em porções de treinamento e de testes. Utiliza-se como base os dados de treinamento para prever recomendações para itens da porção de testes. Em seguida é feita a análise comparativa entre os resultados obtidos e os esperados. A Seção 3.7.2 apresenta algumas métricas comumente utilizadas para comparar o desempenho de cada solução. No entanto, tais análises são prejudicadas em conjuntos de dados esparsos. Não se pode, por exemplo, avaliar a exatidão da recomendação de um item para um usuário se não existe uma avaliação prévia do usuário para tal item.

Por outro lado, nos experimentos "ao vivo" os recomendadores são disponibilizados para uma comunidade de usuários, cujas avaliações são coletadas na medida em que são produzidas. Nesse caso, além de análises objetivas como a acurácia das soluções, pode-se avaliar fatores comportamentais como a participação e satisfação dos usuários. A esparsidade dos dados tem efeito menor nesse tipo de experimento, visto que o usuário está disponível para avaliar se os itens recomendados são de fato relevantes ou não. 
Quando não existem dados previamente disponíveis ou quando não são adequados para o domínio ou a ação principal do sistema a ser avaliado, pode-se ainda optar pelo uso de dados sintéticos. O uso de dados artificiais é aceitável em fases preliminares de testes, porém, tecer conclusões comparativas é arriscado uma vez que os dados produzidos podem se ajustar melhor para uma estratégia do que para outras [Herlocker et al. 2004].

\subsubsection{Métricas}

A utilidade prática de um sistema de recomendação pode ser avaliada a partir da observação de aspectos distintos, que comumente são combinados numa situação de comparação. Existem diversas métricas para avaliar a acurácia dos resultados, ou seja, o quanto que as estimativas previstas pelo sistema se aproximam das reais. Outro quesito é a cobertura do recomendador, que diz respeito à proporção de itens passíveis de serem recomendados entre todos os disponíveis. A satisfação do usuário ao utilizar o sistema também pode ser registrada, e informações como se ele foi surpreendido pelas recomendações pode revelar a qualidade do sistema de produzir recomendações não óbvias.

Para facilitar a percepção dos conceitos apresentados adiante, consideremos a seguinte situação. Um recomendador de aplicativos hipotético recomenda 20 programas a determinado usuário, dos quais apenas 14 são identificados por ele como de fato relevantes. O universo de aplicativos é composto por 500 itens e para participar do experimento pede-se que o usuário aprecie todos os itens e os classifique como relevantes ou irrelevantes. 150 foram apontados como relevantes.

O resultado da predição realizada pelo recomendador pode ser representado pela matriz de contingência da tabela 3.2. A quantidade de itens recomendados que de fato são relevantes é indicada pelos verdadeiros positivos (VP); falsos positivos (FP) representam a quantidade de itens incorretamente classificados como relevantes (rejeitados pelo usuário); os que não fazem parte da recomendação mas posteriormente foram marcados como relevantes são os falsos negativos ( $F N)$; e os verdadeiros negativos ( $V N)$ não foram recomendados nem classificados como relevantes pelo usuário.

\begin{tabular}{|c|cc|c|}
\hline & \multicolumn{2}{|c|}{ Predito } & \\
\hline \multirow{2}{*}{ Real } & $V P=14$ & $F N=136$ & positivo: 150 \\
& $F P=6$ & $V N=344$ & negativo: 350 \\
\hline & positivo: 20 & negativo: 480 & Total: 500 \\
\hline
\end{tabular}

Tabela 3.2: Matriz de contingência de uma recomendação

Duas categorias de métricas de acurácia são consideradas por [Herlocker et al. 2004]: acurácia de classificação, que diz respeito à frequência com a qual o sistema classifica os itens corretamente; e acurácia de predição, que pondera as diferenças entre as pontuações previstas para os itens e as reais.

Um medida simples de acurácia é quantificada pela proporção de itens classificados corretamente do total de itens do conjunto $\left(\frac{V P+V N}{P+N}\right)$. Esta métrica no entanto não considera a quantidade de objetos pertencentes a cada uma das classes e por esta razão pode causar uma falsa impressão de bons resultados. Por exemplo, suponha que $90 \%$ dos itens seja da classe $A$. Se um classificador indica a classe $A$ para todos os casos, ele apresenta uma acurácia de $90 \%$ mesmo sem ser útil na prática.

Algumas métricas comumente utilizadas para avaliar a eficácia de modelos preditivos são apresentadas a seguir e sumarizadas na tabela 3.3 .

\section{Precisão ou preditividade positiva}

Proporção de itens relevantes entre todos os classificados como relevantes. No exemplo dado, a precisão é de $70 \%\left(\frac{14}{20}\right)$. 


\section{Recuperação, sensibilidade ou taxa de verdadeiros positivos}

Proporção de itens apresentados como relevantes dentre todos os relevantes. Mede a capacidade do modelo de identificar resultados positivos. No exemplo, a recuperação é de $9.33 \%\left(\frac{14}{150}\right)$.

\section{Medida $F$}

A medida $F$ ( $F$ score) combina numa mesma métrica os valores de precisão $(p)$ e recuperação $(r)$. Sua forma mais conhecida é $F_{1}=\frac{2 p r}{p+r}$, que representa a média harmônica entre $p$ e $r$. Sua fórmula genérica é $F_{\beta}=\left(1+\beta^{2}\right) \frac{p r}{\beta^{2} p}+r$, sendo que $F_{2}$ prioriza recuperação em detrimento de precisão e $F_{0.5}$ pontua mais a precisão. No exemplo, os valores de $F_{1}, F_{2}$ e $F_{0.5}$ são, respectivamente, $0.16,0.21,0.56$.

\section{Especificidade ou taxa de verdadeiros negativos}

Proporção de verdadeiros negativos entre todos os classificados como negativos. Avalia a capacidade do modelo de identificar itens irrelevantes como tal. No exemplo, a especifidade é de $98 \%\left(\frac{344}{350}\right)$.

\section{Taxa de falsos positivos}

Proporção de negativos que foram classificados erroneamente como positivos. Esta medida é o complemento da especificidade (1-especificidade). No exemplo, tem valor de $2 \%$.

\section{Curva ROC}

As curvas ROC (Receiver Operating Characteristic) foram desenvolvidas em pesquisa para detecção de ruído em sinais de rádio. Atualmente é uma técnica bastante utilizada na definição de valores limítrofes para diagnósticos médicos.

A curva representa graficamente o poder discriminativo de um classificador binário. Cada ponto expressa a qualidade do resultado de um processo de classificação por meio da taxa de verdadeiros positivos (tpr) (sensibilidade) e taxa de falsos positivos (fpr) (complemento da especificidade). Os pontos são dispostos num gráfico com valores de tpr no eixo das ordenadas e $f p r$ nas abcissas.

Muitas técnicas de classificação produzem como resultado uma pontuação associada a cada item, que quando superior a um determinado limiar (ponto de corte) causa sua categorização para um grupo ou outro. Sendo assim, pontos de corte diferentes representam modelos preditivos distintos. A identificação do limiar que produz os melhores resultados de classificação pode ser auxiliada pela análise da curva ROC produzida a partir da variação do ponto de corte.

Alguns pontos do gráfico são bastante informativos. O ponto $(0,0)$ representa uma classificação que não produz resultados, nem positivos nem negativos; o ponto $(0,1)$ indica que todos os positivos são corretamente identificados e não há ocorrência de falsos positivos (situação de sensibilidade e especificidade máximas do recomendador). Um modelo que classifica todos os itens como positivos é representado pelo ponto $(1,1)$, enquanto que o $(1,0)$ representa um modelo que sempre faz predições incorretas.

A curva ROC de um classificador perfeito é desenhada sobre o eixo das abcissas até o ponto $(0,1)$ e segue na horizontal até o ponto $(1,1)$. Já um modelo com comportamento aleatório é representado na diagonal ascendente que liga os pontos $(0,0)$ e $(1,1)$. A Figura 3.6 ilustra o espaço ROC e alguns pontos resultantes de processos de classificação ${ }^{9}$.

Uma medida comum de comparação entre duas curvas ROC é a área sob a curva $(A U C)$, que é numericamente igual à probabilidade de, dados dois exemplos escolhidos

\footnotetext{
${ }^{9}$ Fonte: http://en.wikipedia.org/wiki/Receiver_Operating_Characteristic
} 


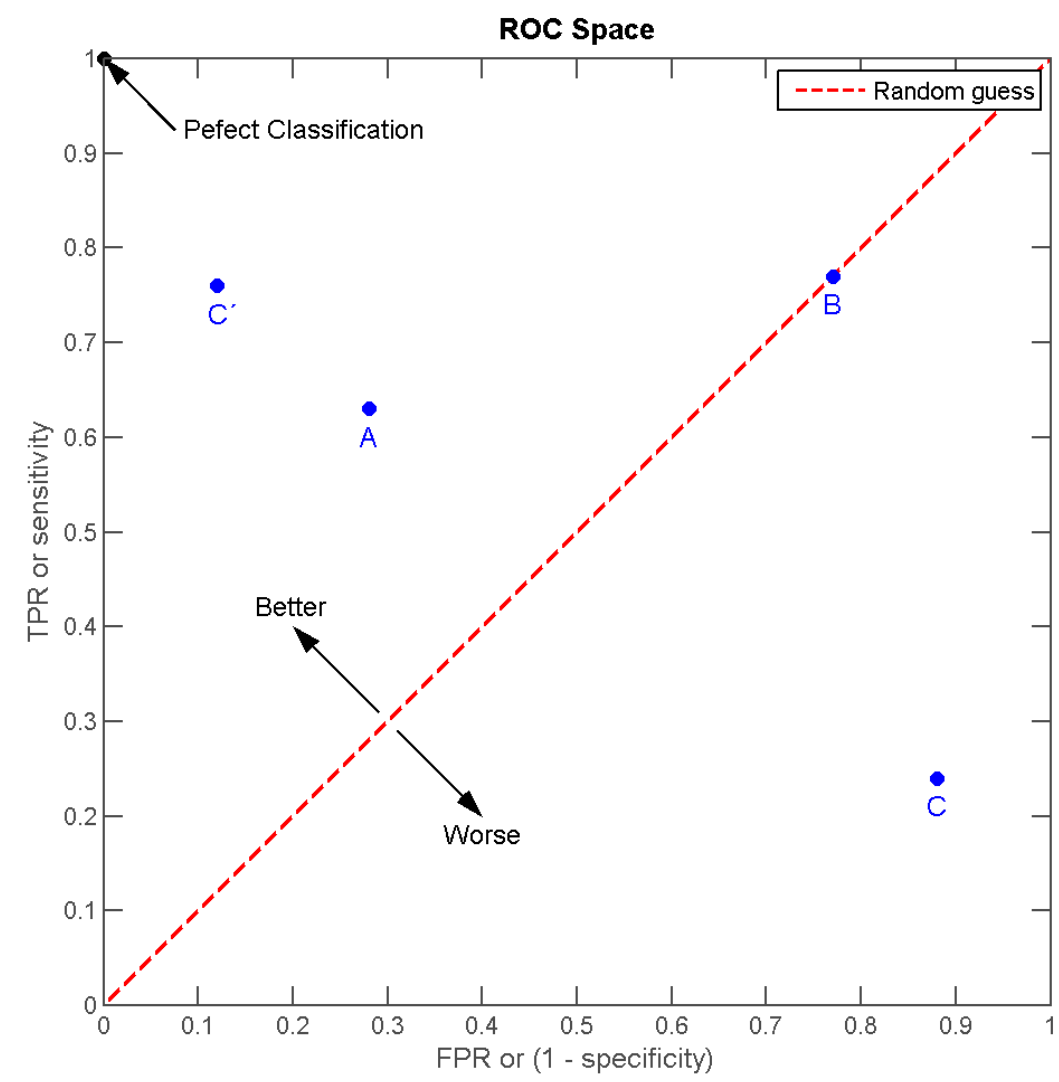

Figura 3.6: Ilustração do espaço ROC

randomicamente, um positivo e outro negativo, o positivo seja melhor pontuado que o negativo [Herlocker et al. 2004]. A figura 3.7 traz dois exemplos de gráficos ROC. A imagem da esquerda apresenta a área sob a curva de duas curvas ROC. A da direita representa a área sob a curva de um classificador discreto (A) e de um probabilístico (B).
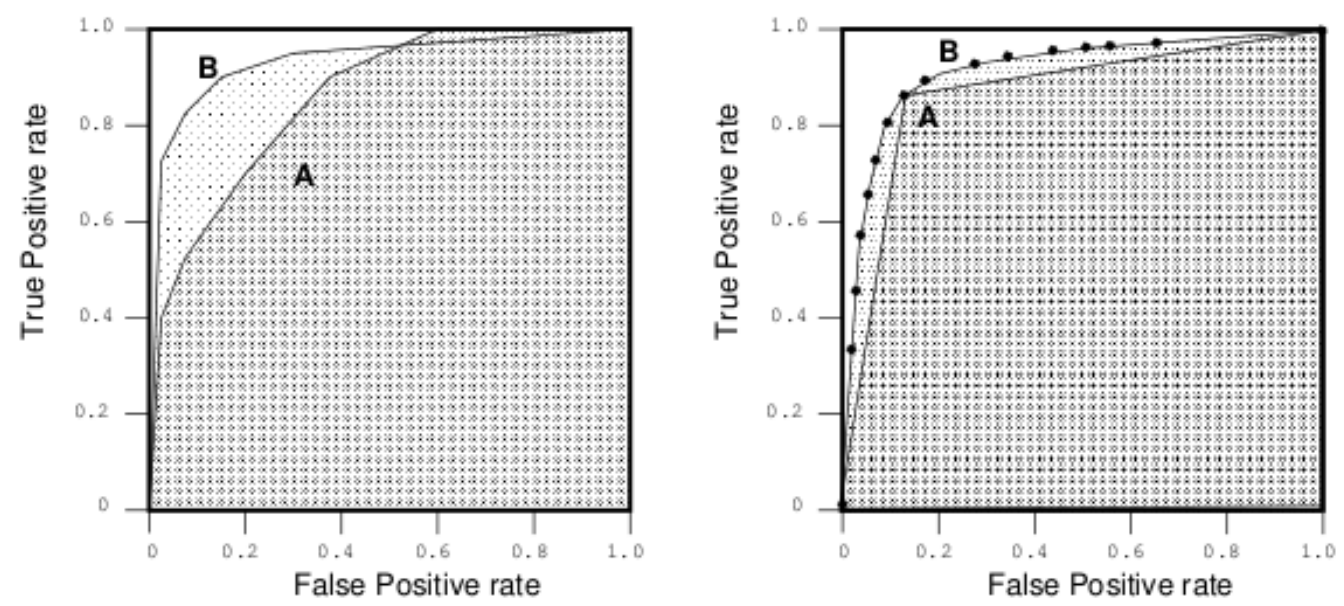

Figura 3.7: Exemplos de gráficos ROC [Fawcett 2007] 


\section{Coeficiente de correlação de Matthews (MCC)}

Resume as informações da matriz de contingência em um único valor. É geralmente utilizado para identificar o limiar com melhor resultado numa curva ROC. Os pontos com melhores MCC estão localizados no quadrante superior esquerdo do gráfico ROC.

\section{Erro absoluto e quadrático médio (MAE e MSE)}

Medidas de desvio médio absoluto (MAE) e quadrático (MSE) entre pontuações previstas $\left(p_{i}\right)$ e reais $\left(r_{i}\right)$. A acurácia do modelo é inferida a partir da comparação numérica entre os valores preditos e pontuações reais indicadas pelo usuário, para os itens cujas medidas são conhecidas.

\begin{tabular}{|c|c|c|}
\hline Métrica & Fórmula & Categoria \\
\hline Precisão & $p=\frac{V P}{(V P+F P)}$ & \multirow{6}{*}{ Acurácia de classificação } \\
\hline Recuperação & $r=\frac{V P}{(V P+F N)}$ & \\
\hline Medida $F_{1}$ & $F_{1}=\frac{2 p r}{p+r}$ & \\
\hline Especificidade & $\frac{V N}{V N+F P}$ & \\
\hline Curva $R O C$ & Área sob a curva (AUC) e MCC & \\
\hline $\mathrm{MCC}$ & $M C C=\frac{(V P * V N)-(F P * F N)}{\sqrt{(V P+F P)(V P+F N)(V N+F P)(V N+F N)}}$ & \\
\hline MAE & $|\bar{E}|=\frac{\sum_{i=1}^{N}\left|p_{i}-r_{i}\right|}{N}$ & \multirow{2}{*}{ Acurácia de predição } \\
\hline MSE & $|\bar{E}|=\frac{\sum_{i=1}^{N}\left|p_{i}-r_{i}\right|^{2}}{N}$ & \\
\hline
\end{tabular}

Tabela 3.3: Métricas de acurácia de sistemas preditivos

\subsubsection{Validação cruzada}

Técnicas de reamostragem, como a validação cruzada, são comumente utilizadas na avaliação de modelos preditivos, principalmente quando se dispõe de uma quantidade limitada de dados para testes. Isola-se uma porção aleatória dos dados cuja classe é conhecida; treina-se o modelo com os demais dados e em seguida a porção reservada é submetida ao modelo para testá-lo. A acurácia dos resultados pode então ser medida por meio da comparação dos resultados obtidos com os esperados. A validação em rodadas ( $k$-fold cross-validation) consiste basicamente nos seguintes passos:

1. O conjunto de dados original é particionado aleatoriamente em $k$ subconjuntos;

2. Em cada uma das $k$ rodadas:

(a) Um dos subconjuntos é reservado para testar o modelo;

(b) Os demais subconjuntos são passados ao modelo como dados de treinamento;

(c) Uma predição é gerada e avaliada por meio de métricas pertinentes.

3. Ao final dos testes, os $k$ resultados são combinados para produzir uma estimativa única. 


\subsection{Segurança da informação}

Por lidar com informações pessoais, ainda que anonimizadas, sistemas de recomendação são vulneráveis a ataques que podem comprometer a privacidade dos usuários. Qualquer possibilidade de revelação de dados não públicos é considerado um vazamento de informações do recomendador.

Considere a equação $F(D, q)=R$, onde $F$ é a função para composição das sugestões, $D$ o conjunto de dados utilizado pelo recomendador, $q$ a consulta e $R$ a recomendação. Em tese, se a função $F$ é pública, um atacante é capaz de realizar infinitas consultas a $F$, variando os valores de $R$ para descobrir quais seriam os possíveis conjuntos de dados $D$ que satisfariam a premissa $F(D, q)=R$. Quanto menos conjuntos de dados possíveis, maior é a vulnerabilidade do recomendador.

Na prática, pode-se partir de uma hipótese cuja validade é checada por meio de consultas ao recomendador. Dado que o atacante tem acesso a $F$, ele é capaz de inferir informações a partir da sugestão produzida. Por exemplo, dado que um usuário comprou os itens $a, b$ e $c$ e deseja-se saber se é provável que ele também tenha comprado $d$. O atacante pode realizar repetidas consultas ao recomendador, observando se $d$ aparece na recomendação com uma dada frequência.

Resultados de pesquisa recente apresentada por [Calandrino et al. 2011] também demonstram que mudanças em recomendações ao longo do tempo podem revelar transações de usuários, no caso em que informações auxiliares sobre os mesmos sejam conhecidas. Por exemplo, suponha que um atacante tenha conhecimento sobre compras anteriores de um cliente, visto que são dados públicos: avaliações de produtos e publicações em redes sociais realizadas pelo próprio usuário. Novas compras afetam os cálculos de similaridade entre os itens novos e antigos, possivelmente causando alterações perceptíveis para recomendações relacionadas aos itens antigos. O estudo demonstra que um atacante pode descobrir quais foram os novos itens comprados por meio de análises das mudanças relacionadas aos itens antigos.

Os ataques até então apresentados são classificados como ataques passivos, dado que o conjunto de dados original não é afetado. Um exemplo de ataque ativo seria o envio de perfis falsos de usuários ao recomendador para modificar seu comportamento, aumentando assim a chance de sucesso em ataques posteriores. 


\section{Capítulo 4}

\section{Trabalhos correlatos}

Nos últimos anos foram publicados, em âmbito nacional e internacional, diversos trabalhos acadêmicos nas áreas de mineração de dados e recuperação da informação aplicadas aos mais diversos domínios. Neste capítulo apresentamos trabalhos correlatos que tratam especificamente do problema de recomendação desenvolvidos no contexto de aplicativos. São também mencionados a seguir projetos desenvolvidos de maneira independente que, mesmo sem o rigor acadêmico, serviram como fontes de inspiração e referências.

\subsection{Anapop/Popsuggest}

Esta solução foi disponibilizada em 2007 pelo desenvolvedor Debian Enrico Zini ${ }^{1}$ como uma ilustração das possibilidades de uso dos dados coletados pelo Popcon - concurso de popularidade de pacotes Debian apresentado na Seção 5.3.3.

A ferramenta anapop indexava previamente a base de dados integral do Popcon. Diante de uma lista de pacotes de determinado usuário, por meio de buscas no índice previamente criado, o popsuggest sugeria pacotes que usuários de perfil similar tinham instalados. Este é um exemplo de aplicação de estratégia de recomendação colaborativa, implementado de forma ingênua, uma vez que nenhuma seleção de atributos era realizada.

O serviço foi disponibilizado na Web por alguns meses, porém, segundo depoimento do autor durante a DebConf $11^{2}$, foi descontinuado por falta de colaboradores interessados em evoluir o protótipo.

\subsection{Debommender}

O Debommender é um sistema de recomendação para pacotes GNU/Linux desenvolvido no âmbito de um trabalho final de graduação, apresentado em 2007 na Universidade Federal do Rio Grande do Sul [Pereira 2007]. Segundo o autor, a ferramenta foi desenvolvida como prova de conceito, não sendo portanto integrada aos serviços da distribuição.

Foram realizados experimentos com cerca de 30 usuários para avaliar a eficácia das soluções implementadas. O modelo que obteve melhores resultados utilizava uma estratégia híbrida por ponderação, onde os resultados de um componente baseado em conteúdo e outro colaborativo eram combinados de acordo com pesos estabelecidos.

A fonte de dados utilizada pelo recomendador para estratégias colaborativas era o conjunto de dados de entrada fornecidos pelos usuários participantes dos experimentos (suas listas de pacotes). Talvez por este motivo, as estratégias baseadas em conteúdo obtiveram melhor

\footnotetext{
${ }^{1}$ http://www.enricozini.org/2007/debtags/popcon-play/

${ }^{2}$ http://penta.debconf.org/dc11_schedule/events/773.en.html)
} 
cobertura (proporção de itens disponíveis passíveis de recomendação) do que as colaborativas, pois, devido ao número reduzido de usuários, muitos pacotes disponíveis não estavam presentes em nenhum perfil e portanto não podiam aparecer nas recomendações produzidas.

\subsection{Mineração de dados do Popcon}

Trabalho de mestrado que experimentou a implementação de técnicas de mineração de dados na base do popcon para produção de regras de associação. A dissertação com título "Projeto e criação de um sistema para produção de sugestões personalizadas para o Instalador Debian"3 foi defendida em agosto de 2007 na Universität Paderborn, na Alemanha [Schröder 2007].

O trabalho foi apresentado na conferência anual de Desenvolvedores Debian (DebConf $7^{4}$ ), ainda em fase de desenvolvimento. Segundo relato do autor durante a DebConf11, a geração de regras de associação se mostrou bastante custosa e, diante do crescimento do repositório de pacotes desde 2007, talvez a solução tenha se tornado impraticável.

\subsection{AppStream}

Grande parte das distribuições GNU/Linux têm investido no desenvolvimento de interfaces para facilitar o gerenciamento de aplicativos e a forma como se obtém informações sobre os mesmos. Entre os dias 18 e 21 de janeiro 2011 aconteceu a primeira reunião acerca desta temática com a presença de desenvolvedores de distribuições variadas (Cross-distribution Meeting on Application Installer). O encontro teve como principais objetivos a definição de padrões entre os diferentes projetos no que diz respeito a: procedimentos de instalação de aplicações; metadados associados aos pacotes; o modo como tais informações devem ser geradas e armazenadas; protocolo para manutenção de metadados dinâmicos; e a definição de quais metadados devem ser compartilhados entre as distribuições, em detrimento de outros considerados específicos de cada projeto [Freedesktop 2011].

Decidiu-se que a colaboração entre os diversos serviços seria guiada pela especificação OCS (Open Collaboration Services) $^{5}$, um padrão aberto projetado para dar suporte à colaboração entre serviços web, permitindo o armazenamento de avaliações de usuários e outras informações do domínio de aplicação.

Apesar de o Software Center não estar em conformidade com a especificação OCS, esta foi a ferramenta escolhida como plataforma base de desenvolvimento do AppStream, dado que há interesse por parte dos desenvolvedores de adequá-lo ao padrão. A única pendência com relação à adoção deste software é a exigência por parte da Canonical - empresa responsável pelo desenvolvimento do Ubuntu - de que todos os colaboradores do projeto assinem um termo de atribuição de copyright (Canonical Contributor License Agreement) ${ }^{6}$. Esta exigência, além de causar antipatia de alguns membros da comunidade que se recusam a assinar o termo por entenderem que ele vai de encontro com a sua liberdade, de fato impossibilita a participação no projeto de desenvolvedores que são contratados por outras empresas as quais não permitem a assinatura de tal termo com terceiros. O impasse ainda não foi resolvido e atualmente o andamento dos trabalhos está suspenso ${ }^{7}$.

\footnotetext{
${ }^{3}$ Tradução do título original do trabalho no idioma alemão.

${ }^{4}$ https://penta.debconf.org/ joerg/events/83.en.html

${ }^{5}$ http://www. freedesktop.org/wiki/Specifications/open-collaboration-services

${ }^{6}$ http://www.canonical.com/contributors

${ }^{7}$ http://lists.freedesktop.org/archives/distributions/2011-May/000583.html
} 


\subsection{Armazenamento de avaliações e comentários}

A Canonical mantém um servidor para armazenar avaliações de usuários sobre aplicativos, com pontuação e comentários (Ubuntu Ratings and Reviews Server ${ }^{8}$ ). Esta pode vir a ser uma poderosa fonte de dados para a produção de recomendações sobre aplicativos, alternativa à base do Popcon, que não foi projetada para fins de recomendação. No entanto, os detalhes de implementação do servidor não são públicos e ao que tudo indica a Canonical deve manter este esforço como uma iniciativa própria.

Embora já faça parte da pauta de discussões no contexto do FreeDesktop.org um esquema global de armazenamento de avaliações sobre aplicativos enviadas por usuários de múltiplas distribuições, ainda não há previsão para tal solução ser implementada [Freedesktop 2011].

\subsection{Recomendadores para dispositivos móveis}

A explosão no uso de dispositivos móveis na última década naturalmente refletiu-se no desenvolvimento em larga escala de aplicativos para estes dispositivos. A maioria destes programas não é livre e a documentação geralmente é escassa, portanto o conhecimento em detalhes das estratégias de recomendação adotadas é prejudicado. Abaixo estão listados alguns recomendadores de aplicativos para os dispositivos iPhone, iPod e iPad, desenvolvidos pela Apple, e Android, desenvolvido pela Google.

\section{Genius}

Sistema de recomendação desenvolvido pela Apple, inicialmente para ser acoplado ao iTunes e oferecer sugestões de músicas para os usuários. A partir do iOS 3.1, o recomendador pode ser utilizado para sugerir aplicativos da loja da Apple (App Store) com base nos programas já instalados no dispositivo. Para compor recomendações, o Genius envia periodicamente à Apple informações sobre os aplicativos instalados. O histórico de compras do usuário na App Store e informações fornecidas por outros clientes também são utilizados para deduzir recomendações mais relevantes ${ }^{9}$.

\section{Appolicious}

Serviço que permite a navegação por categorias de aplicativos, busca simultânea em repositórios de aplicativos para Android e iPhone, além de fornecer listas do tipo "os 10 mais"10.

\section{Heyzap}

Recomendador para Android e iPhone especializado em jogos que utiliza estratégia colaborativa para composição de sugestões personalizadas ${ }^{11}$.

\section{Explor}

Produz recomendações personalizadas para iPhone com compartilhamento de favoritos com rede de amigos $^{12}$.

\footnotetext{
${ }^{8}$ http://launchpad.net/rnr-server

${ }^{9}$ http://support.apple.com/kb/HT2978

${ }^{10}$ http://www . androidapps.com/

${ }^{11}$ http://www.heyzap.com/

${ }^{12}$ http://explorapp.com/
} 


\section{Apptitude}

Sistema de recomendação de aplicativos para iPhone que faz interface com o Facebook ${ }^{13}$ para obtenção da rede de amigos do usuário. Para inferir a lista de aplicativos dos amigos, o sistema analisa as publicações no mural dos usuários da rede social, além de itens marcados como interessantes ("curtir"), portanto não exige que os amigos também sejam usuários cadastrados ${ }^{14}$.

\section{Applause}

Recomendador para Android baseado em informações de contexto, como localização do usuário, passatempo favorito, idade e compromissos agendados. O sistema ainda está em fase de desenvolvimento, no entanto o Departamento de Informática (ICS) da universidade UC Irvine já disponibilizou um survey para avaliar os métodos de aquisição de informações de contexto ${ }^{15}$.

\footnotetext{
${ }^{13}$ http://www.facebook.com

${ }^{14}$ http://www .apptitu.de/

${ }^{15}$ http://ucistudy.ics.uci.edu/android/
} 


\section{Capítulo 5}

\section{AppRecommender}

Este capítulo apresenta o AppRecommender como proposta de um recomendador de aplicativos GNU/Linux. Detalhamento sobre o problema abordado, justificativa de escolha da plataforma, fontes de dados da solução, decisões de projeto e estratégias implementadas são alguns dos tópicos abordados a seguir.

\subsection{Caracterização do problema}

A composição de recomendações de forma automatizada consiste na dedução de um conjunto de itens de potencial interesse para determinado usuário a partir da avaliação prévia realizada por ele acerca de um conjunto de itens de que tem conhecimento. De acordo com a estratégia de recomendação escolhida, podem ser sugeridos por exemplo itens com características semelhantes aos considerados relevantes ou, diante da disponibilidade de avaliações por outros usuários, itens bem avaliados por indivíduos com perfis similares podem fazer parte da recomendação.

No contexto deste trabalho, os clientes do recomendador são instâncias de sistemas GNU/Linux. Os programas são mapeados como itens, de modo que o perfil do usuário é composto a partir da lista de aplicativos instalados no sistema. Neste modelo não existem avaliações explícitas sobre a relevância dos itens para o usuário. O perfil é definido pelo comportamento do sistema, caracterizando uma avaliação implícita, ao assumirmos que a presença de um aplicativo em sua lista de programas é um indicativo de relevância. Para o caso de pontuação multi-valorada, além da lista de aplicativos instalados, informações adicionais precisam ser disponibilizadas. Por exemplo, a indicação de utilização recente de um programa pode resultar numa pontuação superior do que a de um aplicativo que não tenha sido executado há bastante tempo.

Um caso de uso típico do AppRecommender é então caracterizado da seguinte maneira: dada a lista de programas instalados em determinado sistema, o recomendador retorna uma lista de aplicativos sugeridos, que supostamente são aplicativos de potencial interesse para os usuários daquele sistema.

\subsection{Escolha da plataforma}

A distribuição escolhida como base para o desenvolvimento deste trabalho foi o Debian GNU/Linux. No entanto, a independência de plataforma foi sempre levada em consideração na fase de desenvolvimento com o intuito de que os resultados sejam facilmente adaptáveis para outros ambientes. As seguir estão descritos os critérios que pautaram esta escolha.

1. Debian!distribuição de aplicativos 
2. Esquema consistente de distribuição de aplicativos. O gerenciamento de pacotes em sistemas Debian GNU/Linux é realizado pelo apt, cujas funcionalidades foram apresentadas na Seção 2.4.1. Apesar de atualmente outras distribuições oferecerem ferramentas similares, o apt é certamente uma das mais maduras, sendo geralmente apontada como uma das principais razões da explosão no surgimento de distribuições derivadas do Debian, herdeiras do esquema.

3. Disponibilidade de dados estatísticos. A base de dados do Popcon (Seção 5.3.3)

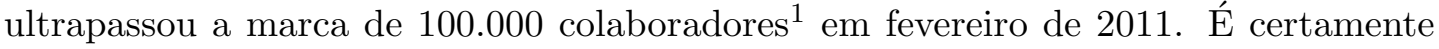
uma das maiores coleções de dados disponíveis atualmente sobre a utilização de pacotes Debian, compondo uma importante fonte de informação para a realização de estratégias colaborativas de recomendação.

4. Popularidade. O Debian é um projeto de destaque no ecossistema do software livre. Desde o lançamento da primeira versão de sua distribuição, em 1993, o projeto cresceu bastante em termos de componentes de software (atualmente provê mais de 25.000 pacotes), colaboradores e usuários. A Distrowatch, que tem 323 distribuições ativas em sua base de dados ${ }^{2}$, classifica o Debian GNU/Linux entre as 10 distribuições mais populares ${ }^{3}$. Em suas estatísticas de páginas mais visitadas o Debian aparece na quinta posição ${ }^{4}$. Já o Linux Counter apresenta o Debian como a segunda distribuição mais popular $-16 \%$ das máquinas cadastradas que rodam o kernel Linux ${ }^{5}$, ficando atrás apenas do Ubuntu ${ }^{6}$, que é uma distribuição derivada do Debian, com $24 \%$. Nas pesquisas da $W^{3}$ Techs sobre tecnologias para serviços web, o Debian aparece em segundo lugar, estando presente em $27 \%$ dos servidores ${ }^{7}$ — na primeira posição está o CentOS com $31 \%$.

5. Maturidade do projeto. De modo geral, quando o projeto Debian é mencionado tratase não somente do sistema operacional, mas de toda a infraestrutura de desenvolvimento e coordenação que dá suporte ao trabalho de cerca de 900 desenvolvedores oficiais ${ }^{8}$, além de outros milhares de colaboradores ao redor do globo. O trabalho é realizado de forma colaborativa, afinado pelo objetivo comum de produzir e disponibilizar livremente um sistema operacional de qualidade para seus usuários [Jackson and Schwarz 1998]. A interação entre os desenvolvedores acontece majoritariamente pela Internet, por meio de canais IRC e listas de discussão públicas. Não existe uma entidade formal ou qualquer tipo de organização que concentre, coordene ou defina as atividades do projeto. O que se observa é um modelo de governança consolidado que emergiu naturalmente ao longo de sua história [O’Mahony and Ferraro 2007].

6. Possibilidade de integração dos resultados do trabalho. De acordo com o contrato social do Debian ${ }^{9}$, o desenvolvimento do projeto é pautado pelas necessidades dos usuários e da comunidade FOSS $^{10}$. Portanto as iniciativas de colaboradores individuais, sejam eles desenvolvedores oficiais ou não, serão igualmente consideradas e poderão fazer

\footnotetext{
${ }^{1}$ http://lists.alioth.debian.org/pipermail/popcon-developers/2011-February/001913.html

${ }^{2}$ Consulta realizada em 24 de janeiro de 2011.

${ }^{3}$ http://distrowatch.com/dwres.php?resource=major

${ }^{4}$ http://distrowatch.com/stats.php?section=popularity

${ }^{5}$ http://counter.li.org/reports/machines.php

${ }^{6}$ http://www . ubuntu.com/community/ubuntu-and-debian

${ }^{7}$ http://w3techs.com/technologies/history_details/os-linux

${ }^{8}$ http://www.perrier.eu.org/weblog/2010/08/07\#devel-countries-2010

${ }^{9}$ http://www.debian.org/social_contract.pt.html

${ }^{10}$ Acrônimo pra Free and Open Source Software
} 
parte da distribuição desde que sigam os princípios do projeto e sejam considerados úteis para a comunidade. A autora deste trabalho colabora com o projeto desde 2005, tendo atuado em esforços de tradução, empacotamento de programas, organização da conferência anual de desenvolvedores e atualmente faz parte da equipe do Debtags ${ }^{11}$.

\subsection{Fontes de dados}

O projeto Debian tem se destacado no universo das distribuições por suas iniciativas pioneiras no campo de gerenciamento de aplicações [Zini 2011b]. Diante da complexa e crescente estrutura do projeto, observa-se um esforço por parte dos desenvolvedores, principalmente da equipe responsável pelo controle de qualidade ${ }^{12}$, de reunir, organizar e disponibilizar as informações ou meta-dados concernentes a esta estrutura [Nussbaum and Zacchiroli 2010].

Algumas destas iniciativas que serviram como fontes de dados para o AppRecommender são detalhadas a seguir. Importante ressaltar que todas estas foram desenvolvidas inicialmente num contexto extra-oficial e, ao passo em que se mostraram úteis e eficazes, foram absorvidas pela comunidade de usuários e desenvolvedores.

\subsubsection{Debtags}

Para fins de organização, o repositório oficial Debian é particionado em seções, que atualmente representam 53 grupos de pacotes ${ }^{13}$. A seção de um pacote é definida no momento do empacotamento, dado que vem declarada em seu conteúdo (arquivo control).

Debtags é um esquema de classificação idealizado por Enrico Zini como uma maneira de categorizar pacotes alternativa às seções [Zini 2011a]. A principal motivação desta iniciativa foi a impossibilidade de relacionar pacotes a múltiplas seções. Um navegador web, por exemplo, não poderia ser categorizado como network e web simultaneamente. O uso de tags (em português, rótulos) possibilitaria a criação de uma coleção estruturada de metadados que poderia ser utilizada para implementar métodos mais avançados do que os existentes para apresentação, busca e manutenção do repositório de pacotes Debian.

A proposta foi apresentada na DebConf5 e foi paulatinamente sendo adotada por desenvolvedores em suas atividades, sendo atualmente utilizada como base de inúmeras ferramentas no Debian, tendo atingido a marca de $45 \%$ de pacotes categorizados ${ }^{14}$.

Utilizando Debtags, os pacotes podem ser caracterizados por múltiplos atributos, que são (propositalmente) definidos num momento posterior à concepção do pacote. Dado que a base de tags é mantida de forma independente ao repositório, as modificações ao longo do tempo não trazem impacto algum ao desenvolvimento de pacotes. A atribuição de tags a pacotes é realizada por colaboradores por meio do website do projeto $^{15}$ e revisada manualmente antes de ser incorporada à base de dados.

A base de dados é armazenada num arquivo texto que segue um formato simples, ilustrado na Figura 5.1. O conjunto de tags disponível faz parte de um vocabulário controlado ${ }^{16}$, que também recebe contribuições de colaboradores. O esquema é estruturado para permitir a classificação por diferentes pontos de vista, que caracterizam as facetas.

Ao indicar novas tags para um pacote, o usuário é surpreendido com sugestões de outras tags que geralmente são aplicadas em conjunto com as já selecionadas. Esta é uma aplicação de recomendação com base em regras de associação descobertas a partir de análise da base de

\footnotetext{
${ }^{11}$ http://www.ime.usp.br/ ${ }^{\sim}$ tassia/debian.html

${ }^{12}$ http://qa.debian.org

${ }^{13}$ http://packages . debian.org/unstable/

${ }^{14}$ Consulta realizada em junho de 2011

${ }^{15}$ http://debtags.alioth.debian.org/todo.html

${ }^{16}$ http://debtags.alioth.debian.org/vocabulary/
} 


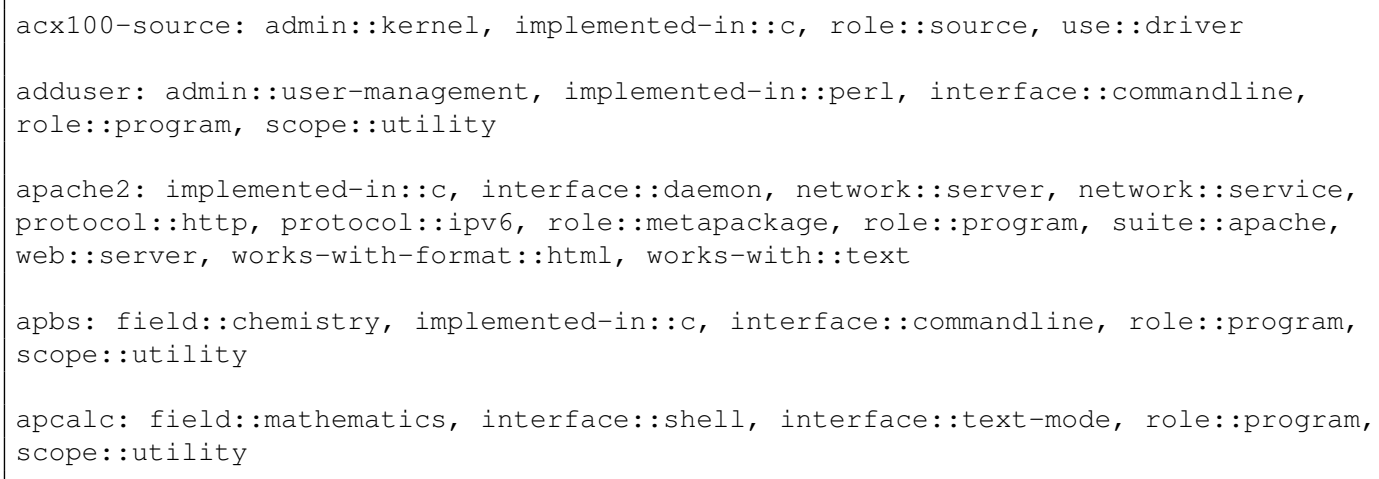

Figura 5.1: Excerto da base do Debtags

dados de tags. O algoritmo utilizado para produção das regras é o Apriori, descrito na Seção A.6.

O Debtags é uma poderosa ferramenta para a construção de estratégias de recomendação de pacotes baseadas em conteúdo. É fato que o conteúdo acerca de pacotes pode ser expresso em termos de atributos extraídos dos próprios pacotes, porém, a caracterização por meio de tags já fornece uma caracterização possível de ser utilizada e a baixo custo computacional.

\subsection{2 Índice de informações sobre pacotes (apt-xapian-index)}

O pacote apt-xapian-index ${ }^{17}$ provê um conjunto de ferramentas para manutenção e busca em um índice Xapian de informações sobre pacotes Debian. update-apt-xapian-index permite a instalação de plugins no diretório / usr/share/apt-xapian-index para indexar qualquer tipo de informação relacionada aos pacotes, como tags, popularidade ou pontuação. A ferramenta axi-cache pode ser utilizada para consultas no índice.

O índice criado é mantido em / var/lib/apt-xapian-index. Cada pacote é representado por um documento e as meta-informações relacionadas são mapeadas em termos dos documentos. Alguns termos são indexados com prefixos especiais para facilitar a busca, por exemplo, "XP" para o nome do pacote, "XS" para a seção do pacote no repositório, "XT" para tags e "Z" para termos lematizados. A Figura 5.2 apresenta a lista de termos indexados para o pacote 2vcard.

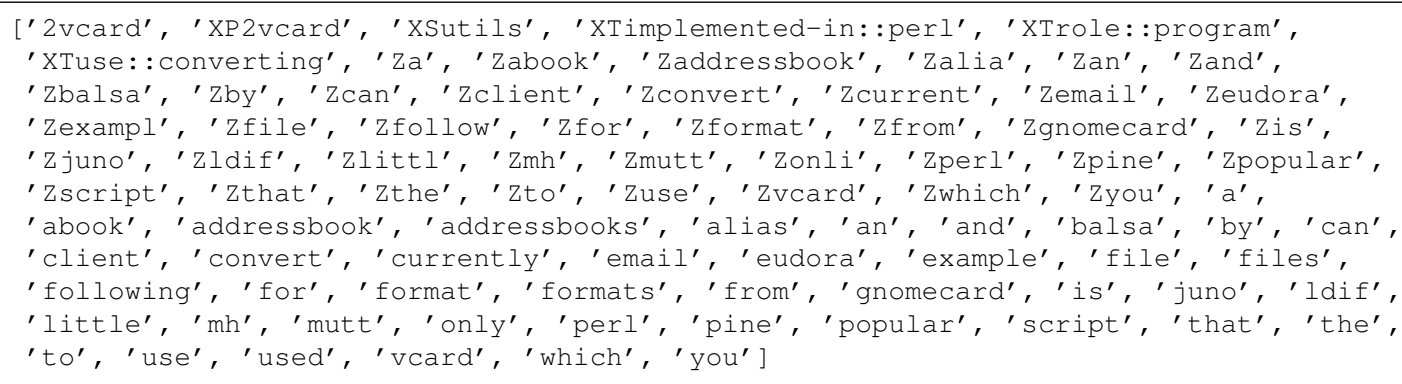

Figura 5.2: Lista de termos indexados para o pacote 2vcard

\footnotetext{
${ }^{17}$ http://www.enricozini.org/sw/apt-xapian-index/
} 


\subsubsection{Popularity Contest (popcon)}

O popcon é um "concurso de popularidade" entre pacotes Debian criado pelo desenvolvedor Avery Pennarun em 1998 com o propósito inicial de auxiliar a escolha dos pacotes que devem ser incluídos no primeiro CD de instalação ${ }^{18}$ (os mais populares são selecionados). Atualmente o repositório de pacotes Debian pode ser obtido em 52 imagens de CDs ou 8 de DVD. Dado que comumente apenas a primeira imagem é obtida por download - os demais pacotes podem ser obtidos diretamente do repositório por meio de uma conexão de rede - a priorização de pacotes populares na primeira imagem tende a contribuir para a satisfação dos usuários.

Na instalação de um sistema Debian o administrador é convidado a participar do concurso. Se aceitar, o software cliente do Popcon é instalado na máquina e envia para um servidor central periodicamente a lista de pacotes instalados naquele sistema, indicando ainda quando cada pacote foi utilizado pela última vez.

A Figura 5.3 apresenta um exemplo de submissão do Popcon. Os campos temporais são indicados no formato Unix time_t $t^{19}$. A primeira linha contém um hash que identifica um sistema unicamente no concurso. Cada linha seguinte representa um pacote instalado no

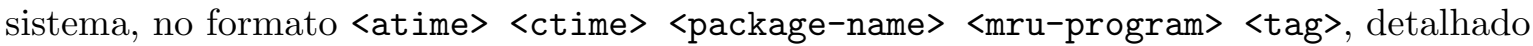
na tabela 5.1.

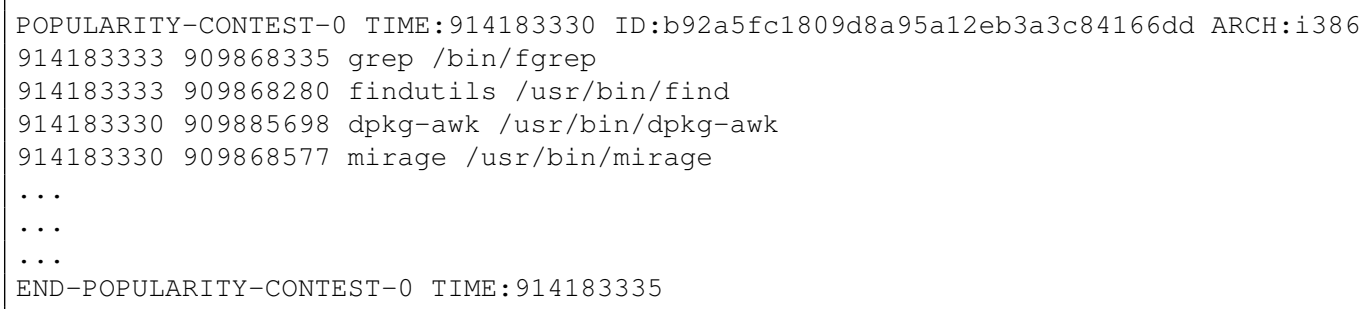

Figura 5.3: Exemplo de submissão do Popcon

\begin{tabular}{|c|l|}
\hline \multicolumn{1}{|c|}{ Campo } & Descrição \\
\hline$<$ package-name $>$ & Nome do pacote Debian que contém o arquivo <mru-program $>$ \\
\hline$<$ mru-program $>$ & $\begin{array}{l}\text { Programa, biblioteca ou cabeçalho contido no pacote que foi utilizado mais } \\
\text { recentemente. }\end{array}$ \\
\hline$<$ atime $>$ & $\begin{array}{l}\text { Tempo de acesso do }<\text { mru-program }>\text { no disco, atualizado pelo kernel cada vez que } \\
\text { o arquivo é aberto. }\end{array}$ \\
\hline$<$ ctime $>$ & $\begin{array}{l}\text { Tempo de criação do }<\text { mru-program }>\text { no disco, definido no momento de instalação } \\
\text { do pacote. }\end{array}$ \\
\hline$<$ tag $>$ & $\begin{array}{l}\text { RECENT-CTIME: indica que }<\text { atime }>\text { é muito próximo de }<\text { ctime }>\text {, geralmente } \\
\text { quando o pacote foi recentemente instalado ou atualizado; OLD: }<\text { atime }>\text { é anterior } \\
\text { a 30 dias atrás, portanto o pacote não foi usado no último mês; NOFILES: o } \\
\text { pacote não contém programas, portanto }<\text { atime }>,<\text { ctime }>\text { e }<\text { mru-program }>\text { são } \\
\text { inválidos. }\end{array}$ \\
\hline
\end{tabular}

Tabela 5.1: Descrição do formato de uma submissão popcon

A informação sobre o uso dos pacotes também tem sido utilizada como guia para o time de qualidade acerca de quais pacotes merecem atenção especial. Os times de tradução também têm considerado estes dados para ordenar sua lista de prioridades de acordo com a popularidade dos pacotes. Por outro lado, a baixa popularidade é um dos parâmetros para a remoção de um pacote do repositório (low-popcon). Pacotes considerados problemáticos ${ }^{20}$ que não são populares tendem a perder a simpatia dos desenvolvedores.

\footnotetext{
${ }^{18}$ http://lists.debian.org/debian-devel-announce/2004/03/msg00009.html

${ }^{19}$ Quantidade de segundos desde meia-noite de primeiro de janeiro de 1970 no horário GMT.

${ }^{20}$ p. ex. pacotes órfãos (sem mantenedor) ou cujo mantenedor está inativo há bastante tempo (na terminologia
} 
Essa abordagem, no entanto, tem sido duramente criticada. Segundo Joey Hess ${ }^{21}$, uma vantagem do Debian é justamente que não apenas programas populares são empacotados, mas os incomuns e específicos de um nicho de usuário também costumam estar disponíveis em pacotes. E de fato o popcon não mede o benefício de pacotes pouco usados estarem disponíveis no repositório, prontos para serem usados. Portanto, ao remover pacotes que aparentemente não são populares corre-se o risco de transformar o Debian numa distribuição homogênea, submetida à "tirania da maioria".

Existem ainda questões relativas a (1) representatividade desses dados, visto que alguns perfis de usuários dificilmente participam do concurso (p. ex. sistemas embarcados); e (2) acurácia de informações temporais, dado que <atime> e <ctime> podem ser inconsistentes caso o sistema de arquivos tenha sido montado com a opção noatime.

Todas essas ressalvas devem ser consideradas quando pretende-se utilizar os dados do Popcon. No entanto, desde que as informações sejam manejadas de forma consciente e responsável, acredita-se que valiosas correlações possam ser reveladas após uma série de análises.

As submissões recebidas são processadas diariamente e as estatísticas geradas são disponibilizadas na página web do projeto ${ }^{22}$. As listas de pacotes originais submetidas não são publicadas a fim de preservar a privacidade dos usuários. No entanto, para a realização deste trabalho o acesso foi permitido mediante supervisão de desenvolvedores oficiais do projeto. Os dados "crus" (antes do processamento de estatísticas) são essenciais para a realização de estratégias de recomendação colaborativas por preservarem os relacionamentos usuários-itens, e já foram utilizados anteriormente para o mesmo fim (seções 4.1 e 4.3).

\subsubsection{Ultimate Debian Database (UDD)}

O UDD $^{23}$ é uma iniciativa recente do time de qualidade criada com o intuito de reunir informações de diversos aspectos do Debian numa base de dados única [Nussbaum and Zacchiroli 2010].

O fluxo de dados do UDD é apresentado na Figura 5.4. Existe um coletor para cada fonte de dados (p. ex. o BTS, sistema de acompanhamento de bugs ${ }^{24}$ ) que implementa uma interface comum e esconde a complexidade e especificidade de acessar cada uma dessas fontes. Existe um processo central no UDD que invoca os coletores periodicamente, provocando a inserção dos dados na base única.

A principal motivação para o desenvolvimento do UDD foi a de auxiliar a equipe de qualidade em suas atividades, além de facilitar a colaboração com distribuições derivadas do Debian. Apesar de ser possível, dificilmente usuários consultariam esta base para tomar decisões acerca de que pacotes utilizar, visto que os dados armazenados no UDD geralmente são acessíveis por outros meios. No entanto, para fins de mineração de dados ou para o desenvolvimento de um recomendador automático, a possibilidade de acesso a dados de tamanha heterogeneidade numa fonte de dados única é um grande benefício.

\subsubsection{Debian Data Export (DDE)}

Informações sobre o Debian e seus pacotes são publicadas em diversos tipos de formato, por vezes específicos e obscuros, e nem sempre de fácil localização. O $\mathrm{DDE}^{25}$ foi criado para facilitar a publicação e aquisição destas informações e a descoberta de quais informações estão

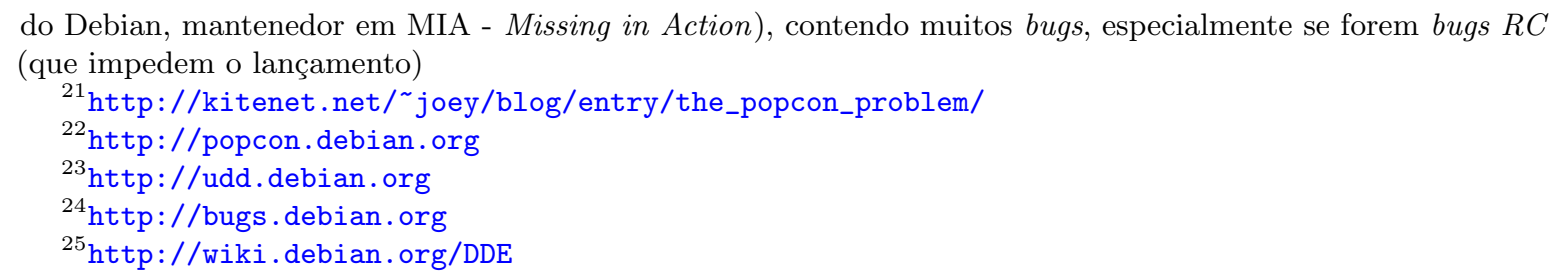




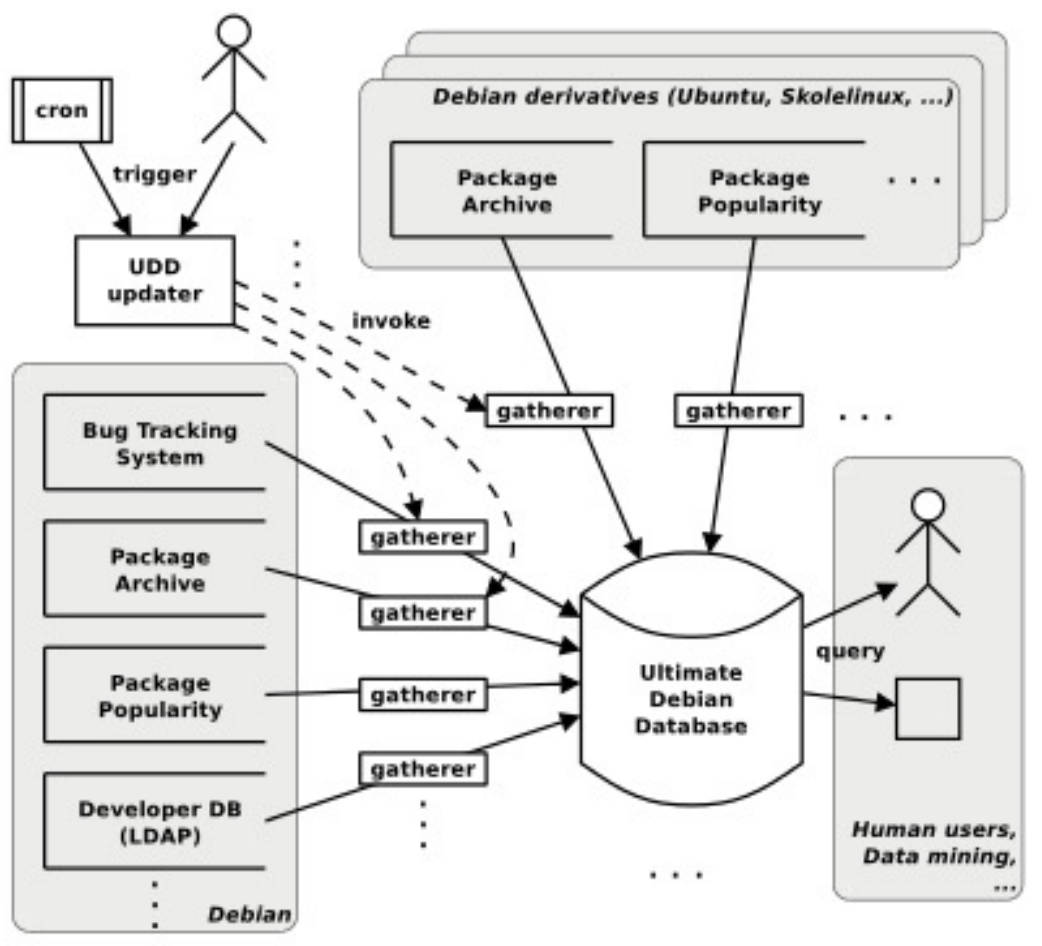

Figura 5.4: Fluxo de dados no UDD [Nussbaum and Zacchiroli 2010]

disponíveis sem a necessidade de se preocupar com formatos de dados, protocolos e controle de acesso.

DDE e UDD são serviços complementares. Enquanto o UDD tem como meta criar um ponto central de acesso aos dados, o DDE provê o acesso de forma simples e padronizada a determinados conjuntos de dados. Os dois serviços se completam: quanto mais dados são coletados pelo UDD, mais informações são disponibilizadas via DDE, que atua como uma interface simplificada para as consultas mais úteis e populares do UDD.

Além do UDD, existem plugins para o DDE que importam dados do apt-file ${ }^{26}$, apt-xapianindex e BTS. Atualmente os dados podem ser exportados na notação de objetos JavaScript (JSON), formato de serialização YAML, valores separados por vírgula (CSV) ou objetos Python serializados (pickled objects).

Os dados são representados numa grande árvore. Pode-se escolher um nó nesta árvore por meio de sua URL para adquirir todos os dados contidos na sub-árvore que contém este nó como raiz. A Figura 5.5 apresenta o resultado de uma consulta ao plugin BTS pelo pacote gnome-subtitles, por meio da url http://dde.debian.net/dde/q/bts/bypackage/ gnome-subtitles.

\subsubsection{Screenshots}

O Screenshots ${ }^{27}$ é um repositório público de capturas de tela de aplicativos da distribuição Debian GNU/Linux e derivadas. O serviço foi criado para permitir que os usuários conheçam a aparência dos programas antes de instalá-los em seu ambiente de trabalho. A submissão de imagens é aberta, podendo ser realizada por qualquer usuário, no entanto uma revisão humana é realizada antes que as imagens se tornem públicas.

\footnotetext{
${ }^{26}$ Busca por arquivos no conteúdo de pacotes Debian

${ }^{27}$ http://screenshots.debian.net/
} 


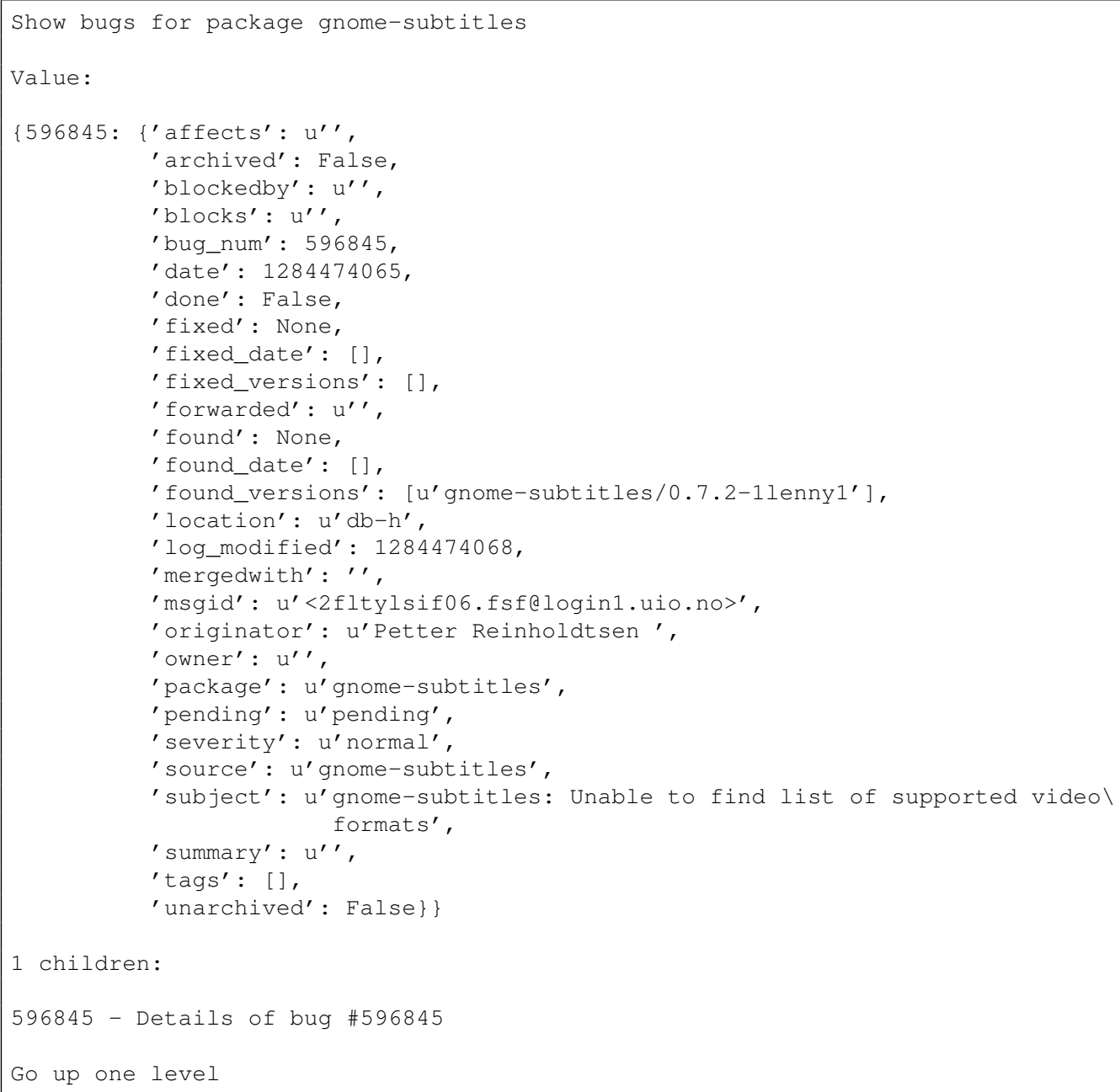

Figura 5.5: Exemplo consulta ao plugin BTS

\subsection{Decisões de projeto}

Técnicas de busca foram selecionadas como base de implementação do AppRecommender devido ao desempenho das soluções com a construção prévia de índices. O desenvolvimento dos componentes de indexação e busca baseou-se na biblioteca Xapian.

Ao ser instanciado, o recomendador recebe como parâmetros dois índices - neste contexto denominados repositórios - cujo conteúdo está descrito a seguir.

(a) Repositório de itens: armazena todos os itens disponíveis para recomendação juntamente com seus meta-dados. Fisicamente, é um índice xapian em que cada pacote é representado por um documento cujos termos são os meta-dados relacionados ao pacote. $\mathrm{O}$ Apt-xapian-index pode ser utilizado como repositório de itens, porém geralmente se utiliza um índice filtrado, dado que nem todos os pacotes existentes deveriam ser considerados pelo recomendador.

(b) Repositório de usuários: armazena escolhas anteriores de usuários, representadas por relações to tipo usuário $\rightarrow$ conjunto de itens. Fisicamente, é um índice xapian onde cada sistema (usuário do recomendador) é representado por um documento cujos termos são pacotes presentes em sua submissão ao Popcon. Além dos nomes, são indexadas 
também as tags de cada pacote, permitindo assim uma caracterização de conteúdo de cada documento do índice.

Além dos índices Xapian, a solução coleta informações do UDD por meio do DDE, utiliza captura de telas do Screenshots e pode coletar também informações do APT local. A Figura 5.6 apresenta o fluxo de dados da solução proposta.

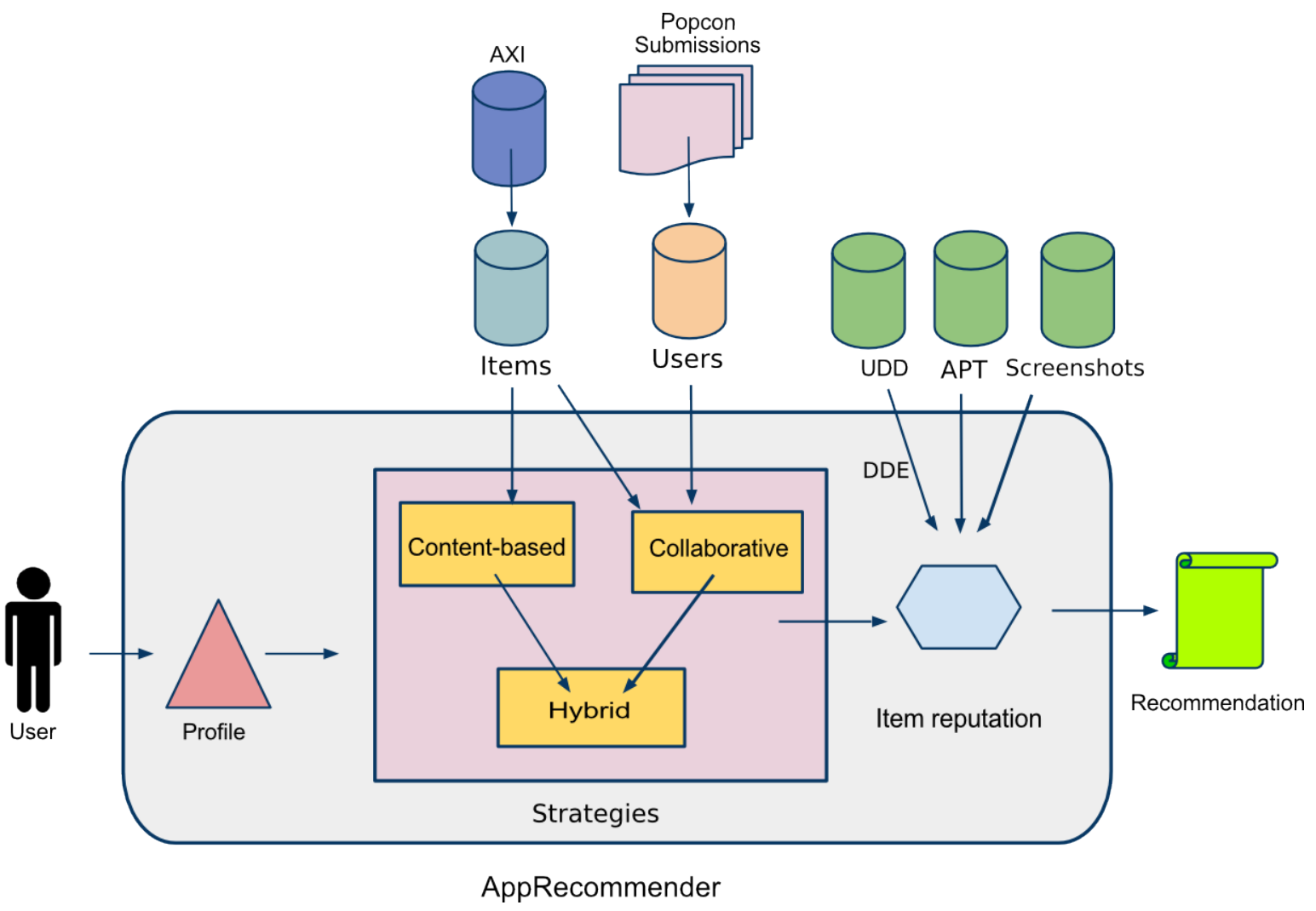

Figura 5.6: Fluxo de dados no AppRecommender

Foram realizados experimentos preliminares com algoritmos para mineração de regras de associação com base no Apriori. No entanto, devido à alta complexidade computacional destes algoritmos, seria necessário um maior planejamento e estudo de técnicas mais avançadas para o desenvolvimento de soluções computacionalmente executáveis. Em virtude de esta estratégia já ter sido abordada anteriormente num trabalho correlato (Seção 4.3), buscou-se o reaproveitamento das regras já produzidas de sorte a integrá-las no AppRecommender. O autor demonstrou interesse neste sentido e pretende atualizar seu código, que apresenta-se inativo desde 2007

Houve também uma tentativa de pré-processamento da base de dados do Popcon utilizando a técnica de agrupamento $k$-medoids. Contudo, a solução também demandaria um aprofundamento nas técnicas para que fosse capaz de lidar com a base de dados completa do Popcon. Diante da limitação de tempo para conclusão deste trabalho, optou-se por focar apenas em técnicas de busca, deixando estes esforços como base para trabalhos futuros.

\subsubsection{Seleção de atributos}

A seguir são apresentadas peculiaridades do domínio de aplicativos que foram consideradas na modelagem dos procedimentos de seleção de atributos do AppRecommender. Acredita-se que tal pré-processamento dos dados de entrada proporciona ganhos na eficiência do recomendador e qualidade das sugestões produzidas, na medida em que diminui o montante de dados a 
ser considerado e o ruído nos dados. A popular expressão "Garbage in, garbage out" pode ser utilizada neste contexto: se o sistema recebe "lixo" como entrada, independentemente da corretude do algoritmo, a saída provavelmente será inútil.

\section{Pacotes versus aplicativos}

De acordo com o conceito de empacotamento apresentado no Capítulo 2, um pacote instalado num sistema GNU/Linux pode ou não representar um aplicativo. Existem pacotes no repositório que consistem apenas em documentação, dados complementares, ou ainda, bibliotecas que são requisitos para outros aplicativos.

Esta característica do pacote pode ser identificada por meio da faceta XTrole do debtags, que pode assumir valores como program, data, shared-lib, examples, entre outros. Para recomendador de aplicativos, apenas os pacotes marcados com a tag XTrole: : program são considerados como itens válidos.

\section{Mapeamento das necessidades de um usuário}

No caso de uso típico do recomendador de aplicativos, determinado usuário entrega ao sistema o conjunto de aplicativos que ele possui, e a função do recomendador é sugerir, dentre os que ele não conhece, os que melhor atendem a suas necessidades. Todavia, nem sempre aquilo que o usuário busca pode ser mapeado diretamente na instalação de pacotes específicos. Necessidades do usuário dizem respeito às funcionalidades que os aplicativos oferecem. Visto que aplicativos diferentes podem executar funções similares, o mais apropriado seria representar a necessidade ou desejo do usuário como um conjunto de funcionalidades, em vez de um conjunto de aplicativos ou pacotes.

Atualmente o perfil do usuário pode ser composto por palavras extraídas das descrições de pacotes ou debtags. O vocabulário de debtags é composto por 621 tags, porém nem todas são úteis para fins de recomendação. Por exemplo, a linguagem em que o aplicativo foi implementada é irrelevante para a caracterização de suas funcionalidades. Portanto, todas as tags da faceta implemented-in foram desconsideradas. Após uma análise manual, o conjunto de tags válidas para o AppRecommender foi reduzido para 276.

\section{Aplicativos básicos}

Para um sistema operacional ou distribuição GNU/Linux, quaisquer que sejam, necessariamente haverá um conjunto de componentes que fazem parte da instalação padrão, previamente selecionados pela equipe de desenvolvimento. Considerando que os usuários do recomendador utilizam um sistema funcional, existem dois casos a considerar: (1) todo o conjunto de componentes da instalação padrão está instalado no sistema e (2) alguns componentes não estão presentes porque foram propositalmente removidos pelo usuário. Em ambos os casos a recomendação de tais pacotes certamente não interessaria ao usuário, portanto todos eles são desconsiderados sem prejuízo para a recomendação.

\section{Aplicativos instalados automaticamente}

Uma característica peculiar da recomendação neste contexto é que, diferentemente de outros domínios nos quais os itens não se relacionam entre si, um aplicativo pode requisitar a presença (ou ausência) de outros aplicativos no sistema para que funcione adequadamente. Portanto, muitos programas são instalados automaticamente por serem dependências de outros, e não em decorrência de uma ação do administrador do sistema. A relevância de tais aplicativos para a composição de um perfil de usuário é considerada de forma diferenciada dos outros ou simplesmente desconsiderada, a depender da configuração do recomendador. 
No caso em que o recomendador é executado localmente (o cliente é o próprio sistema no qual ele é executado), têm-se acesso à base local do $A P T$ que guarda a informação de quais pacotes foram instalados automaticamente. Sendo assim, a seleção de atributos pode considerar apenas os que foram instalados voluntariamente.

No entanto, para o caso em que o recomendador recebe apenas a lista de pacotes instalados sem informação adicional sobre auto-instalação, uma outra estratégia é adotada. Neste cenário, a seleção de atributos desconsidera todos os pacotes que fazem parte da lista de dependências de qualquer outro pacote do perfil original. O resultado é uma lista de pacotes minimal que representa aquele sistema. Apesar de ligeiramente diferente do anterior, esta foi a abordagem que produziu resultados mais próximos da eliminação de pacotes instalados automaticamente quando não se tem acesso à base do $A P T$.

\section{Frequência de uso dos aplicativos}

As informações temporais coletadas pelo Popcon (descritas na Seção 5.3.3) podem ser utilizadas para atribuição de pesos diferenciados para pacotes do perfil, de acordo com a frequência de utilização dos mesmos. Uma configuração baseada na solução Popsuggest (Seção 4.1) atribui peso 3 para pacotes utilizados pela última vez há mais de 30 dias, peso 8 para os recentemente instalados e 10 para os recentemente utilizados. Outra configuração plausível é a consideração apenas dos aplicativos utilizados no último mês, visto que este período representa a atividade recente do usuário, e geralmente há grandes chances de seus interesses ainda serem os mesmos.

\subsubsection{Perfis demográficos}

Uma característica peculiar do AppRecommender é que o cliente deste recomendador é um sistema GNU/Linux com caráter multi-usuário. Seu uso é comumente compartilhado por diversas pessoas, possivelmente apresentando interesses conflitantes. O questionamento ao usuário sobre suas áreas de interesse pode não representar de fato os "interesses" do sistema cliente. Optou-se então por inferir automaticamente perfis básicos a partir da lista de aplicativos recebida como entrada, em vez de expressamente consultar o usuário.

A seguir são descritos os perfis utilizados na implementação atual e o comportamento do AppRecommender diante de cada um deles.

\section{Desktop}

Em conformidade com as decisões no escopo do AppStream, para os casos que o cliente do recomendador é um sistema utilizado como estação de trabalho, decidiu-se que a recomendação deve conter prioritariamente os pacotes que representam aplicativos desktop. Definiu-se então o filtro "desktop" para a identificação dos pacotes que possuem um arquivo .desktop em seu conteúdo (padrão estabelecido pelo FreeDesktop.org).

Testes realizados com sistemas minimais com interface gráfica, Debian e Ubuntu, apresentaram o perfil de desktop com 16 pacotes. Portanto, assumiu-se a caracterização deste perfil para os casos em que o sistema possui ao menos 10 aplicativos desktop instalados, além do sistema de janelas $X^{28}$.

\section{Desktop KDE/GNOME}

Sistemas gerenciadores de janelas evoluíram a tal ponto que atualmente alguns constituem ambiente desktop completos, com uma série de aplicativos desenvolvidos especialmente para tais ambientes, como é o caso do $K D E^{29}$ e $G N O M E^{30}$. Devido à popularidade de ambos

\footnotetext{
${ }^{28} \mathrm{X}$ Window System, implementação de interface gráfica em sistemas GNU/Linux

${ }^{29}$ http://www.kde.org/

${ }^{30}$ http://www.gnome.org/
} 
os projetos, alguns programas são desenvolvidos em versões específicas para um ou outro baseados na biblioteca $Q t^{31}$ ou $G T K+^{32}$ respectivamente.

No caso em que o usuário do recomendador possui apenas um dos dois ambientes instalados, deve-se priorizar a sugestão do pacote específico para aquele gerenciador. O AppRecommender considera como sinônimos pacotes distintos que são versões do mesmo aplicativo, variando apenas a biblioteca gráfica na qual é baseado. Por exemplo, suponha que o pacote autokey-gtk faça parte da recomendação para determinado usuário. Caso apenas o KDE esteja instalado naquele sistema, o recomendador irá alterar a sugestão para conter o pacote autokey-qt em detrimento da versão para $G T K+$ que fazia parte da recomendação original.

\section{Servidor}

Apesar de conceitualmente todo sistema GNU/Linux ser um servidor, esta foi a nomenclatura adotada para caracterizar sistemas cuja principal função é prover serviços, aparentemente não sendo utilizados como estações de trabalho. Neste caso, o filtro "program" é aplicado, considerando como pacotes válidos para recomendação todos aqueles marcados com a tag "XTrole: : program".

\section{Arquitetura}

Os pacotes binários do Debian são automaticamente compilados para as arquiteturas de hardware indicadas pelo mantenedor do pacote. Se o pacote não está disponível para determinada arquitetura, muito provavelmente ele não tem utilidade para aquela categoria de hardware, ou simplesmente não foi portado adequadamente para ser executado naquela arquitetura. Nestes casos, o pacote deve ser desconsiderado de possíveis recomendações.

A arquitetura do cliente é um dado coletado pelo Popcon, indicado na primeira linha do arquivo de submissão (Figura 5.3). Se o AppRecommender recebe este arquivo como entrada, esta informação será considerada e apenas pacotes disponíveis para a referida arquitetura serão sugeridos. Se o formato da entrada é uma lista de pacotes simples, esta informação pode ainda ser coletada pela interface do recomendador. Caso contrário, todos os aplicativos são passíveis de recomendação, sem considerar a arquitetura de hardware.

\subsubsection{Bugs e popularidade}

A quantidade de bugs e popularidade do pacote foram fatores inicialmente considerados para compor a reputação dos itens, resultando numa implementação de recomendação em cascata (3.5.6). Esta estratégia foi anulada por ser considerada inadequada.

Houve uma discussão recente entre desenvolvedores sobre a validade do uso dos dados do Popcon para fins de comparação entre pacotes. Joey Hess defende que a popularidade não deveria ser utilizada como uma medida de competição entre pacotes porque pacotes de naturezas distintas não são comparáveis ${ }^{33}$. Por exemplo, é um engano comparar um pacote popular como o gnome-terminal com um de baixa popularidade como udhcpc. O primeiro é instalado por padrão nos sistemas desktop, apesar de muitos usuários de desktop não fazerem uso do aplicativo. Por outro lado, o udhcpc é instalado apenas em sistemas embarcados e, mesmo que seja absurdamente popular, não aparecerá como popular nas estatísticas do Popcon, visto que este tipo de sistema geralmente não participa do concurso de popularidade.

Tratando-se de bugs, pensava-se em recomendar prioritariamente pacotes com poucos bugs, assumindo que estes recebiam atenção constante de seu mantenedor. Contudo notouse que tal critério seria falho, uma vez que bugs abertos podem também representar

\footnotetext{
${ }^{31}$ http://qt.nokia.com/

${ }^{32}$ http://www.gtk.org/

${ }^{33}$ http://kitenet.net/ joey/blog/entry/the_popcon_problem/
} 
atividade no desenvolvimento e popularidade, tese corroborada por um estudo recente de [Davies et al. 2010]. Optou-se então por não se utilizar esta informação como base para composição de reputação do item.

\subsubsection{Privacidade dos usuários}

O tópico privacidade no desenvolvimento do AppRecommender foi cuidadosamente considerado. Dado que os usuários do recomendador não são pessoas e sim sistemas GNU/Linux, uma quebra de privacidade neste contexto pode significar o comprometimento da segurança destes sistemas. Por exemplo, se a partir de um conjunto de ferramentas sabidamente instalados em um sistema pode-se deduzir que um outro conjunto de ferramentas também está presente, vulnerabilidades das ferramentas descobertas podem ser exploradas num ataque.

Aplicativos com poucas instalações reportadas pelo Popcon oferecem um risco de segurança neste aspecto. Considere um pacote $a$ com apenas uma instalação reportada. Há grandes chances de uma consulta ao recomendador pelo aplicativo $a$ resultar numa lista de pacotes instalados na máquina do mantenedor do pacote. Outra vulnerabilidade é que o Popcon exibe em suas estatísticas pacotes não-oficiais, muitos gerados pelo próprio usuário, inclusive revelando informações capazes de identificá-lo, como por exemplo o pacote "mec-dpjoao.da.cruz.e.sousa". Para evitar este tipo de vazamento de informações o AppRecommender desconsidera pacotes considerados low-popcon, ou seja, com menos de 20 instalações.

Vulnerabilidades referentes a mudanças nas recomendações ao longo do tempo, como mencionado na Seção 3.8 não afetam este trabalho em seu estágio atual, dado que os dados do Popcon foram obtidos uma única vez para construção dos índices. No caso de um esquema de atualização desses dados, testes de vulnerabilidade deveriam ser implementados antes de o sistema ser disponibilizado ao público.

\subsection{Estratégias de recomendação}

As diferentes estratégias de recomendação implementadas no AppRecommender são apresentadas a seguir e sumarizadas na tabela 5.2.

\subsubsection{Baseadas em conteúdo}

O ponto chave das estratégias baseadas em conteúdo é a capacidade de percepção das características dos itens. Sua aplicação é bastante dificultada nos casos em que a representação de itens por conteúdo não pode ser realizada de forma automática.

O processo de recomendação pode ser sumarizado da seguinte maneira: a partir da lista de aplicativos do usuário, é composto um perfil em termos de conteúdo; é realizada então uma consulta no repositório de itens pelo conteúdo característico daquele usuário e os pacotes indicados como mais relevantes são recomendados (cada pacote é representado por um documento no repositório).

Estratégias baseadas em conteúdo são parametrizáveis pelo tamanho do perfil do usuário. Quanto maior a quantidade de termos considerados no perfil, mais diversificado será o resultado da busca. Perfis menores tendem a ser mais especializados, porém, corre-se o risco de não representarem suficientemente bem as características de um usuário.

As variações implementadas para a abordagem baseada em conteúdo diferem entre si em dois pontos: o tipo de conteúdo considerado e o método de composição do perfil.

\section{Tipo de conteúdo}

No âmbito deste trabalho, itens são aplicativos, que fisicamente são representados por pacotes. Por princípio, quaisquer informações relacionadas a pacotes poderiam ser utilizadas como 
característica. Considerando as questões sobre as necessidades do usuário abordadas na Seção 5.4.1, a implementação atual faz uso das tags e descrições dos pacotes para extração de atributos. As abordagens implementadas são apresentadas a seguir.

(a) Tags: restringe-se a termos com prefixo XT, representa o conjunto de tags mais relevantes para determinado conjunto de pacotes.

(b) Descrição: restringe-se a termos com prefixo $\mathrm{Z}$ ou em texto livre, além de descartar a lista de palavras comuns stop words), retorna os termos mais frequentes em descrições de seus pacotes.

(c) Misto: composto por tags e termos de descrição, sem limitação na quantidade de cada um, os que tiverem maior peso são retornados.

(d) Meio-a-meio: resultado da combinação dos perfis de tags e termos de descrição de pacotes, limitando-se a um número igual de cada tipo.

\section{Método de composição do perfil}

Foram utilizados dois métodos de busca básicos para composição do perfil de um usuário, detalhados a seguir.

(a) Expansão de query: é feita uma busca no repositório de itens pela lista de pacotes do usuário; cada documento retornado é marcado como relevante, e pede-se ao Xapian que execute uma expansão de query (ESet), obtendo-se termos representativos para aquele conjunto de documentos relevantes.

(b) tf_idf sub-linear: é feita uma busca no repositório de itens pela lista de pacotes do usuário; percorre-se a lista de documentos retornados acumulando-se todos os termos num único documento; calcula-se a pontuação $t f \_i d f$ sub-linear para cada termo deste documento, e os que obtiverem maior $t f_{-} i d f$ são retornados.

\subsubsection{Colaborativas}

Para esta categoria de estratégias, o perfil do usuário é composto pelos próprios nomes de pacotes instalados em seu sistema. As recomendações são baseadas no que outros usuários com interesses semelhantes aos dele têm instalado em seus sistemas e ele não tem.

O processo de recomendação pode ser sumarizado da seguinte maneira: a vizinhança é composta a partir de uma busca no repositório de usuários pela lista de pacotes do cliente da recomendação; a partir de análise das listas de pacotes dos vizinhos a recomendação é produzida.

A maneira como a análise da vizinhança é realizada produz recomendações diferenciadas. A seguir são descritos os três métodos implementados.

\section{Método de colaboração}

(a) Expansão de query: cada documento da vizinhança é marcado como relevante (cada vizinho é representado por um documento do repositório de usuários); pede-se ao Xapian que execute uma expansão de query (ESet), obtendo termos representativos para aquele conjunto de documentos relevantes, que neste caso são nomes de pacotes.

(b) tf_idf sub-linear: percorre-se a lista de vizinhos acumulando-se todos os nomes de pacote num único documento; calcula-se a pontuação $t f \_i d f$ sub-linear para cada termo deste documento, retornando-se os que obtiverem maior $t f \_i d f$. 
(c) $t f \_i d f$ "plus": comportamento similar ao $t f \_i d f$ sub-linear, porém a função de peso considera a distância de cada vizinho ao cliente da recomendação no momento de agregar todos os pacotes num só documento; quanto mais próximo do usuário o vizinho estiver, mais influência seus pacotes terão no cálculo geral.

\subsubsection{Híbridas}

A seguir são detalhadas as estratégias de recomendação híbridas disponíveis no AppRecommender, de acordo com a taxonomia apresentada na Seção 3.5.6.

(a) Acréscimo de atributo: recomendações produzidas de forma colaborativa com base em conteúdo. Após a composição da vizinhança, os termos de conteúdo encontrados nos vizinhos são ordenados por relevância (apenas tags são indexadas juntamente com pacotes no repositório de usuários) ; as tags mais relevantes compõem um perfil por conteúdo (expansão de query ou $t f \_i d f$ sub-linear), que é então submetido à estratégia baseada em conteúdo.

(b) Revezamento: de acordo com a inferência de dados demográficos, se o sistema for caracterizado como desktop, este filtro é aplicado a todos os repositórios (de itens e usuários) e apenas aplicativos de desktop podem ser recomendados. Se o perfil for KDE ou GNOME, a lista de sinônimos é consultada e a recomendação é atualizada caso necessário. Caso contrário, a recomendação acontece normalmente, considerando integralmente o repositório de aplicativos;

(c) Combinação: apresentação em conjunto dos resultados de múltiplos recomendadores básicos.

\begin{tabular}{|c|c|c|c|}
\hline Estratégia & Classificação & Método & Conteúdo \\
\hline $\mathrm{cb}$ & \multirow{8}{*}{ Baseada em conteúdo } & \multirow{4}{*}{$t f \_i d f$} & misto \\
\hline cbt & & & tags \\
\hline cbd & & & descrição \\
\hline $\mathrm{cbh}$ & & & meio-a-meio \\
\hline cb_eset & & \multirow{4}{*}{ ESet } & misto \\
\hline cbt_eset & & & tags \\
\hline cbd_eset & & & descrição \\
\hline cbh_eset & & & meio-a-meio \\
\hline $\mathrm{knn}$ & \multirow{3}{*}{ Colaborativa } & $t f \_i d f$ & - \\
\hline knn_plus & & $t f \_i d f$ "plus" & - \\
\hline knn_eset & & ESet & - \\
\hline knnco & \multirow{2}{*}{ Híbrida } & $t f \_i d f$ & tags \\
\hline knnco_eset & & ESet & tags \\
\hline
\end{tabular}

Tabela 5.2: Descrição das estratégias de recomendação implementadas

\subsection{Protótipo do AppRecommender}

O protótipo do AppRecommender pode ser obtido a partir do repositório do projeto no github $^{34}$. A ferramenta deve ser executada em um terminal, por meio do script apprec.py, como indicado na Figura 5.7. Uma interface web para o recomendador foi desenvolvida utilizando o módulo python webpy e layout inspirado no Screenshots (Seção 5.3.6).

\footnotetext{
${ }^{34}$ http://github.com/tassia/AppRecommender
} 


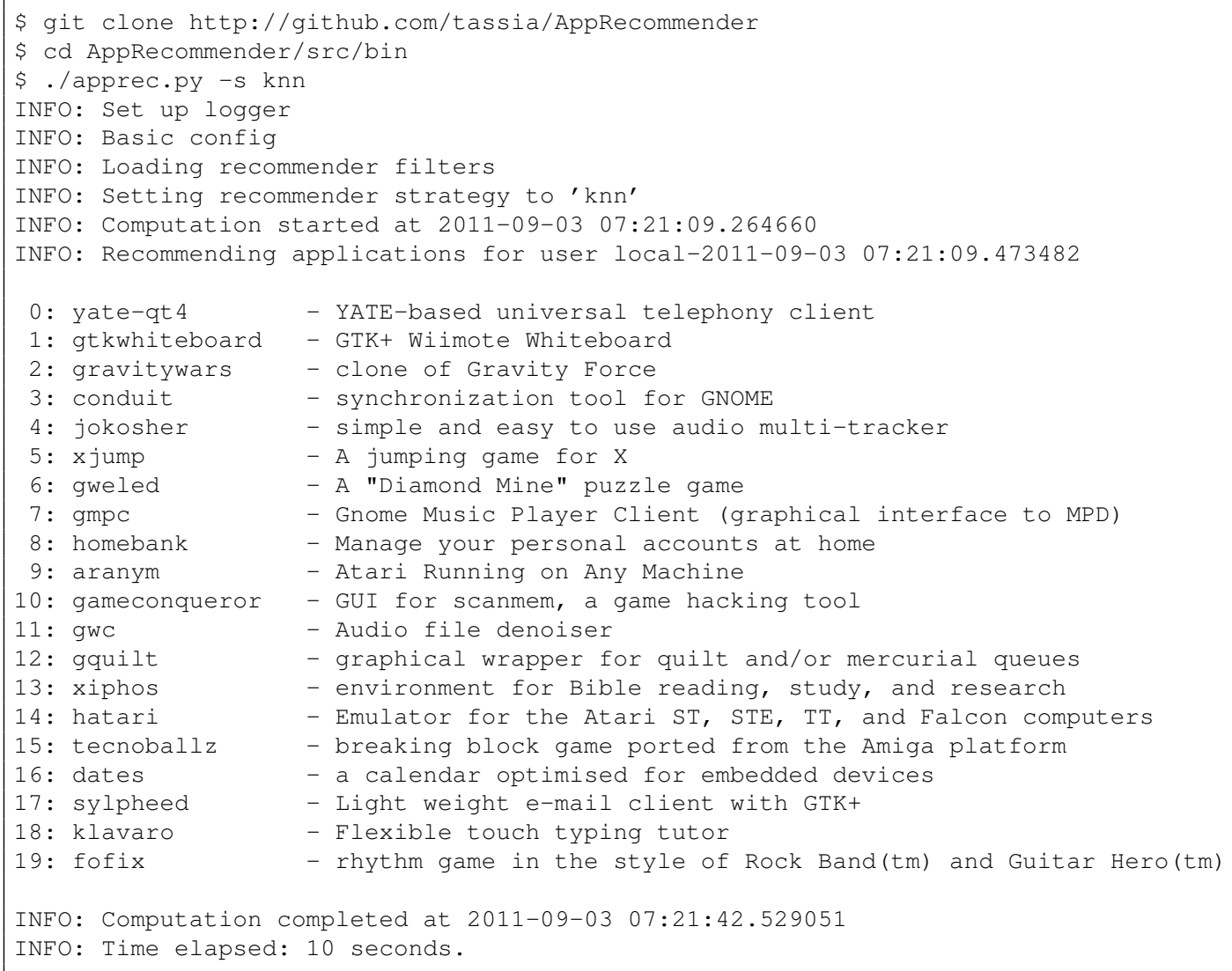

Figura 5.7: Execução do recomendador para o sistema local

Os parâmetros para instanciação do recomendador podem ser definidos por meio de opções na linha de comando ou por um arquivo de configuração. A tabela 5.3 traz a descrição dos parâmetros básicos.

\begin{tabular}{|c|l|}
\hline Parâmetro & Descrição \\
\hline Repositório de itens & Índice Xapian contendo informações sobre os aplicativos \\
\hline Repositório de usuários & Índice Xapian que armazena escolhas anteriores de usuários \\
\hline Estratégia & Método para composição da recomendação \\
\hline Tamanho do perfil & $\begin{array}{l}\text { Quantidade de termos (palavras, tags ou ambos) que caracterizam o usuário } \\
\text { perante o recomendador }\end{array}$ \\
\hline Tamanho da vizinhança & $\begin{array}{l}\text { Quantidade de usuários mais próximos a considerar para estratégias colabo- } \\
\text { rativas }\end{array}$ \\
\hline
\end{tabular}

Tabela 5.3: Descrição dos parâmetros ajustáveis do AppRecommender

\subsubsection{Codificação}

O desenvolvimento foi majoritariamente realizado na linguagem de programação Python ${ }^{35}$, principalmente pela facilidade de integração com outras ferramentas do Debian também desenvolvidas nesta linguagem.

O código-fonte está licenciado pela GNU GPL e disponível em um repositório público ${ }^{36}$.

\footnotetext{
${ }^{35}$ http://www.python.org/

${ }^{36}$ http://github.com/tassia/AppRecommender
} 
O desenvolvimento obedeceu ao guia de estilo para código em python ${ }^{37}$, fez uso de testes automatizados e padrões de projeto. A documentação é automaticamente gerada pelo Doxygen $^{38}$ e disponibilizada no repositório git ${ }^{39}$.

\footnotetext{
${ }^{37}$ http://www . python.org/dev/peps/pep-0008/

${ }^{38}$ http://www. stack.nl/ dimitri/doxygen/

${ }^{39}$ http://www.ime.usp.br/ ${ }^{\sim}$ tassia/doc/html/index.html
} 



\section{Capítulo 6}

\section{Avaliação da proposta}

Neste capítulo são descritos os experimentos realizados com o intuito de avaliar a ferramenta desenvolvida. Resultados comentados, o conjunto completo de gráficos gerados e outras atualizações podem ser acessados no website da pesquisa ${ }^{1}$.

\subsection{Fase 1: Experimentos offline}

A primeira fase de testes teve caráter exploratório, com a variação de ajustes dos modelos em busca da configuração mais adequada ao domínio de aplicação e conjunto de dados estudado. Estes testes são caracterizados como offline por fazerem uso de uma base de dados previamente coletada, o conjunto de submissões do Popcon (ver Seção 3.7.1).

Considerando cada configuração distinta do AppRecommender como um modelo preditivo, a análise de desempenho foi pautada pelas métricas precisão, medida $F_{0.5}$, cobertura e curva ROC. O uso das métricas é justificado na descrição de cada experimento.

Os usuários dos experimentos são criados a partir de submissões do Popcon selecionadas aleatoriamente para compor a amostra de testes. Notamos que o tamanho da lista de aplicativos instalados utilizada para compor o perfil primário dos usuários causava uma certa variação nos resultados, então para cada experimento consideramos apenas usuários cujo tamanho de perfil estivesse numa determinada faixa. A distribuição dos usuários na base do Popcon com relação à quantidade de aplicativos no perfil está representada na Figura 6.1.

A eficácia de um modelo é mensurada a partir da validação cruzada com cada usuário da amostra. Em cada rodada é extraída uma porção de aplicativos do seu perfil para compor o conjunto de testes. Um usuário artificial é criado com a lista de aplicativos restantes, que é submetida ao recomendador. Considerando a porção de testes como o conjunto de itens relevantes (positivos reais) e a recomendação como o conjunto de itens supostamente relevantes (positivos preditos), uma matriz de contingência é criada e as métricas consideradas pertinentes são aplicadas. Ao final das iterações, as médias das estimativas são calculadas para sumarização dos resultados por usuário. Para avaliar os resultados na amostra, além da média consideramos o desvio padrão das medidas.

\subsubsection{Avaliação por ação}

Nesta etapa de experimentos variamos os parâmetros de configuração de cada modelo e analisamos como o desempenho do recomendador é afetado. Para as estratégias baseadas em conteúdo, o parâmetro investigado é o tamanho do perfil do usuário a ser considerado (profile size); para estratégias colaborativas, o tamanho da vizinhança (neighborhood size); e para estratégias híbridas ambas as variações são estudadas.

\footnotetext{
${ }^{1}$ http://recommender.debian.net/experiments
} 


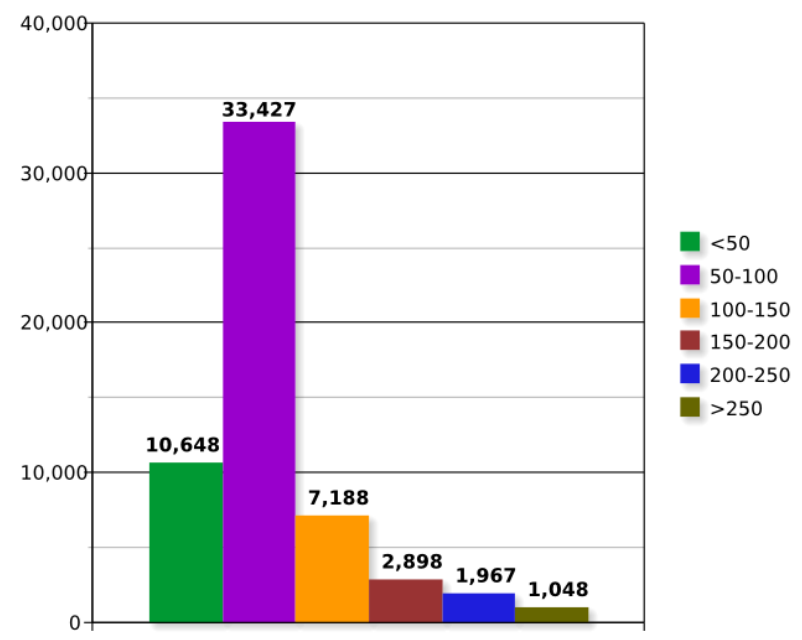

Figura 6.1: Distribuição de submissões do Popcon por tamanho de perfil

A escolha das métricas para esta primeira etapa de testes foi guiada pela ação do recomendador em cada contexto de aplicação (ver Seção 3.3).

No caso de uso típico do AppRecommender, em que o usuário explicitamente requisita sugestões de aplicativos, consideramos que a oferta de 10 sugestões é razoável. A apresentação de muitos itens pode comprometer a usabilidade da interface, causando o indesejável excesso de opções para o usuário. Neste cenário deseja-se maximizar a taxa de acertos do recomendador com relação aos 10 itens recomendados, que pode ser avaliada pela precisão $\left(\frac{V P}{V P+F P}\right)$. Outra característica analisada é a cobertura representada pela proporção de itens do repositório que aparecem em alguma recomendação. Cobertura baixa revela recomendadores viciados numa faixa restrita do repositório. Consideramos esta medida como um indicativo da capacidade de produzir recomendações variadas, com a ressalva de que ela depende diretamente da variabilidade dos dados de entrada dos testes.

Há situações, no entanto, em que o recomendador deve ser capaz de produzir uma maior quantidade de sugestões válidas. Por exemplo, o usuário pode solicitar mais recomendações do que o montante apresentado; ou ainda, no caso em que o recomendador é acoplado a um navegador de aplicativos que deve apresentar primeiramente as opções mais suscetíveis a aceitação. Neste cenário, além da cobertura, analisamos a variação da medida $F_{0.5}$ para recomendações de tamanho 100. Consideramos que para sugestões mais amplas a recuperação também é uma métrica importante. A medida $F$ combina os dois conceitos, sendo que $F_{0.5}$ prioriza um pouco mais a precisão (ver Seção 3.7.2).

\section{Descrição dos testes}

Os dados de entrada para estes testes são a estratégia do recomendador e uma amostra de usuário. Neste momento utilizamos amostras de 50 usuários. Cada configuração da estratégia (diferentes tamanhos de perfil ou vizinhança) é testada para todos os usuários da amostra por meio de validação cruzada e os resultados são sumarizados em dois gráficos:

(a) Limiar 10: referente à recomendação de 10 aplicativos, com a representação de precisão média e cobertura, à medida que o tamanho do perfil ou vizinhança é variado;

(b) Limiar 100: referente à recomendação de 100 aplicativos, com a representação de $F_{0.5}$ médio e cobertura, à medida que os parâmetros são variados.

A Figura 6.2 apresenta os gráficos gerados para a estratégia knn_eset para os dois limiares testados, aplicada à amostra de usuários com perfil entre 100 e 150 aplicativos. 

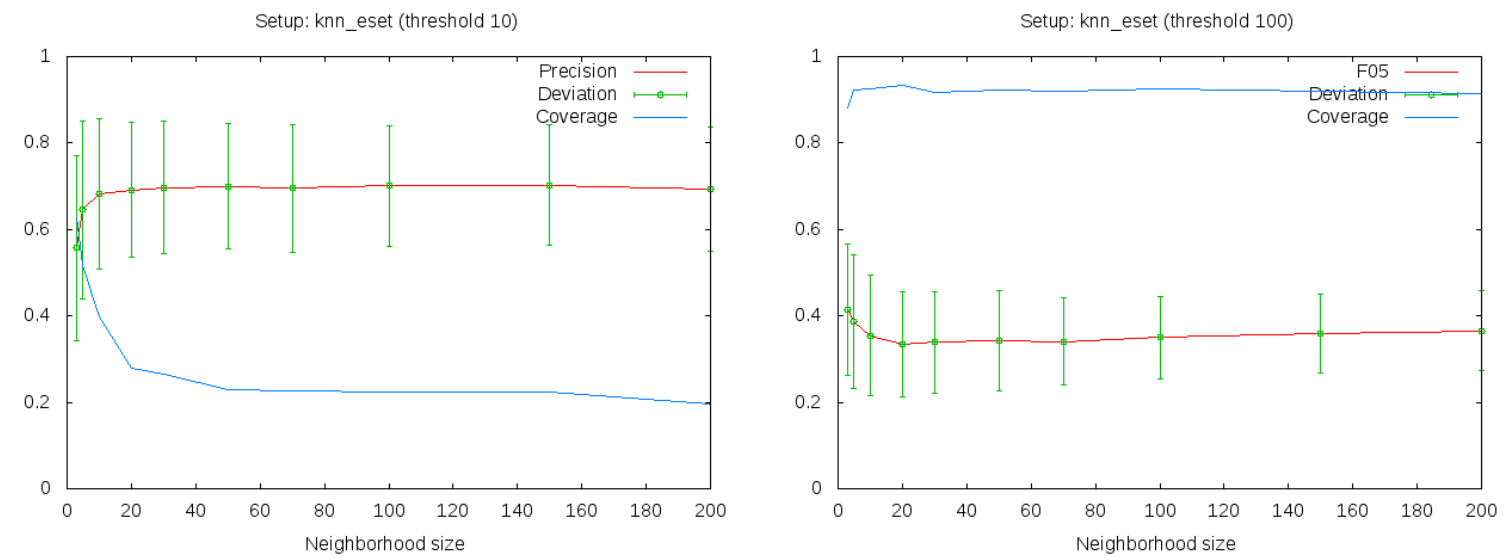

Figura 6.2: Aplicação de métricas para recomendação de 10 (esquerda) e 100 itens (direita)

Para cada ponto $(x, y)$ das linhas de precisão ou $F_{0.5}$, a coordenada $y$ é resultado da média dos valores obtidos para cada usuário da amostra, quando o recomendador é configurado com o parâmetro $x$. Por exemplo, o ponto $(20,0.6919)$ indica que a estratégia knn_eset com tamanho de vizinhança 20 produziu na média uma precisão de $69.19 \%$. O desvio padrão da medida é indicado no gráfico pela linha vertical, traçada acima e abaixo do valor médio, neste caso com valor 0.1551. Os valores de cobertura indicam a proporção do repositório de itens que aparecem em alguma das recomendações produzidas pelo modelo.

Os detalhes de cada gráfico estão registrados em arquivo no formato da Figura 6.3 e também são disponibilizados na visão detalhada da imagem ${ }^{2}$, no website da pesquisa.

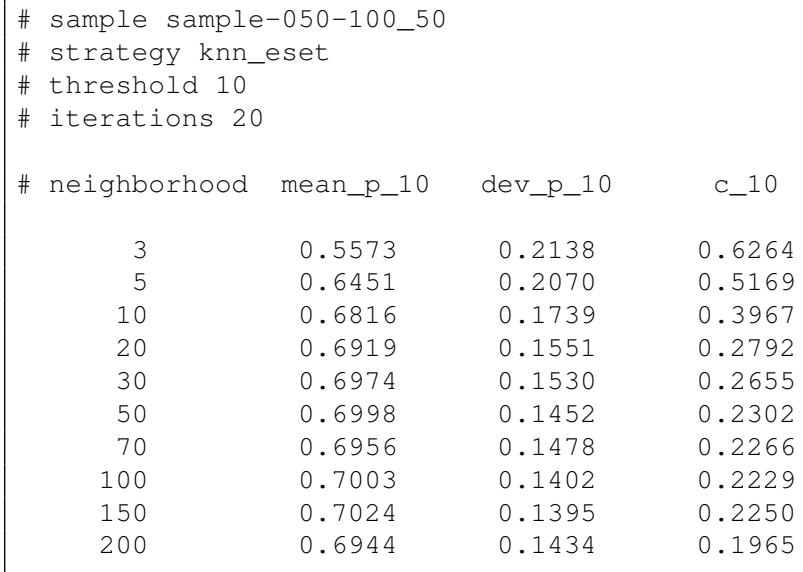

Figura 6.3: Registro de execução de experimento

A cobertura é considerada métrica secundária na comparação entre resultados. No entanto, nos casos em que a cobertura diminui à medida que a precisão ou $F_{0.5}$ aumenta, consideramos uma cobertura de $50 \%$ como o limite aceitável. Por exemplo, para a estratégia cb com limiar 10, consideramos como melhor desempenho um perfil de tamanho 100 (Figura 6.4 esquerda). Nos casos em que a cobertura é sempre inferior a $50 \%$, consideramos o exemplo com maior valor de cobertura, mesmo que esse não represente a melhor acurácia. Por exemplo, na estratégia cbt com limiar 10 (Figura 6.4 direita).

\footnotetext{
${ }^{2}$ http://recommender.debian.net/graphs/metrics/collaborative/sample-050-100_50/ sample-050-100_50-knn_eset-10.html
} 

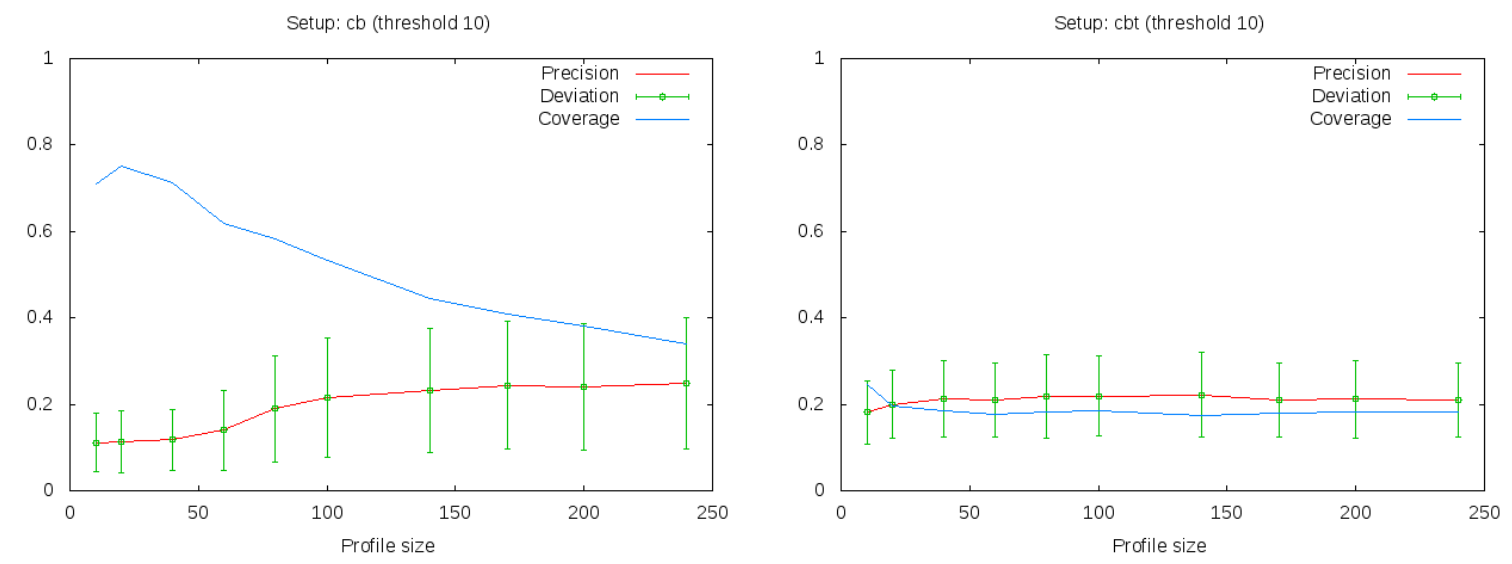

Figura 6.4: Cobertura como limitante ou indicador de melhor desempenho

\section{Resultados}

Para uma mesma configuração de recomendador, em geral não houve variação de comportamento entre as diferentes amostras testadas. Todavia, em termos absolutos as amostras de usuários com perfil maior produziram melhores resultados, fortalecendo a ideia de que quanto mais o modelo "conhece" o usuário, maior a chance de que recomendações acertadas sejam produzidas.

As tabelas 6.1 e 6.2 apresentam os melhores resultados para a amostra de perfis entre 50 e 100 aplicativos, escolhida por ser a mais representativa da base do Popcon (de acordo com a Figura 6.1, cerca de $58 \%$ dos usuários correspondem a este caso).

Para o limiar de 10 sugestões, a estratégia que se destacou nesta série de experimentos foi a colaborativa knn_eset, que de fato foi a única que apresentou precisão superior a $50 \%$. As demais estratégias obtiveram desempenho similar no melhor caso, com exceção de knnco_eset, cbh_eset, cbt_eset e cbt, cujos resultados foram comprometidos pela cobertura (apresentados em cor cinza na tabela).

\begin{tabular}{|l|c|c|c|c|}
\hline Estratégia & Perfil & Vizinhança & Precisão & Cobertura \\
\hline knn_eset & - & 5 & $0.6451 \pm 0.2070$ & 0.5169 \\
\hline cbd_eset & 60 & - & $0.2384 \pm 0.1420$ & 0.5479 \\
\hline knn & - & 3 & $0.2338 \pm 0.1701$ & 0.7524 \\
\hline cb_eset & 60 & - & $0.2306 \pm 0.1282$ & 0.5358 \\
\hline knnco & 10 & 3 & $0.2233 \pm 0.1721$ & 0.7619 \\
\hline cb & 100 & - & $0.2163 \pm 0.1383$ & 0.5342 \\
\hline cbd & 100 & - & $0.2145 \pm 0.1312$ & 0.5479 \\
\hline knn_plus & - & 3 & $0.2086 \pm 0.1766$ & 0.7692 \\
\hline cbh & 10 & - & $0.1817 \pm 0.0939$ & 0.5564 \\
\hline knnco_eset & 10 & 100 & $0.2689 \pm 0.0796$ & 0.2329 \\
\hline cbh_eset & 10 & - & $0.2096 \pm 0.0898$ & 0.4800 \\
\hline cbt_eset & 10 & - & $0.2039 \pm 0.0858$ & 0.2529 \\
\hline cbt & 10 & - & $0.1818 \pm 0.0737$ & 0.2460 \\
\hline
\end{tabular}

Tabela 6.1: Melhores desempenhos para 10 sugestões

Considerando o limiar de 100 recomendações, as três com melhores resultados foram knnco, knn_plus e knn, que têm em comum a aplicação do $t f \_i d f$. As estratégias baseadas em conteúdo e a híbrida knnco_eset produziram resultados insatisfatórios, com $F_{0.5}$ inferior a $13 \%$.

O desvio padrão das medidas de acurácia foi relativamente alto, indicando que para alguns usuários os resultados foram muito bons e para outros muito ruins. Isto pode significar uma grande variância de características entre os usuários da amostra. Tal fato revela a necessidade 


\begin{tabular}{|l|c|c|c|c|}
\hline Estratégia & Perfil & Vizinhança & $F_{0.5}$ & Cobertura \\
\hline knnco & 240 & 3 & $0.5240 \pm 0.1534$ & 0.8246 \\
\hline knn_plus & - & 3 & $0.5024 \pm 0.1894$ & 0.8836 \\
\hline knn & - & 3 & $0.5014 \pm 0.1806$ & 0.8841 \\
\hline knn_eset & - & 3 & $0.4142 \pm 0.1524$ & 0.8820 \\
\hline cbh_eset & 60 & - & $0.1211 \pm 0.0254$ & 0.8936 \\
\hline knnco_eset & 10 & 100 & $0.1188 \pm 0.0196$ & 0.6264 \\
\hline cbh & 40 & - & $0.1105 \pm 0.0237$ & 0.8793 \\
\hline cbt_eset & 20 & - & $0.1099 \pm 0.0245$ & 0.6091 \\
\hline cbt & 100 & - & $0.1095 \pm 0.0232$ & 0.6017 \\
\hline cb_eset & 10 & - & $0.0920 \pm 0.0286$ & 0.9557 \\
\hline cb & 240 & - & $0.0848 \pm 0.0236$ & 0.8488 \\
\hline cbd_eset & 60 & - & $0.0788 \pm 0.0333$ & 0.9515 \\
\hline cbd & 240 & - & $0.0722 \pm 0.0236$ & 0.8109 \\
\hline
\end{tabular}

Tabela 6.2: Melhores desempenhos para 100 sugestões

de um estudo mais aprofundado buscando identificar grupos de usuários com características comuns.

A seguir estão relacionados alguns comportamentos recorrentes identificados na análise dos gráficos.

(a) Tanto para estratégias baseadas em conteúdo quando para as híbridas, a precisão aumenta à medida que o tamanho do perfil do usuário aumenta. No entanto, dado que geralmente o aumento do perfil provoca queda na cobertura, nem sempre o maior valor de acurácia é aproveitável, visto que para melhor desempenho busca-se o equilíbrio entre estas duas medidas. Por exemplo, para a estratégia $c b$ com limiar 10 (Figura 6.4 esquerda), consideramos que o tamanho de perfil com melhor performance foi 100, que teve precisão em torno de $21 \%$ e cobertura $53 \%$. Com perfis maiores a precisão ainda aumenta, mas a cobertura cai abaixo de $50 \%$.

(b) Abordagens para composição de perfil baseadas puramente em tags (cbt e cbt_eset) resultam em cobertura muito baixa (exemplo na Figura 6.4 direita). Isto deve-se provavelmente ao fato de o conjunto de tags válidas ser limitado e de nem todos os pacotes do repositório possuírem tags associadas. O resultado é que as buscas no repositório de aplicativos por estas consultas restritas não são capazes de retornar todos os itens disponíveis.

(c) O perfil das estratégias híbridas também é composto por tags, mas a cobertura atinge valores acima de 70\%, como vemos na estratégias knnco com vizinhança 3 e 10 (Figura 6.5). Neste caso a colaboração com outros usuários deve contribuir para a ocorrência de recomendações mais variadas. Percebe-se que a cobertura cai drasticamente com o aumento do tamanho do perfil e aparentemente o tamanho de perfil que traria uma melhor performance seria algo entre 10 e 40 . Novos experimentos foram realizados variando o tamanho o perfil entre 10 e 50 e a melhor performance com cobertura aceitável foi alcançada com perfil de tamanho 20 (Figura 6.6).

(d) O desempenho das estratégias cb e cbd segue o mesmo padrão (Figura 6.7); o mesmo acontece para as estratégias cb_eset e cbd_eset (Figura 6.8), que apresentam resultados bastante similares. Notamos que, na prática, o perfil misto é praticamente dominado por termos de descrição dos aplicativos. Este tipo de perfil não impõe restrição alguma quanto à quantidade de tags e termos que o perfil final deve conter, e geralmente os termos livres ganham a disputa. O conjunto de termos de descrição de pacotes é ilimitado e por isto tem mais poder de caraterização dos itens, enquanto o de tags limita-se ao subconjunto de debtags que o AppRecommender considera como válidas. Sendo assim, é natural que não 

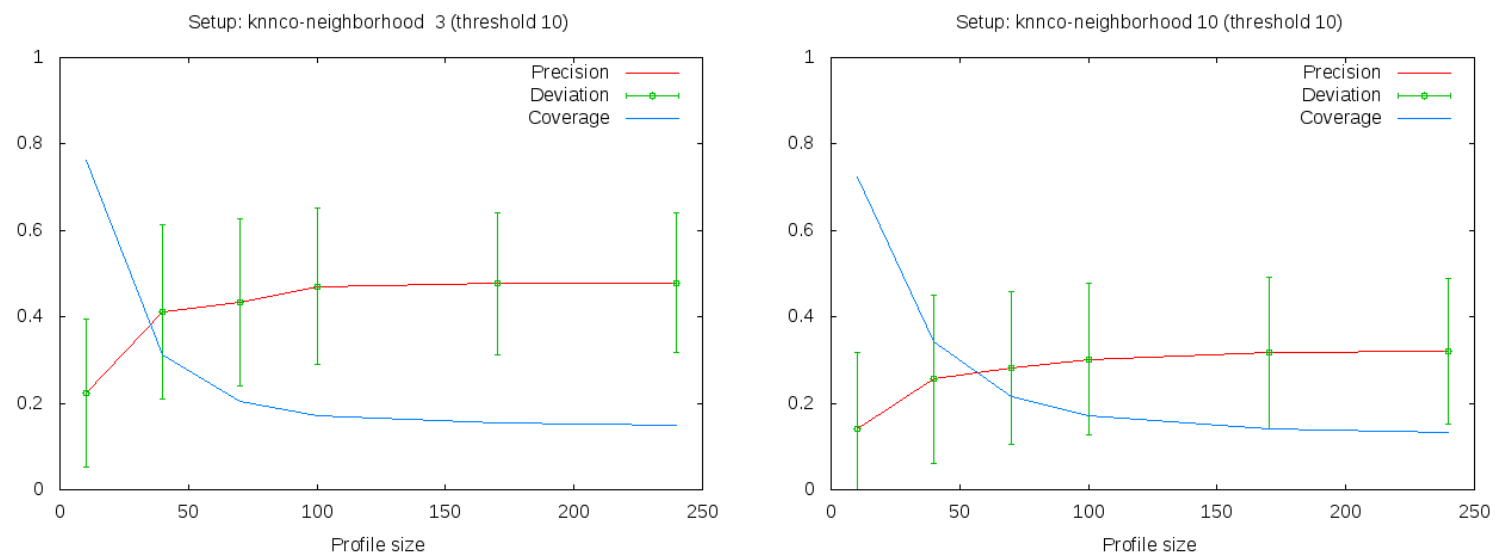

Figura 6.5: Cobertura em estratégias híbridas favorecida pela colaboração
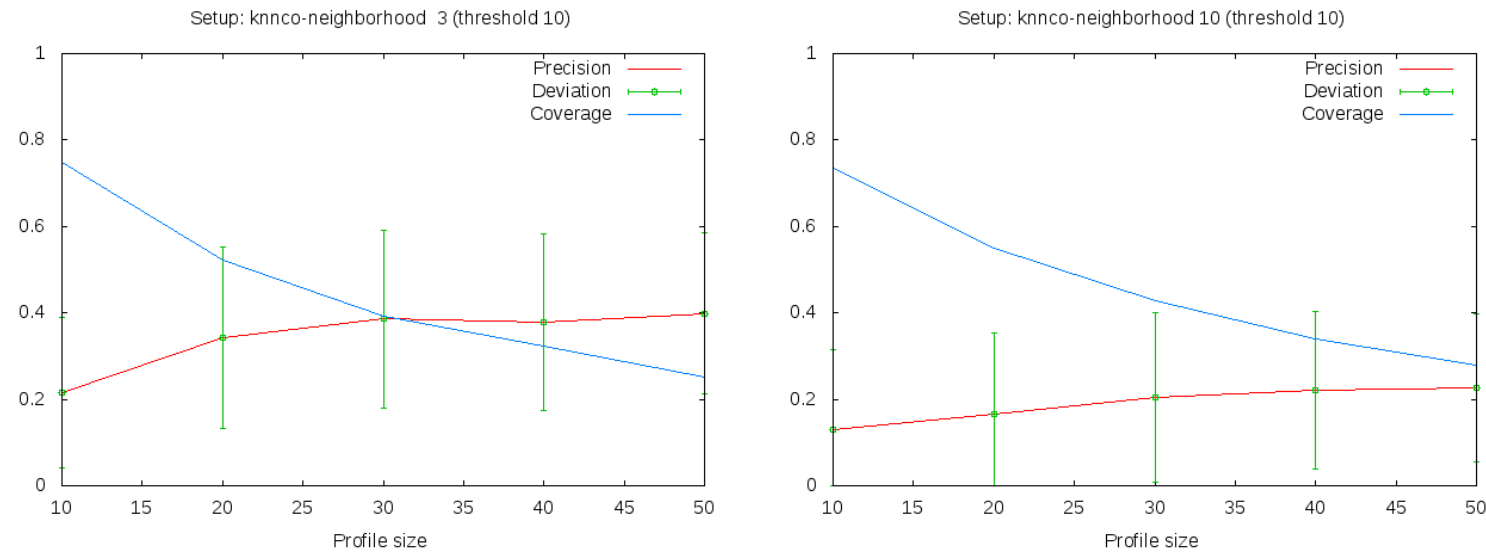

Figura 6.6: Desempenho limitado pela cobertura em estratégias híbridas
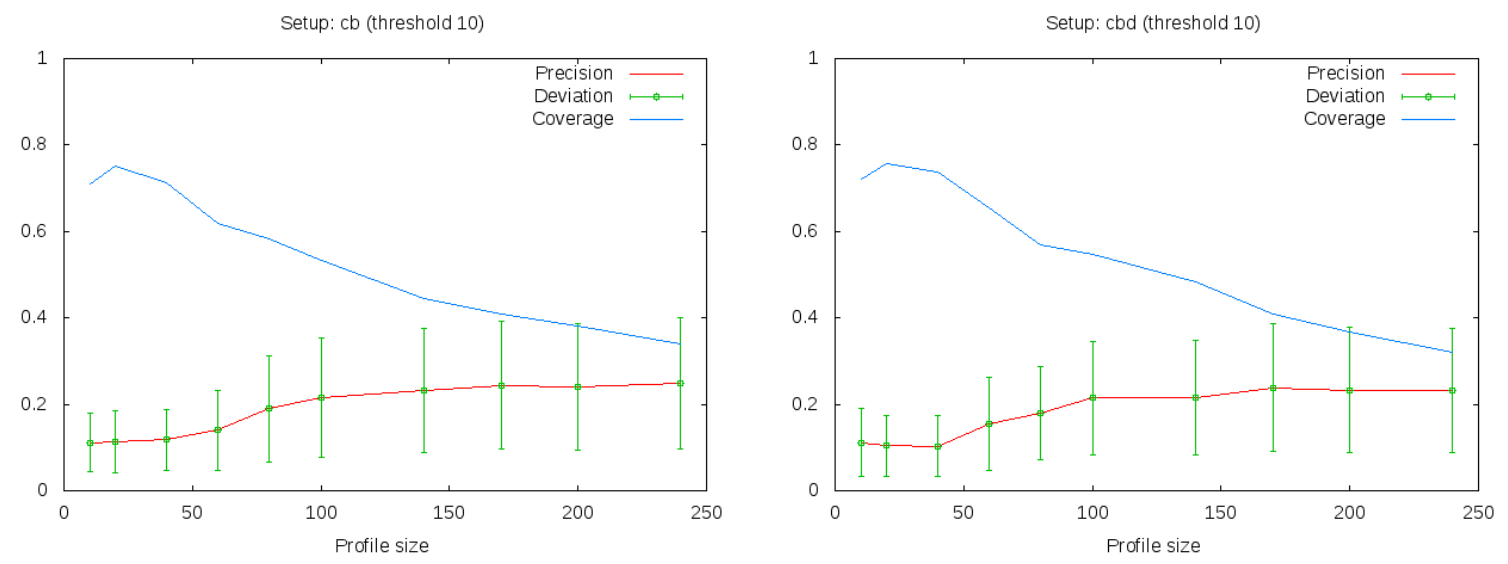

Figura 6.7: Resultados similares para estratégias cb e cbd

haja grandes variações entre as estratégias com perfil misto e composto exclusivamente por termos de descrição dos pacotes.

(e) Cobertura cai à medida que o tamanho do perfil aumenta para as estratégias cb, cb_eset, cbd, e cbd_eset (Figuras 6.7 e 6.8). Essas são as abordagens de composição de perfil dominadas por termos livres. Perfis pequenos representam buscas especializadas e com alta variabilidade provocada pelo processo de re-amostragem. Perfis grandes tendem a 

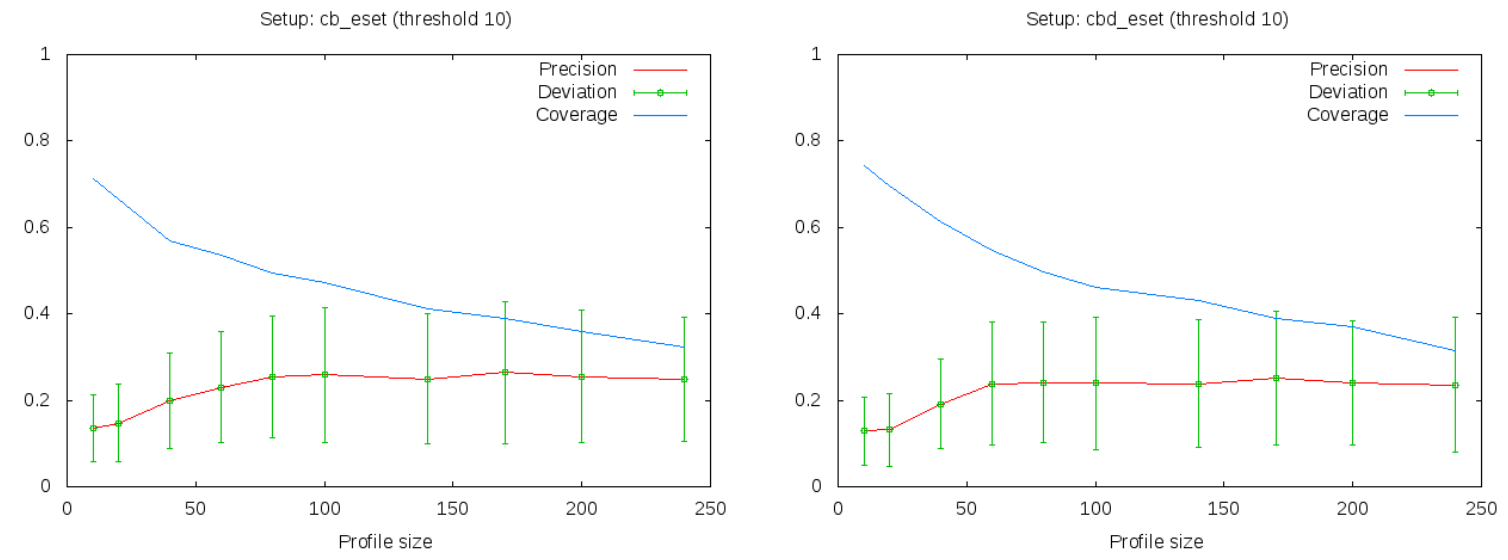

Figura 6.8: Resultados similares para estratégias cb_eset e cbd_eset

incluir grandes conjuntos de termos populares, que geralmente provocam recomendações dentro de um padrão.

(f) A estratégias cb_eset e cbd_eset em geral conseguem bom desempenho com perfis menores do que suas correspondentes por $t f_{-} i d f(\mathrm{cb}$ e cbd). Como vemos nas Figuras 6.7 e 6.8, nas abordagens baseadas em eset, apesar de a precisão alcançar valores maiores com perfis menores, a cobertura também cai mais rapidamente, comprometendo o uso de perfis maiores.

(g) Recomendação baseada em conteúdo com limiar 100 apresentou desempenho insatisfatório para todas as estratégias, com $F_{0.5}$ sempre abaixo de 0.2 e quase sem variação de acordo com o tamanho do perfil do usuário. A Figura 6.9 apresenta os gráficos referentes às estratégias cb e cb_eset.
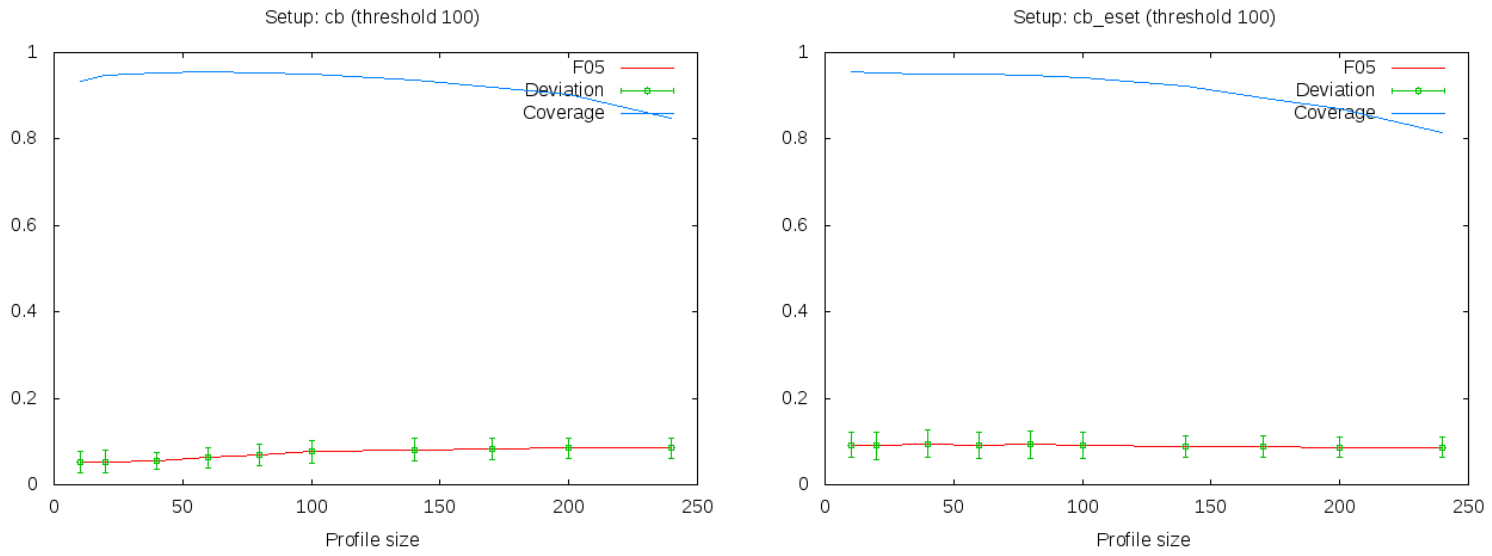

Figura 6.9: Desempenho insatisfatório de estratégias baseadas em conteúdo para limiar 100

(h) Em geral, para estratégias colaborativas, tanto para 10 quanto para 100 recomendações, o melhor desempenho é alcançado com menor tamanho de vizinhança (consideramos 3 o menor tamanho), como vemos na Figura 6.10. Este comportamento é previsível, visto que quanto maior for a vizinhança, serão considerados usuários com perfis mais diferenciados do cliente da recomendação, aumentando a chance de itens recomendados não fazerem parte do perfil original. Acreditamos no entanto que este resultado não compromete o uso de vizinhanças maiores, e sim indica a incapacidade de avaliação deste parâmetro por meio de validação cruzada. 

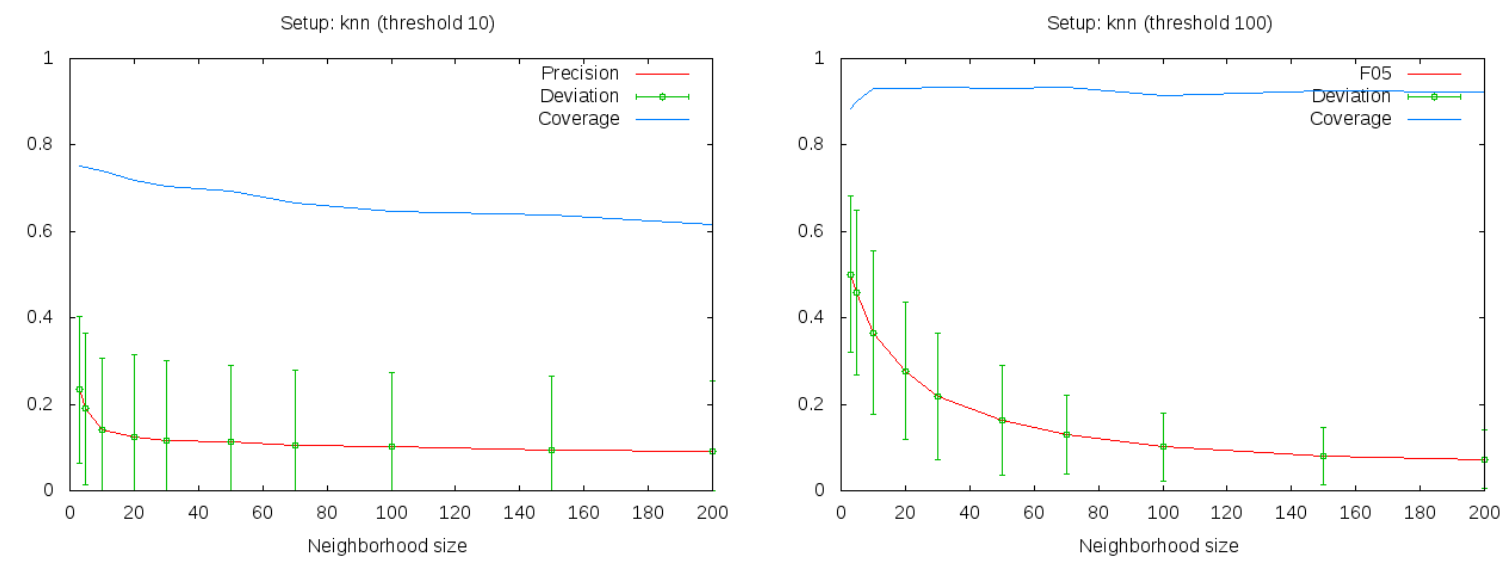

Figura 6.10: Validação cruzada favorece vizinhanças pequenas

(i) A estratégia knn_eset para 10 recomendações apresentou um comportamento inesperado, que a distingue das demais estratégias colaborativas. Este foi o único caso em que houve aumento da precisão à medida que o tamanho da vizinhança assumiu valores entre $3 \mathrm{e}$ 50. Um estudo mais aprofundado do método de colaboração por expansão de query será realizado com o intuito de identificar o que o diferencia dos métodos baseados em $t f \_i d f$, mas no momento não há considerações conclusivas a este respeito. Visto que a cobertura cai com o aumento da vizinhança, o desempenho considerado mais satisfatório foi com vizinhança de tamanho 5 .

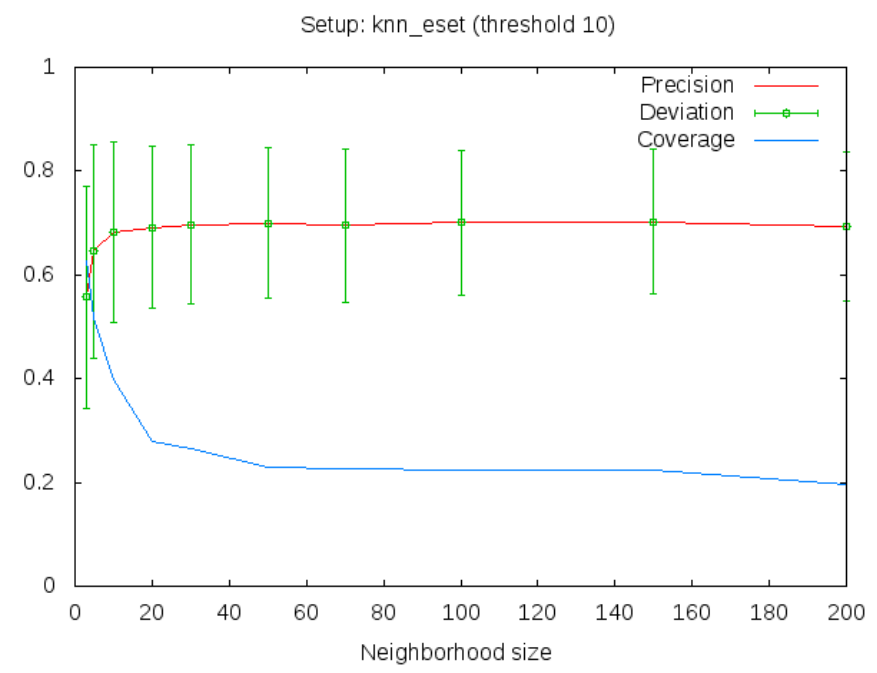

Figura 6.11: Comportamento diferenciado para knn_eset com limiar 10

\subsubsection{Comparação entre modelos}

Os experimentos apresentados até o momento nos permitem ter uma visão ampla da interferência da variação de parâmetros em cada modelo, no entanto a comparação entre os diversos modelos não é uma tarefa trivial de ser conduzida de maneira objetiva. Decidimos então realizar novos testes para analisar o comportamento dos modelos preditivos independentemente do tamanho da recomendação produzida, utilizando como suporte a análise de curvas ROC. 


\section{Descrição dos experimentos}

Os dados de entrada desta série são novamente a estratégia do recomendador e uma amostra de usuários. O tamanho das amostras foi reduzido para 20 em virtude do alto poder de processamento demandado para a execução destes experimentos.

Considerando a quantidade de aplicativos recomendados como o ponto de corte de um recomendador, foram produzidas curvas ROC a partir da variação desse limiar, facilitando assim a percepção de quais modelos apresentam melhor poder preditivo.

Cada modelo é testado em cada ponto de corte para todos os usuários da amostra por meio de validação cruzada. As taxas de falso negativo $(f p r)$ e verdadeiro positivo $(t p r)$ são registradas para produção da curva ROC. As diferentes curvas produzidas são condensadas a partir das médias de fpr e tpr para cada ponto de corte, conforme descrito em [Fawcett 2007].

Uma característica das curvas produzidas é que, pelo fato de o AppRecommender se basear em técnicas de busca, a ordenação dos aplicativos por relevância não engloba todos os programas do repositório, mas apenas aqueles incluídos no resultado da busca. Portanto, para possibilitar a comparação entre os modelos pelo cálculo da área sob a curva, estendemos cada curva ROC com uma linha ligando seu ponto mais à direita ao ponto $(1,1)$. Estamos assim considerando que após apresentar todos os pacotes retornados pela busca, o recomendador apresenta os pacotes restantes de forma aleatória, até que todos os itens tenham sido contemplados.

Foram produzidos dois gráficos por modelo: o primeiro representa a curva ROC média que facilita a interpretação da curva nos moldes tradicionais; o segundo desenha os mesmos pontos médios, registrando também os desvios padrão para cada ponto nas duas dimensões. A Figura 6.12 apresenta dois desses gráficos, produzidos para a estratégia de recomendação cbt. Os detalhes dos gráficos estão registrados em arquivo no formato da Figura 6.13.
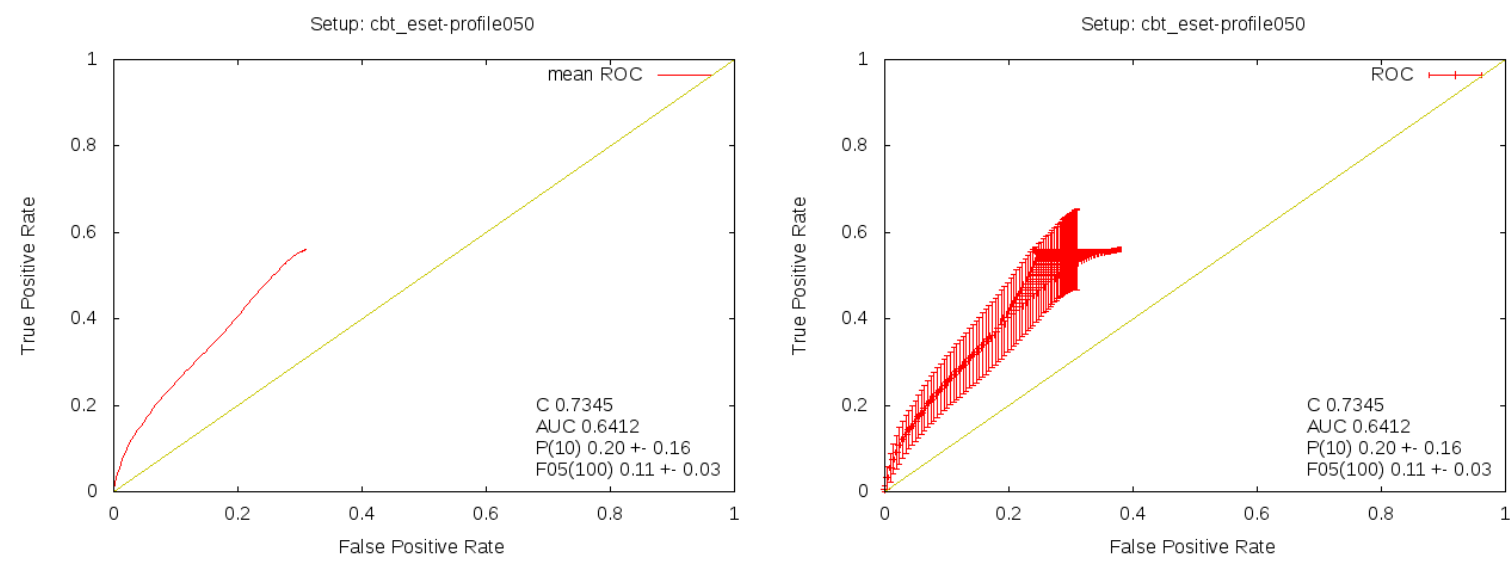

Figura 6.12: Curva ROC média (esquerda) e com desvios (direita) de um recomendador cbt

A análise gráfica das curvas ROC nos permite inferir acerca do desempenho do modelo. Quanto mais próxima do eixo das ordenadas estiver a curva, mais eficaz será o modelo preditivo; por outro lado, a diagonal ascendente representa o comportamento de um modelo aleatório 3.7.2). Todavia, para uma análise mais objetiva, utilizamos como métrica a área sob a curva (AUC), e mais uma vez a cobertura como medida secundária.

\section{Resultados}

Os gráficos produzidos indicam que as estratégias knn e knn_plus com vizinhança 10 (Figuras 6.14 e 6.15) e knnco com vizinhança 3 e perfil entre 50 e 200 (Figura 6.16) representam os melhores modelos preditivos. 


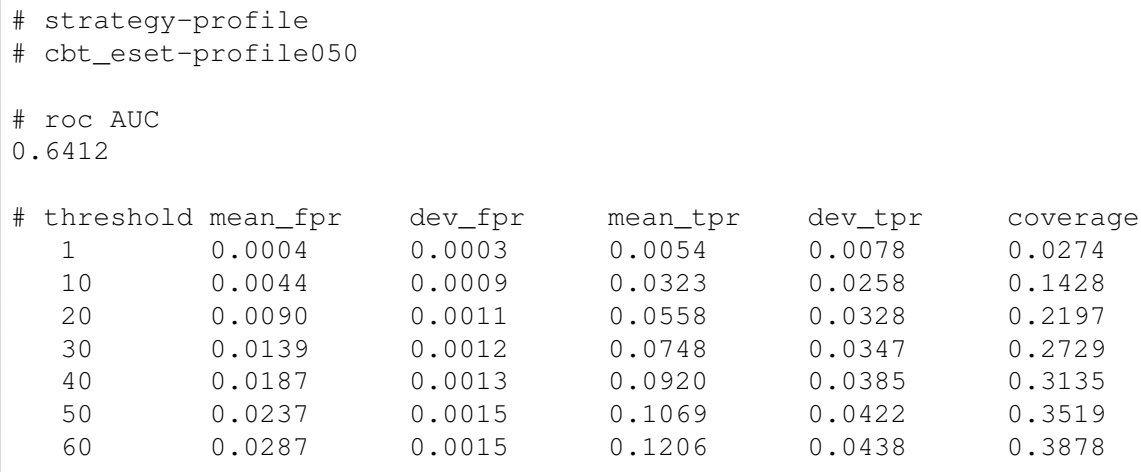

Figura 6.13: Registro de desenho da curva ROC
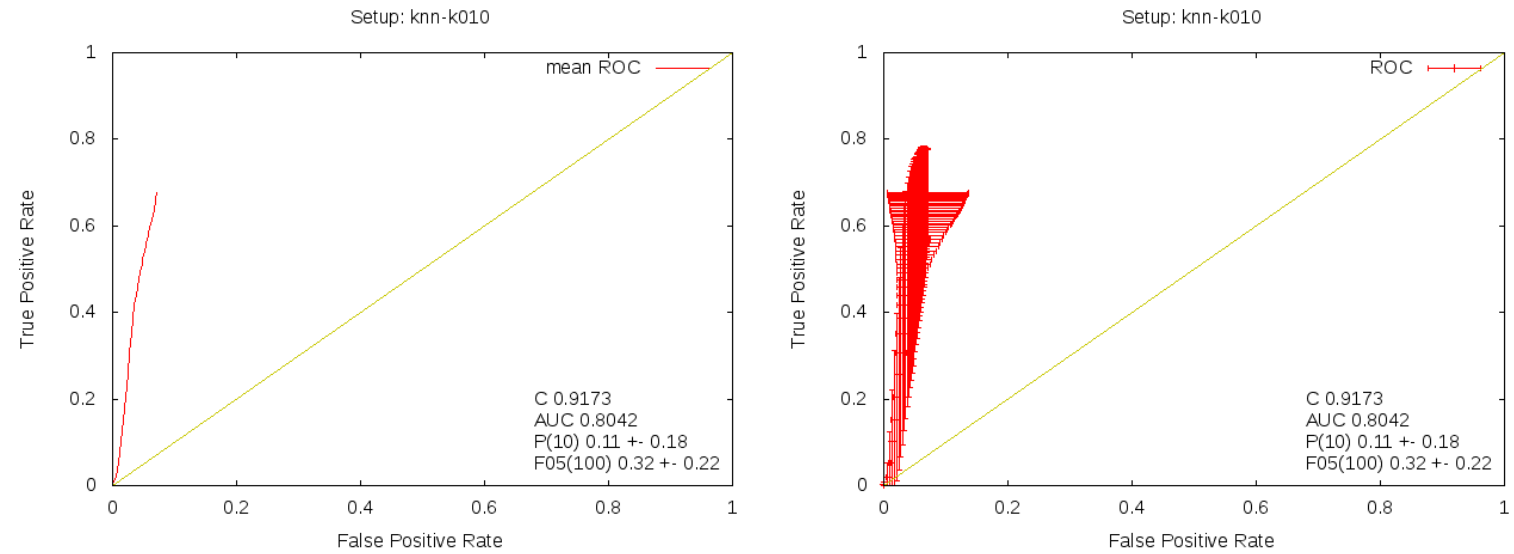

Figura 6.14: Curva ROC média (esquerda) e com desvios (direita) para estratégia knn
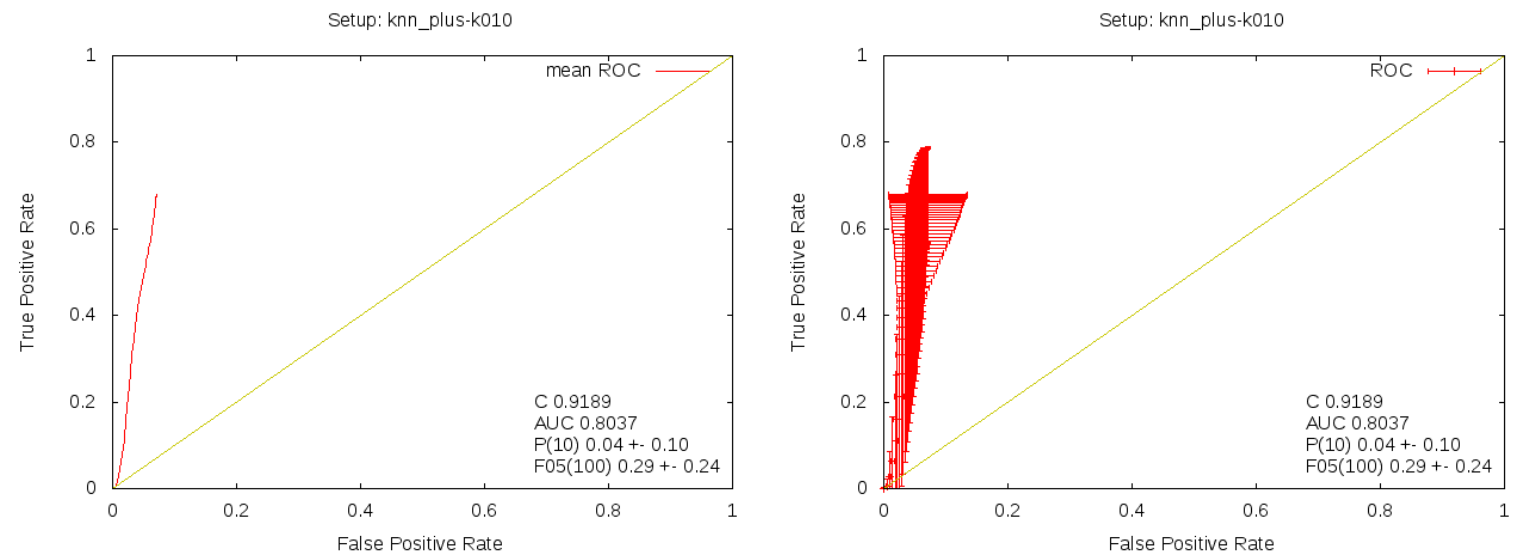

Figura 6.15: Curva ROC média (esquerda) e com desvios (direita) para estratégia knn_plus

A tabela 6.3 sumariza os resultados dos experimentos, indicando os melhores desempenhos obtidos para cada modelo. Os resultados são apresentados em ordem decrescente de AUC e corroboram a análise gráfica apresentada anteriormente.

Este experimento também possibilitou o descarte de modelos inválidos, nos casos em que o desempenho era pior do que o de um modelo aleatório. Por exemplo, a implementação inicial da estratégia knn_plus não considerava nenhuma normalização dos pesos dos vizinhos, o que provocava um comportamento inesperado do recomendador. Percebemos o problema por meio 

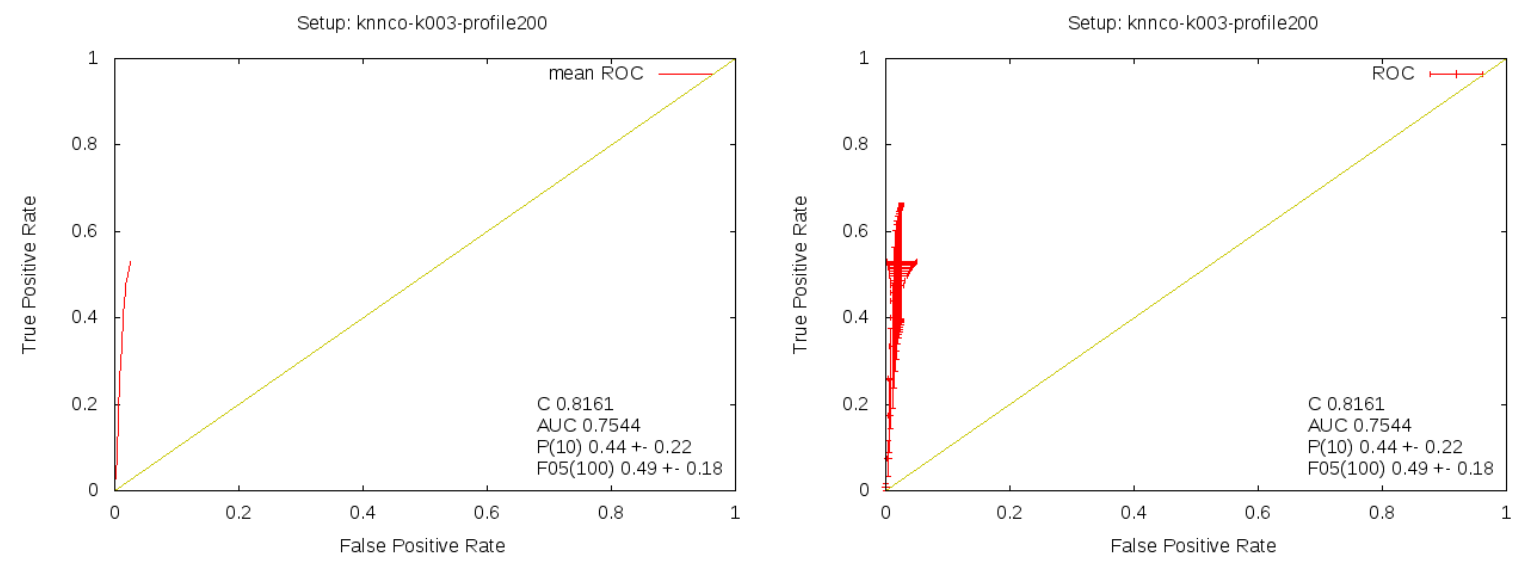

Figura 6.16: Curva ROC média (esquerda) e com desvios (direita) para estratégia knnco

\begin{tabular}{|l|c|c|c|c|}
\hline Estratégia & Perfil & Vizinhança & AUC & Cobertura \\
\hline knn & - & 10 & 0.8042 & 0.9173 \\
\hline knn_plus & - & 10 & 0.8037 & 0.9189 \\
\hline knnco & 200 & 3 & 0.7544 & 0.8161 \\
\hline knn_eset & - & 100 & 0.7206 & 0.9557 \\
\hline knnco_eset & 50 & 50 & 0.6653 & 0.7540 \\
\hline cbt_eset & 50 & - & 0.6412 & 0.7345 \\
\hline cbt & 20 & - & 0.6401 & 0.7339 \\
\hline cbh & 50 & - & 0.6357 & 0.9531 \\
\hline cbh_eset & 50 & - & 0.6118 & 0.9557 \\
\hline cb_eset & 50 & - & 0.5674 & 0.9557 \\
\hline cb & 100 & - & 0.5642 & 0.9557 \\
\hline cbd_eset & 10 & - & 0.5489 & 0.9557 \\
\hline cbd & 100 & - & 0.5377 & 0.9557 \\
\hline
\end{tabular}

Tabela 6.3: Melhores desempenhos analisados por curvas ROC

da análise das curvas ROC (Figura 6.17) e evoluímos a implementação conforme orientação de [Hechenbichler and Schliep 2006], obtendo assim melhores resultados.

\subsection{Fase 2: Consulta pública}

Os resultados dos experimentos offline não foram conclusivos. Em geral as estratégias colaborativas obtiveram melhores resultados, porém bastante variados a depender da situação de teste.

Um ponto positivo de experimentos offline é a independência de agentes externos à pesquisa, visto que baseiam-se em processamento automatizado de dados. No entanto, esta classe de testes não assegura um nível de confiabilidade como se pode obter em experimentos realizados com usuários reais. Ademais, o conceito de utilidade de um aplicativo é subjetivo e apenas um indivíduo dotado de subjetividade é capaz fazer esta avaliação. Métricas como a novidade promovida por uma recomendação dificilmente seria mensurável por meio de validação cruzada.

Tais fatos motivaram a implementação de uma consulta pública online ${ }^{3}$ por meio da qual usuários reais avaliaram a utilidade das recomendações produzidas por diferentes estratégias do AppRecommender, visando assim integrar avaliações de caráter subjetivo aos resultados até então obtidos pelos testes offline.

\footnotetext{
${ }^{3}$ http://recommender.debian.net/survey
} 


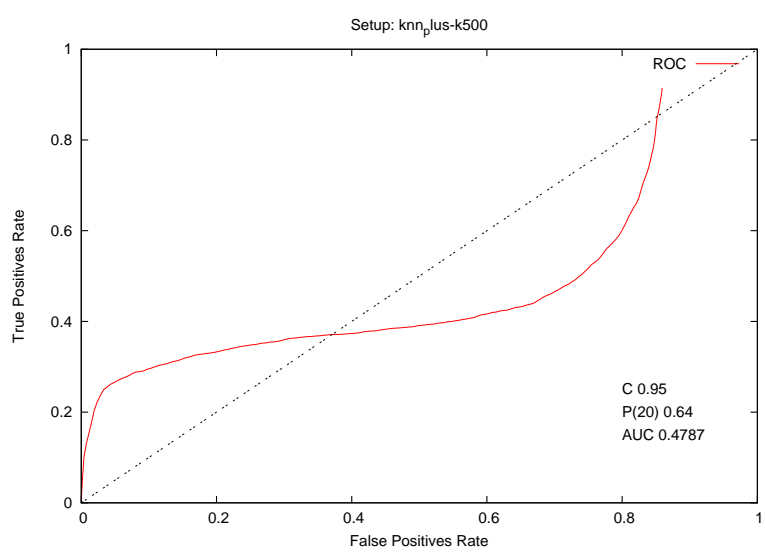

Figura 6.17: Descarte de modelo com comportamento inesperado

A consideração de todas as estratégias nesta fase de experimentos dificultaria a comparação entre os modelos, visto que dificilmente um mesmo usuário avaliaria todas elas. Selecionamos então apenas 6 das 13 estratégias para esta etapa, excluindo as que obtiveram cobertura insatisfatória (cbt, cbt_eset, e knnco_eset) e as estratégias baseadas em conteúdo cuja precisão tivesse apresentado desvio padrão superior a $10 \%$ (cb, cb_eset, cbd e cbd_eset).

A consulta foi conduzida pelos seguintes passos:

(1) O participante envia a lista de pacotes instalados em seu sistema.

(2) O AppRecommender utiliza como estratégia primária a recomendação híbrida por revezamento, e a partir da análise do perfil do usuário determina o conjunto de estratégias disponíveis para aquele tipo de usuário.

(3) Uma estratégia é escolhida aleatoriamente dentre as disponíveis e a computação da recomendação é realizada.

(4) As sugestões são apresentadas individualmente. Para cada aplicativo recomendado são exibidos: uma descrição curta, uma descrição longa, o website do upstream, o mantenedor do pacote e uma captura de tela. É também apresentado um quadro de avaliação, onde o usuário deve avaliar a recomendação e seguir para avaliar o próximo item.

(5) Ao final de 10 avaliações, o resultado é enviado ao servidor e o usuário pode escolher se deseja realizar uma nova rodada de avaliações (uma nova estratégia será sorteada) ou finalizar o experimento.

(6) Se decidir continuar com o experimento, o passo 3 é retomado.

(7) Quando o usuário decidir finalizar sua participação, ele recebe uma mensagem de agradecimento e um formulário de identificação opcional.

(8) Os resultados da avaliação são armazenados no servidor para posterior análise.

A Figura 6.18 apresenta a interface web desenvolvida para realização da consulta pública. 


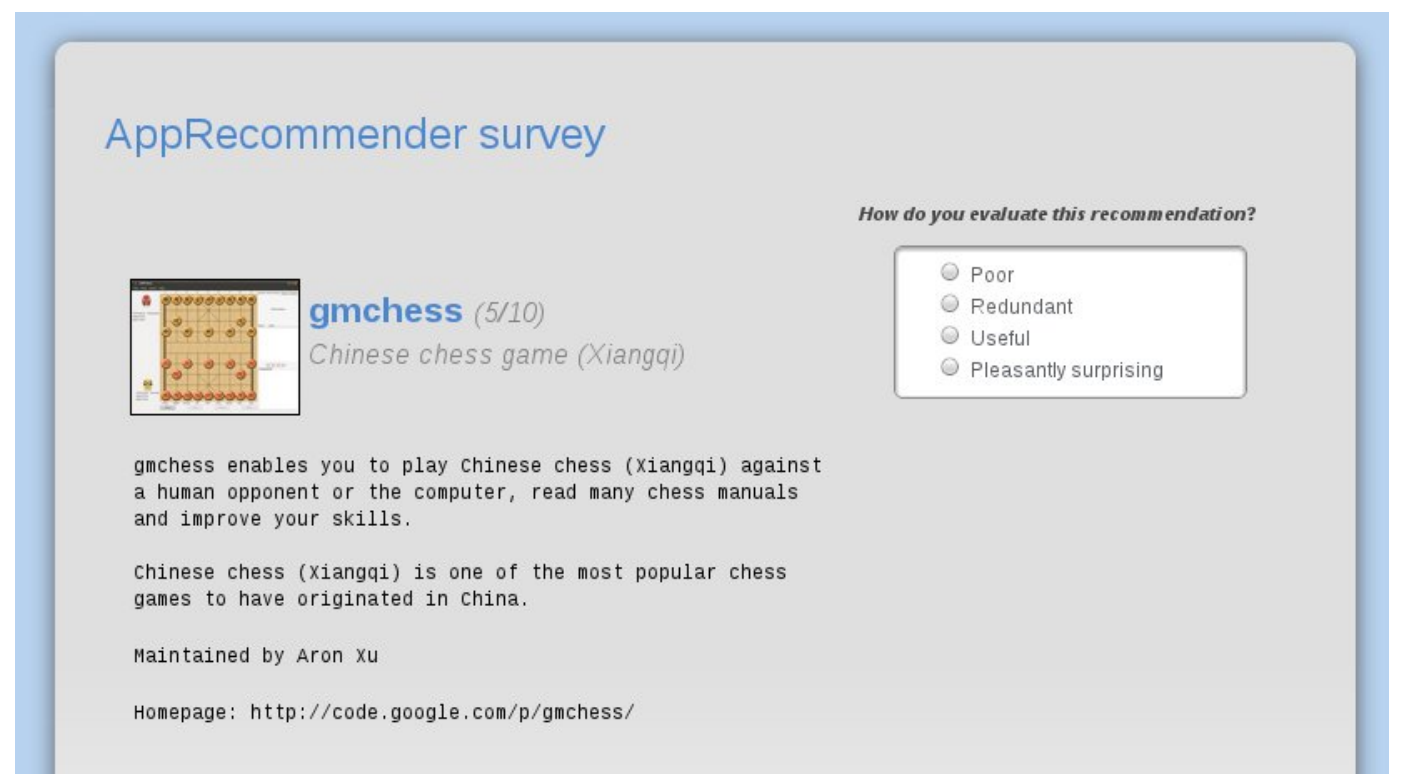

Figura 6.18: Interface da consulta pública

\subsubsection{Avaliação de uma recomendação}

Em cada rodada de avaliação 10 aplicativos recomendados por uma determinada estratégia são apresentados ao usuário, que deve avaliar a recomendação como:

- Ruim: sugestão fraca, o usuário não instalaria o aplicativo;

- Redundante: o programa está relacionado com os interesses do usuário, mas ele não instalaria porque já possui aplicativos similares;

- Útil: boa recomendação, o usuário provavelmente experimentaria;

- Surpresa boa: sugestão útil e inesperada; ou o usuário não conhecia o programa, ou até conhecia, mas não havia pensado nele recentemente.

Para a aplicação de métricas de comparação entre estratégias, consideramos que as recomendações ruins são falsos positivos $(F P)$ e as redundantes, úteis ou surpreendentemente boas são verdadeiros positivos (VP). Essa diferenciação é feita para que possamos distinguir modelos conservadores, que erram pouco mas apresentam muitas recomendações óbvias, dos que realmente apresentam novidades em suas sugestões.

\subsubsection{Métricas}

As métricas selecionadas para avaliar as diferentes estratégias nesta fase de experimentos foram as seguintes:

(a) Precisão $\left(\frac{V P}{V P+F P}\right)$ : das métricas de acurácia clássicas apresentadas na Seção 3.7.2, a precisão é a única que pode ser calculada de forma objetiva após a avaliação do usuário, pois depende apenas da sua apreciação sobre os itens recomendados (preditos positivos). Outras métricas, como recuperação e medidas $F_{\beta}$, dependeriam da avaliação do usuário de todos os itens do repositório para que o conjunto de itens positivos (reais positivos) fosse conhecido.

(b) Novidade: esta é uma métrica que só pode ser mensurada com a participação de usuários reais e foi a grande motivadora para a realização do survey. É mensurada de forma similar 
à precisão, como a proporção de itens marcados como novidade $(\mathrm{N})$ do conjunto de itens recomendados $\left(\frac{N}{(V P+F P)}\right)$.

(c) Variedade: devido à aleatoriedade na ordem de execução das estratégias e à liberdade dos participantes da consulta de avaliar quantas recomendações pudessem, ao final da coleta cada estratégia havia sido avaliada por uma quantidade diferente de usuário. Sendo assim, em vez de medir a proporção do repositório de itens que fez parte de alguma recomendação (cobertura), para cada modelo foi calculada a proporção de itens únicos (U) dentre todos os recomendados ao longo de todo o experimento $\left(\frac{U}{(V P+F P)}\right)$.

\subsubsection{Resultados}

A pesquisa foi divulgada por email e em canais IRC e ao longo de cerca de 30 dias de consulta pública 28 pessoas participaram do experimento. Foram executadas 93 rodadas de recomendação/avaliação, com um tempo médio de resposta de 8 minutos e 51 segundos para cada rodada (avaliação de 10 recomendações). Assume-se portanto que em geral os usuários dedicaram tempo suficiente para ler as descrições dos pacotes e realizar uma avaliação consciente.

A tabela 6.4 apresenta os resultados obtidos nesta etapa de experimentos. As estratégias que mais se destacaram, apresentando boas taxas de precisão, novidade e variedade nas recomendações foram knn_eset e knn_plus. A estratégia cbh apresentou boa precisão e novidade, porém a baixa variedade indica um comportamento viciado numa determinada porção de itens do repositório. Por outro lado, cbh_eset apresentou um comportamento conservador, típico de estratégias baseadas em conteúdo: apesar da alta precisão tem baixas taxas de novidade e variedade, que não são características desejáveis para um recomendador. Por fim, as estratégias knn e knnco apresentaram baixa precisão sem que houvesse ganho no quesito novidade com relação às demais estratégias.

\begin{tabular}{|l|c|c|c|}
\hline Estratégia & Precisão & Novidade & Variedade \\
\hline knn_eset & 82.31 & 17.69 & 93.08 \\
\hline knn_plus & 72.63 & 18.42 & 88.42 \\
\hline cbh & 84.62 & 16.92 & 72.31 \\
\hline cbh_eset & 81.25 & 12.50 & 76.88 \\
\hline knn & 72.50 & 15.00 & 98.13 \\
\hline knnco & 68.12 & 15.00 & 85.00 \\
\hline
\end{tabular}

Tabela 6.4: Desempenho das estratégias na consulta pública

O perfil dos usuários quanto à instalação de aplicativos foi outra informação coletada na pesquisa, como parte do formulário de preenchimento facultativo. Aproximadamente 54\% dos usuários declararam que procuram ativamente novos programas para instalar; $10.5 \%$ geralmente instalam quando recebem recomendações confiáveis e também 10.5\% declararam que raramente instalam novos aplicativos. 25\% dos participantes se abstiveram desta pergunta.

Para as próximas etapas de testes, pretende-se investir na atração do público-alvo mais provável de um recomendador, que seriam os usuários mais passivos (os curiosos geralmente já sabem o que querem). Idealmente, a própria interface do recomendador deve conter um ambiente onde o usuário possa realizar avaliações do que foi recomendado. 


\section{Capitulo 7}

\section{Considerações finais}

Apontamos como a contribuição mais relevante deste trabalho a concepção e desenvolvimento de um recomendador de aplicativos GNU/Linux, atualmente disponível para a comunidade por meio de um serviço $W e b^{1}$. O trabalho foi apresentado na conferência anual de Desenvolvedores Debian (DebConf11 $)^{2}$, onde recebeu críticas e sugestões, inclusive de desenvolvedores que já trabalharam em iniciativas semelhantes no Debian (seções 4.1 e 4.3).

A avaliação da proposta aconteceu num primeiro momento por meio de experimentos offline, com a aplicação de métodos para avaliar modelos preditivos. Os resultados dos experimentos guiaram o ajuste de parâmetros das estratégias de recomendação, além de possibilitar o descarte de algumas que apresentaram desempenho insatisfatório. Na segunda fase houve uma consulta pública por meio da qual usuários reais avaliaram a eficácia do recomendador. $\mathrm{O}$ fechamento desta fase de testes apontou quais estratégias obtiveram destaque em desempenho e merecem ser mais investigadas e aperfeiçoadas, para se adequarem cada vez mais ao domínio da aplicação.

A seguir são apresentados alguns desdobramentos possíveis deste trabalho, que no nosso entendimento abrem portas para futuras colaborações entre a academia e a comunidade de desenvolvimento de programas livres, em especial o projeto Debian.

\section{Ciclos de testes e atualizações}

Os primeiros experimentos foram executados, mas a interpretação dos dados gerados pode ser ainda mais aprofundada. Ademais, ao fim de cada fase de testes, o recomendador deve ser ajustado de acordo com as configurações que obtiveram melhor desempenho nos experimentos. Após os ajustes, é importante que se realize outro ciclo de testes, já que o modelo preditivo sofreu alterações. Em seguida, outra fase de ajustes, e assim por diante.

Entendemos a calibragem dos algoritmos e estratégias como um processo contínuo, sendo esta apenas a primeira fase de ajustes. A configuração do recomendador será passível de refinamento por todo o tempo em que estiver a serviço da comunidade.

\section{Fortalecimento de estratégias baseadas em conteúdo}

De acordo com as métricas de avaliação adotadas, estratégias baseadas puramente em conteúdo não apresentaram bons resultados. Acreditamos que um investigação ainda mais detalhada na base do Popcon possa revelar novos perfis de usuário que auxiliem a produção de recomendações mais acertadas. Integrantes da equipe responsável por programas científicos no Debian ${ }^{3}$

\footnotetext{
${ }^{1}$ http: //recommender. debian. net

${ }^{2}$ http://penta.debconf.org/dc11_schedule/events/773.en.html

${ }^{3}$ http://wiki.debian.org/DebianScience
} 
mostraram interesse em aprofundar a pesquisa sobre estes perfis, possivelmente utilizando técnicas de agrupamento.

É importante ressaltar a relevância das estratégias baseadas em conteúdo no contexto do AppRecommender, devido principalmente ao fato de não dependerem do acesso a uma base de dados contendo informações de outros usuários. Nesta abordagem a recomendação pode ser computada no sistema do cliente, mediante o acesso a uma base local de informações sobre os aplicativos. Esta seria uma alternativa para os usuários que optam por não enviar seus dados a servidores mantidos por terceiros.

O tema foi discutido durante a Debconf11, onde surgiu a ideia de disponibilizar uma versão do recomendador de aplicativos que funcionasse de forma descentralizada, e que a colaboração pudesse acontecer de um para poucos, não necessariamente entre todos os usuários. Desenvolvedores do FreedomBox ${ }^{4}$ colocaram-se a disposição para colaborar com experimentos do AppRecommender como uma aplicação piloto do projeto.

\section{Melhorias na solução}

São apresentadas a seguir algumas ideias de melhoria para o processo de composição da recomendação que surgiram ao longo do desenvolvimento e ainda não foram implementadas na versão atual.

- Atestação de relevância: Aplicar o conceito de atestação de relevância apresentado na Seção A.5.2 ao resultado de uma recomendação. Após receber um conjunto de aplicativos recomendados, o usuário indicaria quais são de fato relevantes para ele e o recomendador utilizaria essa informação para estender a primeira consulta realizada. Desta forma o recomendador seria realimentado com as avaliações do usuário para produzir recomendações ainda mais específicas às suas necessidades.

- Ranking de aplicativos: Adaptar o conceito de page rank utilizado em buscas na Web ao contexto do AppRecommender. Motores de busca na Internet "premiam" as páginas que possuem mais links incidentes, como um indicativo de confiabilidade do conteúdo. No caso do repositório de aplicativos, entendemos que as relações de dependência entre pacotes poderiam conduzir um parâmetro de confiabilidade análogo. Quando maior for a quantidade de programas que dependem de um determinado aplicativo, maior será a comunidade de desenvolvedores e usuários do aplicativo que se importam com seu bom funcionamento. Sendo assim, bugs tendem a ser resolvidos mais rapidamente e atualizações do upstream tendem a ser incorporadas com maior frequência.

- Log de atividades: Utilizar um sistema de log de atividades para registrar informações que forneçam um maior detalhamento acerca do perfil do usuário ou sistema. O programa Zeitgeist $t^{5}$, por exemplo, registra informações sobre a utilização de arquivos no sistema, navegação na Internet, conversas por chat ou e-mail. A coleta dessas informações é mais intrusiva que a do Popcon, pois as informações submetidas não limitam-se ao perfil do sistema, mas da pessoa que o utiliza. Portanto, o uso de tais dados deveria ser ainda mais criterioso e a coleta só deveria ser iniciada mediante expressa solicitação do usuário.

\section{Análise de riscos de privacidade}

Atualmente a base do Popcon utilizada pelo AppRecommender não é atualizada constantemente, portanto, dificilmente estaria vulnerável a ataques que monitoram o comportamento do recomendador ao logo do tempo. Contudo, a frequente atualização destes dados certamente permitiria a produção de sugestões mais eficazes, dado que se basearia em informações mais

\footnotetext{
${ }^{4}$ http://freedomboxfoundation.org/learn/

${ }^{5}$ https://launchpad.net/ ${ }^{\sim}$ zeitgeist
} 
"frescas". Acreditamos na necessidade de um estudo mais aprofundado dos riscos de exposição dos dados dos usuários, antes que um esquema de atualização seja proposto.

\section{Aperfeiçoamento da interface}

A interface $W e b$ do recomendador disponível atualmente ${ }^{6}$, além de computar a recomendação personalizada de aplicativos, fornece uma série de informações sobre os mesmos, por meio da integração de serviços providos pelo Debian, como o screenshots.debian.org e UDD. No entanto, seria de utilidade para o público a integração de outras funcionalidades relacionadas com o repositório de pacotes, como a navegação por seções ou tags, busca, possibilidade de instalação de pacotes por meio do protocolo $A p t U R L$, entre outras. Um exemplo de serviço nesta linha é $A p p N R^{7}$.

Outro ponto concernente à interface que merece atenção neste trabalho é a internacionalização do AppRecommender. Pretendemos implementar uma infraestrutura que permita a tradução dos textos de interface com o usuário para outros idiomas (processo conhecido como localização).

\section{Empacotamento para o Debian}

Estamos trabalhando na criação de um pacote Debian para o AppRecommender. Estando em conformidade com a política de empacotamento de programas para a distribuição, não encontraremos barreiras para incorporá-lo oficialmente ao projeto. A inclusão do pacote no repositório do Debian daria uma maior visibilidade ao AppRecommender, resultando na atração de novos usuário e colaboradores, contribuindo assim para o amadurecimento do trabalho.

\section{Integração com outras distribuições}

A integração com outras distribuições foi sempre uma meta no desenvolvimento do recomendador. Acompanhamos as discussões do projeto AppStream até o ponto que surgiu o impasse sobre o uso do Software-center - ainda não resolvido.

Uma alternativa simples para esta questão, que não necessita de infraestrutura adicional alguma, é o mapeamento da lista de pacotes do usuário para uma lista de pacotes Debian; computação da recomendação e mapeamento de volta para a referida distribuição. A função de mapeamento pode ser realizada pelo programa distromatch ${ }^{8}$.

\section{Documentação no idioma inglês}

Pretendemos sumarizar o conteúdo desta dissertação num documento de referência para colaboradores externos, incluindo principalmente a arquitetura do serviço e as decisões tomadas ao longo do desenvolvimento que dizem respeito ao funcionamento do recomendador. A criação de uma documentação em inglês é de grande importância para que os desdobramento deste trabalho de fato envolvam a comunidade internacional.

\section{Palavras finais}

A realização deste projeto não seria possível sem a colaboração da comunidade Debian que, além de disponibilizar os dados utilizados como base da composição de recomendações, possibilitou o aproveitamento de esforços anteriores e a frequente interação com desenvolvedores mais experientes nos temas abordados.

\footnotetext{
${ }^{6}$ http://recommender.debian.net

${ }^{7}$ http://appnr.com

${ }^{8}$ http://enricozini.org/2011/debian/distromatch/
} 
Além da dedicação contínua para que o presente trabalho ofereça contribuições no âmbito acadêmico, estamos confiantes de que fomos também capazes de retribuir um pouco ao projeto Debian os benefícios que este tem proporcionado aos seus usuários nestes 18 anos de existência. Por fim, seguimos bastante motivados a prosseguir com os trabalhos, de sorte que o AppRecommender siga um processo natural de aperfeiçoamento e consequente integração com outros sistemas já consolidados. 


\section{Referências Bibliográficas}

[Abate et al. 2009] Abate, P., Boender, J., Cosmo, R. D., and Zacchiroli, S. (2009). Strong Dependencies between Software Components. Technical report, MANCOOSI - Managing the Complexity of the Open Source Infraestructure.

[Adomavicius and Tuzhilin 2005] Adomavicius, G. and Tuzhilin, A. (2005). Toward the next generation of recommender systems: A survey of the state-of-the-art and possible extensions. IEEE Transactions on Knowledge and Data Engineering, 17(6):734-749.

[Agrawal and Srikant 1994] Agrawal, R. and Srikant, R. (1994). Fast Algorithms for Mining Association Rules in Large Databases. In Proceedings of the 20th International Conference on Very Large Data Bases, VLDB '94, pages 487-499. Morgan Kaufmann Publishers Inc.

[Betts 2007] Betts, O. (2007). Xapian: BM25 Weighting Scheme. Disponível em http: //xapian. org/docs/bm25. html.

[Burke 2002] Burke, R. (2002). Hybrid Recommender Systems: Survey and Experiments. User Modeling and User-Adapted Interaction, 12:331-370.

[Calandrino et al. 2011] Calandrino, J. A., Kilzer, A., Narayanan, A., Felten, E. W., and Shmatikov, V. (2011). You Might Also Like: Privacy Risks of Collaborative Filtering. pages 231-246.

[Castells 2006] Castells, M. (2006). A Era da Intercomunicação. Le Monde Diplomatique Brasil, Agosto 2006.

[Cazella et al. 2010] Cazella, S. C., Reategui, E. B., and Nunes, M. A. (2010). A ciência da opinião: estado da erte em sistemas de recomendação. In JAI: Jornada de Atualização em Informática da SBC, pages 161-216.

[Cosmo et al. 2008] Cosmo, R. D., Zacchiroli, S., and Trezentos, P. (2008). Package upgrades in FOSS distributions: details and challenges. In Proceedings of the 1st International Workshop on Hot Topics in Software Upgrades, pages 7:1-7:5. ACM.

[Davies et al. 2010] Davies, J., Zhang, H., Nussbaum, L., and Germán, D. M. (2010). Perspectives on bugs in the debian bug tracking system. In 7th IEEE Working Conference on Mining Software Repositories (MSR), MSR'10, pages 86-89.

[Fawcett 2007] Fawcett, T. (2007). ROC Graphs: Notes and Practical Considerations for Researchers. Technical report.

[Freedesktop 2011] Freedesktop (2011). Distributions Wiki: Cross-distro Meeting on Application Installer. Disponivel em http://distributions. freedesktop. org/wiki/Meetings/ AppInstaller2011. 
[Hechenbichler and Schliep 2006] Hechenbichler, K. and Schliep, K. (2006). Weighted knearest-neighbor techniques and ordinal classification. In Discussion Paper 399, SFB 386.

[Hegland 2003] Hegland, M. (2003). Algorithms for association rules. In Mendelson, S. and Smola, A., editors, Advanced Lectures on Machine Learning, volume 2600 of Lecture Notes in Computer Science, pages 226-234. Springer Berlin / Heidelberg.

[Herlocker 2000] Herlocker, J. L. (2000). Understanding and improving automated collaborative filtering systems. $\mathrm{PhD}$ thesis.

[Herlocker et al. 2004] Herlocker, J. L., Konstan, J. A., Terveen, L. G., and Riedl, J. T. (2004). Evaluating collaborative filtering recommender systems. ACM Trans. Inf. Syst., 22:5-53.

[Iyengar 2010] Iyengar, S. (2010). The Art of Choosing. Twelve.

[Jackson and Schwarz 1998] Jackson, I. and Schwarz, C. (1998). Debian Policy Manual. Disponivel em http: //www. debian. org/doc/debian-policy.

[Jones et al. 2000] Jones, K. S., Walker, S., and Robertson, S. E. (2000). A probabilistic model of information retrieval: development and comparative experiments (Parts 1 and 2). Inf. Process. Manage., 36:779-840.

[Kaufman and Rousseeuw 2005] Kaufman, L. and Rousseeuw, P. J. (2005). Finding Groups in Data: An Introduction to Cluster Analysis (Wiley Series in Probability and Statistics). Wiley-Interscience.

[Kotsiantis and Kanellopoulos 2006] Kotsiantis, S. and Kanellopoulos, D. (2006). Association rule mining: a recent overview. GESTS International Transactions on Computer Science and Engineering, 32:71-82.

[Manning et al. 2009] Manning, C. D., Raghavan, P., and Schütze, H. (2009). An Introduction to Information Retrieval. Cambridge University Press.

[Nussbaum and Zacchiroli 2010] Nussbaum, L. and Zacchiroli, S. (2010). The Ultimate Debian Database: Consolidating Bazaar Metadata for Quality Assurance and Data Mining. IEEE Working Conference on Mining Software Repositories.

[O'Mahony and Ferraro 2007] O'Mahony, S. and Ferraro, F. (2007). The Emergence of Governance in an Open Source Community. Academy of Management Journal, 50(5):10791106.

[Paul 2010] Paul, R. (2010). Shuttleworth: Unity shell will be default desktop in Ubuntu 11.04. Disponivel em http://arstechnica.com/open-source/news/2010/10/ shuttleworth-unity-shell-will-be-default-desktop-in-ubuntu-1104.

[Pereira 2007] Pereira, D. (2007). Uma aplicação de sistemas de recomendação: sistema de recomendação para pacotes gnu/linux. Master's thesis, Universidade Federal do Rio Grande do Sul.

[Pérez-Iglesias et al. 2009] Pérez-Iglesias, J., Pérez-Agüera, J. R., Fresno, V., and Feinstein, Y. Z. (2009). Integrating the Probabilistic Models BM25/BM25F into Lucene. CoRR. Disponivel em http://arxiv. org/abs/0911. 5046.

[Robertson 1977] Robertson, S. E. (1977). The Probability Ranking Principle in IR. Journal of Documentation, 33(4):294-304. 
[Robertson and Walker 1994] Robertson, S. E. and Walker, S. (1994). Some simple effective approximations to the 2-Poisson model for probabilistic weighted retrieval. In Proceedings of the 17th annual international ACM SIGIR conference on Research and development in information retrieval, SIGIR '94, pages 232-241. Springer-Verlag.

[Schröder 2007] Schröder, A. (2007). Konzeption und erstellung eines systems zur generierung personalisierter installationsratschläge für das debian. Master's thesis, Universität Paderborn.

[Simon and Vieira 2008] Simon, I. and Vieira, M. S. (2008). O rossio não rival. Disponível em http: //www. ime. usp. br/ ${ }^{\sim} i s /$ papir/RNR_v9. pdf.

[Torvalds and Diamond 2001] Torvalds, L. and Diamond, D. (2001). Just for Fun: The Story of an Accidental Revolutionary. HARPER USA.

[Vozalis and Margaritis 2003] Vozalis, E. and Margaritis, K. G. (2003). Analysis of Recommender Systems' Algorithms. In Proceedings of the 6th Hellenic European Conference on Computer Mathematics and its Applications.

[Zhang 2004] Zhang, H. (2004). The Optimality of Naive Bayes. In Barr, V. and Markov, Z., editors, FLAIRS Conference. AAAI Press.

[Zini 2011a] Zini, E. (2011a). A cute introduction to Debtags. Disponivel em http: //debtags. alioth. debian. org/paper-debtags. html.

[Zini 2011b] Zini, E. (2011b). Cross-distro Meeting on Application Installer. Disponível em http://www. enricozini.org/2011/debian/appinstaller2011. 



\section{Apêndice $A$}

\section{Técnicas}

A seguir são apresentadas com mais detalhes as técnicas mencionadas no capítulo 3, que servem como base para a construção de sistemas recomendadores.

\section{A.1 $k$-Nearest Neighbor $(k$-NN)}

$k$-Nearest Neighbors ( $k$-NN), em português $k$ vizinhos mais próximos, é um algoritmo de aprendizado supervisionado para classificação. Este método baseia-se no conceito de vizinhança, que representa um conjunto de objetos que estão próximos no espaço de busca.

O $k-N N$ não exige nenhum treinamento prévio com os dados de exemplo, que podem ser diretamente armazenados como vetores de atributos acompanhados por suas devidas classes. A classificação de um novo objeto parte do cálculo da vizinhança do mesmo, que é composta por $k$ objetos.

A determinação da vizinhança está diretamente relacionada com o conceito de proximidade entre objetos, que pode ser expressa em termos de similaridade ou de distância entre os mesmos (quanto maior a distância, menor a similaridade). Existem diversas medidas para mensurar tais conceitos; deve-se adotar a métrica que melhor se adeque ao domínio da aplicação e conjunto de dados. A tabela A.1 apresenta algumas dessas medidas, onde os objetos $X$ e $Y$ são representados por seus vetores $\vec{X}=\left(x_{1}, \ldots, x_{n}\right)$ e $\vec{Y}=\left(y_{1}, \ldots, y_{n}\right)$. A similaridade entre dois vetores pode ser mensurada utilizando o cosseno do ângulo entre os vetores (Similaridade de Cosseno). O Coeficiente de Pearson é equivalente ao cosseno do ângulo entre os vetores centralizados na média. E o Coeficiente de Tanimoto é uma extensão da Similaridade de Cossenos que resulta no índice de Jaccard para atributos binários.

\begin{tabular}{|l|l|}
\hline Distância euclidiana & $D(X, Y)=\sqrt{\left(x_{1}-y_{1}\right)^{2}+\left(x_{2}-y_{2}\right)^{2}+\ldots+\left(x_{n}-y_{n}\right)^{2}}$ \\
\hline Similaridade de Cosseno & $\operatorname{sim}(X, Y)=\frac{\vec{X} \cdot \vec{Y}}{|\vec{X}||\vec{Y}|}=\frac{\sum_{1 \leq i \leq n} x_{i} y_{i}}{\sqrt{\sum_{1 \leq i \leq n} x_{i}^{2}} \sqrt{\sum_{1 \leq i \leq n} y_{i}^{2}}}$ \\
\hline Coeficiente de Pearson & $P(X, Y)=\frac{\sum_{1 \leq i \leq n}\left(x_{i}-\bar{x}\right)\left(y_{i}-\bar{y}\right)}{\sqrt{\sum_{1 \leq i \leq n}\left(x_{i}-\bar{x}\right)^{2}} \sqrt{\sum_{1 \leq i \leq n}\left(y_{i}-\bar{y}\right)^{2}}}$ \\
\hline Coeficiente de Tanimoto & $T(X, Y)=\frac{\vec{X} \cdot \vec{Y}}{|\vec{X}|^{2}+|\vec{Y}|^{2}-\vec{X} \cdot \vec{Y}}$ \\
\hline
\end{tabular}

Tabela A.1: Medidas de distância e similaridade entre objetos

Após a definição de vizinhança, a classe mais frequente entre seus $k$ vizinhos é atribuída ao novo objeto. Sendo assim, a similaridade também pode ser entendida como o grau de influência entre os objetos. Os objetos mais semelhantes a um novo objeto terão maior influência no cálculo de sua classificação. 


\section{A.2 Agrupamento}

Agrupamento (clustering) é uma técnica de aprendizado de máquina não supervisionado. $\mathrm{O}$ algoritmo particiona a base de dados de forma a criar automaticamente grupos que reúnam usuários com comportamentos semelhantes. Para fins de recomendação o agrupamento pode ser utilizado na composição de vizinhança de um usuário na aplicação de técnicas colaborativas.

A escolha dos algoritmos a ser utilizado deve depender do tipo de dados disponível e nos objetivos específicos da aplicação. É aceitável experimentar diversos algoritmos no mesmo conjunto de dados porque geralmente não se quer provar ou refutar uma hipótese pré-concebida, mas sim ver "o que os dados estão tentando nos dizer" [Kaufman and Rousseeuw 2005].

Entre as técnicas mais populares de agrupamento está o $k$-Means, que consiste basicamente nos seguintes passos:

1. Seleção de $k$ elementos considerados sementes;

2. Associação de cada elemento da base de dados com a semente mais próxima a ele;

3. Cálculo de novos pontos no espaço centrais (centroides) para cada grupo, a partir dos elementos que o compõem.

O passo 3 é repetido até que não seja mais necessário calcular novos centroides.

$k$-Medoids é uma variação do $k$-Means, onde as partições giram em torno de medoides em vez de pontos no espaço. Medoides são os elementos que acumulam menor dissimilaridade com o restante dos objetos do grupo. Esta é uma solução mais genérica do que o primeiro método porque pode ser utilizada mesmo quando um centroide não pode ser definido (a depender do tipo das variáveis), já que se apoiam em coeficientes de dissimilaridades. É utilizado também quando há interesse em preservar os objetos representativos de cada grupo, por exemplo, para fins de redução de dados ou caracterização.

\section{A.3 Classificador bayesiano}

Bayes ingênuo é uma solução para classificação que Figura entre os algoritmos de aprendizado de máquina supervisionados. O classificador apoia-se num modelo probabilístico que aplica o teorema de Bayes com fortes suposições de independência de atributos - por esta razão o método é considerado ingênuo. Em outras palavras, a presença ou ausência de um atributo em um objeto de uma classe não estaria relacionada com a incidência de nenhum outro atributo.

A decisão acerca da classe à qual um objeto pertence é tomada de acordo com o modelo de probabilidade máxima posterior $(M A P)$, indicada na equação A.1. Dado que $C$ é o conjunto de classes e $x$ o objeto a ser classificado, a classe atribuída será a que apresentar maior probabilidade condicionada a $x . \hat{P}$ é utilizado em vez de $P$ porque geralmente não se sabe o valor exato das probabilidades, que são estimadas a partir dos dados de treinamento.

$$
c_{M A P}=\underset{c \in C}{\arg \max } \hat{P}(c \mid x)
$$

A equação A.2 aplica o Teorema de Bayes para probabilidades condicionadas. Na prática, apenas o numerador da fração interessa, visto que o denominador é constante para todas as classes, portanto não afeta o $\arg \max$ (equação A.3).

$$
\begin{aligned}
c_{M A P} & =\underset{c \in C}{\arg \max } \frac{\hat{P}(x \mid c) \hat{P}(c)}{\hat{P}(x)} \\
& =\underset{c \in C}{\arg \max } \hat{P}(x \mid c) \hat{P}(c)
\end{aligned}
$$


É nesse ponto que a independência de atributos é importante. Considera-se que um documento $x$ pode ser caracterizado por uma série de atributos $x_{i}$ - no caso de documentos de texto, os atributos são os próprios termos. Assumindo que a ocorrência de atributos acontece independentemente, tem-se que:

$$
\hat{P}(x \mid c)=\hat{P}\left(x_{1}, x_{2}, \ldots, x_{n} \mid c\right)=\hat{P}\left(x_{1} \mid c\right) \hat{P}\left(x_{2} \mid c\right) \ldots \hat{P}\left(x_{n} \mid c\right)
$$

Portanto, a função de decisão pode ser reescrita como na equação A.5. Cada parâmetro condicional $\hat{P}\left(x_{i} \mid c\right)$ é um peso que representa a qualidade do atributo $x_{i}$ como indicador da classe $c$, enquanto que $\hat{P}(c)$ é a frequência relativa da classe $c$.

$$
c_{M A P}=\underset{c \in C}{\arg \max } \hat{P}(c) \prod_{1 \leq i \leq n} \hat{P}\left(x_{i} \mid c\right)
$$

Os parâmetros são obtidos por meio da estimativa de maior probabilidade ( $M L E)$, que corresponde ao valor mais provável de cada parâmetro de acordo com os dados de treinamento. A equação A.6 traz a estimativa de $\hat{P}(c)$, onde $N_{c}$ é o número de objetos da classe $c$ e $N$ é o número total de documentos.

$$
\hat{P}(c)=\frac{N_{c}}{N}
$$

As probabilidades condicionais são estimadas como a frequência relativa do atributo $x \mathrm{em}$ objetos que pertencem à classe $c$. Na equação A.7, $T_{c x}$ é o número de ocorrências de $x$ em objetos de exemplo da classe $c$ e $V$ é o conjunto de atributos que os objetos podem apresentar.

$$
\hat{P}(x \mid c)=\frac{T_{c x}}{\sum_{x^{\prime} \in V} T_{c x^{\prime}}}
$$

No entanto, a estimativa $M L E$ é zero para combinações atributo-classe que não ocorrem nos dados de treinamento. Considerando que as probabilidades condicionais de todos os atributos serão multiplicadas (equação A.5), a simples ocorrência de uma probabilidade zerada resulta na desconsideração da classe na referida classificação. E de fato, dados de treinamento nunca são abrangentes o suficiente para representar a frequência de eventos raros de forma adequada [Manning et al. 2009]. Para eliminar zeros, adiciona-se 1 a cada termo da equação A.7:

$$
\hat{P}(x \mid c)=\frac{T_{c x}+1}{\sum_{x^{\prime} \in V} T_{c x^{\prime}}+1}
$$

O classificador bayesiano também é sensível a ruídos, logo, sua performance é igualmente beneficiada pelo processo de seleção de atributos descrito na Seção 3.4.

Apesar de a independência de atributos não ser verificada para a maioria dos domínios de aplicação, na prática o Bayes ingênuo apresenta resultados satisfatórios. [Zhang 2004] atribui a surpreendente boa performance desse método ao fato de que a mera existência de dependências entre atributos não prejudicaria a classificação, mas sim o modo como as dependências estão distribuídas ao longo das classes. Segundo o autor, desde que as dependências estejam distribuídas igualmente nas classes, não há problema em haver dependência forte entre dois atributos.

\section{A.3.1 Variantes do modelo Bayes ingênuo}

As duas principais variantes de implementação do classificador bayesiano, denominadas de modelo multinomial e de Bernoulli, diferem fundamentalmente na maneira como os objetos são representados. 
O primeiro modelo utiliza uma representação que considera informações espaciais sobre o objeto. Na classificação de documentos de texto, por exemplo, o modelo gera um atributo para cada posição do documento, que corresponde a um termo do vocabulário. Já o modelo de Bernoulli produz um indicador de presença ou ausência para cada possível atributo (no caso de texto, cada termo do vocabulário).

A escolha da representação de documentos adequada é uma decisão crítica no projeto de um classificador, visto que o próprio significado de um atributo depende da representação. No multinomial, um atributo pode assumir como valor qualquer termo do vocabulário, o que resulta numa representação do documento correspondente à sequência de termos do mesmo. Já para o modelo de Bernoulli, um atributo pode assumir apenas os valores 0 e 1, e a representação do documento é uma sequência de 0s e 1s do tamanho do vocabulário.

\section{A.4 Medida $t f \_i d f$}

Acrônimo para term frequency - inverse document frequency, tf_idf é uma medida de peso clássica utilizada em ferramentas de busca em texto para ordenação do resultado da consulta pela relevância dos documentos.

O universo da busca é uma coleção de documentos de texto. Um documento por sua vez é uma coleção de palavras, geralmente referenciadas como termos do documento. O conjunto de todas as palavras presentes nos documentos da coleção é denominado dicionário ou vocabulário. Sendo assim, um documento $d$ composto por $n$ termos do vocabulário $V$ pode ser representado como $d=\left\{t_{1}, t_{2}, \ldots, t_{n} \mid 1 \leq i \leq n, t_{i} \in V\right\}$.

Contudo, alguns termos do vocabulário, designados como stop words, são normalmente desconsiderados no cálculo de relevância dos documentos por serem muito frequentes na coleção e, em decorrência disto, pouco informativos acerca do teor dos textos. Artigos e pronomes, por exemplo, geralmente figuram nesta categoria.

Outra consideração acerca da representação dos documentos como conjuntos de termos é a realização de normalizações morfológicas. Diferentes palavras que dizem respeito ao mesmo conceito podem ser utilizadas ao longo de uma coleção, por exemplo, os termos casa, casinha e casas. Em certos contextos, deseja-se que a busca por uma determinada variante retorne ocorrências de todas as outras possibilidades. Nesse caso, os termos devem ser tratados em sua forma normalizada, eliminando variações como plurais e flexões verbais. Os processos mais comuns de normalização são: stemming, que reduz a palavra ao seu radical; e lematização, que reduz a palavra à sua forma canônica (por exemplo, verbos no infinitivo, substantivos no singular masculino etc). A Figura A.1 apresenta um documento de texto numa coleção hipotética ${ }^{1}$ e a sua representação após eliminação de stop words e procedimento de stemming.

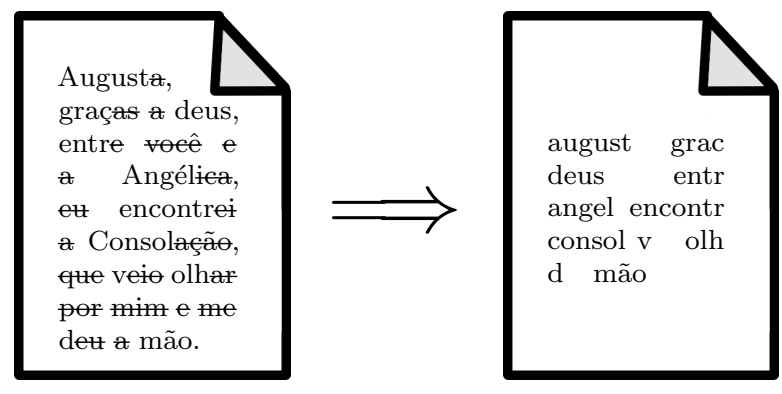

Figura A.1: Eliminação de stop words e normalização do documento por stemming

A simples presença de um termo da query em um documento da coleção já é um indicativo de que o mesmo tem alguma relação com a consulta. No entanto, a quantidade de vezes que

\footnotetext{
${ }^{1}$ Os textos utilizados nos exemplos desta seção são excertos de letras de música de diversos compositores brasileiros.
} 
o termo ocorre é ainda mais informativa sobre sua relação com o conteúdo do documento. Intuitivamente, os documentos que referenciam os termos de uma query com mais frequência estão mais fortemente relacionados com a mesma, e por isso deveriam receber uma maior pontuação de relevância. O peso $t f_{t, d}$ (term frequency) quantifica esta noção intuitiva, relacionando documentos da coleção e termos do dicionário de acordo com a frequência desses nos documentos. Em sua abordagem mais simples, $t f_{t, d}$ é igual ao número de ocorrências do termo $t$ no documento $d$.

A Figura A.2 ilustra uma coleção de documentos, cujos valores de $t f_{t, d}$ para alguns termos do dicionário são apresentados na tabela A.2. Por exemplo, a palavra morena ocorre duas vezes no documento (1), por isso $t f_{m o r e n, 1}=2$. O cálculo do $t f \mathrm{~s}$ já considera os radicais dos termos, resultantes de um processo de stemming. Em razão disto, $t f_{o l h, 2}=3$, pois tanto a palavra olho quanto as diferentes flexões do verbo olhar contribuem para a contagem de frequência do termo olh. Na tabela A.2, os radicais dos vocábulos são seguidos por algumas variações, a título de ilustração.

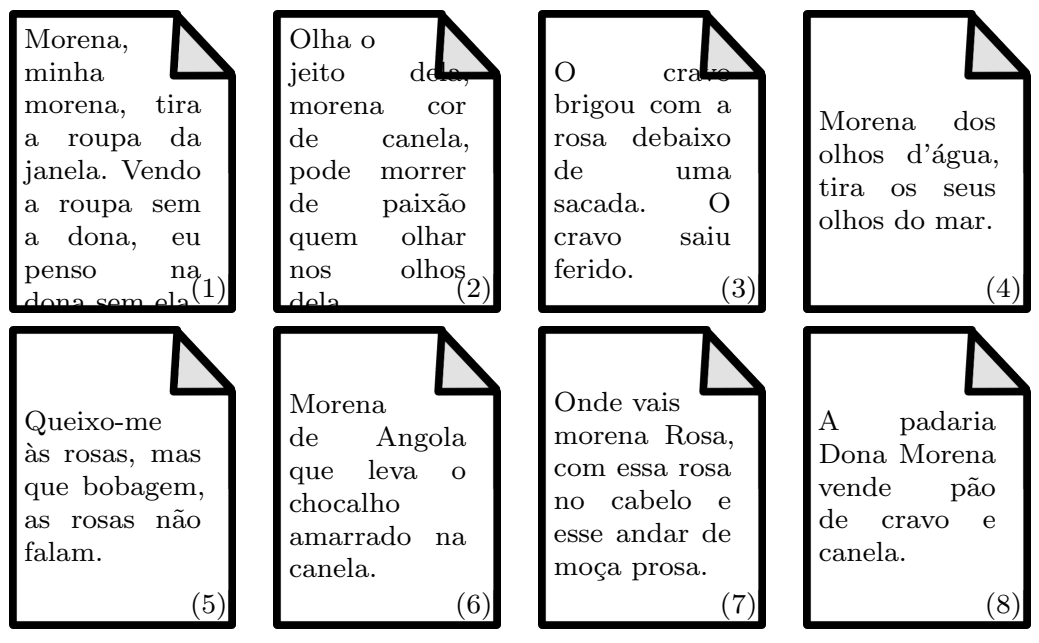

Figura A.2: Coleção de documentos

\begin{tabular}{|l|c|c|c|c|c|c|c|c|}
\hline \multicolumn{10}{|c|}{ Doc } & $(\mathbf{1})$ & $\mathbf{( 2 )}$ & $\mathbf{( 3 )}$ & $\mathbf{( 4 )}$ & $\mathbf{( 5 )}$ & $\mathbf{( 6 )}$ & $\mathbf{( 7 )}$ & $\mathbf{( 8 )}$ \\
\hline Termo & 2 & 1 & 0 & 1 & 0 & 1 & 1 & 1 \\
\hline moren $\{a, o\}$ & 2 & 0 & 0 & 0 & 0 & 0 & 0 & 0 \\
\hline $\operatorname{roup}\{a, \tilde{a} o\}$ & 2 & 0 & 0 & 0 & 0 & 0 & 0 & 1 \\
\hline $\operatorname{don}\{a, o\}$ & 0 & 0 & 2 & 0 & 0 & 0 & 0 & 1 \\
\hline $\operatorname{crav}\{$ o,eiro $\}$ & 0 & 1 & 0 & 0 & 0 & 1 & 0 & 1 \\
\hline $\operatorname{canel}\{a, e i r a\}$ & 0 & 3 & 0 & 2 & 0 & 0 & 0 & 0 \\
\hline olh $\{$ o,ar $\}$ & 0 & 0 & 1 & 0 & 2 & 0 & 2 & 0 \\
\hline $\operatorname{ros}\{a$, eira $\}$ & 0 & 0 & 0 & 0 & 1 & 0 & 0 & 0 \\
\hline bob $\{$ o,agem $\}$ & & &
\end{tabular}

Tabela A.2: Frequência dos termos nos documentos da coleção

O conjunto de pesos determinado pelos $t f \mathrm{~s}$ dos termos de um documento pode ser entendido como um resumo quantitativo do mesmo. Essa visão do documento é comumente referenciada na literatura como "saco de palavras", onde a disposição das palavras é ignorada e apenas a quantidade de ocorrências para cada termo é considerada.

Uma medida de relevância baseada simplesmente na incidência dos termos da query nos documentos $(R I)$ poderia ser calculada por meio da equação A.9.

$$
R I_{d, q}=\sum_{t \in q} t f_{t, d}
$$


No entanto, alguns termos têm pouco poder de discriminação na determinação de relevância de um documento, por estarem presentes em quase todos os documentos. Ao passo que existem outros muito raros que quando presentes são forte indicativo de relevância. No contexto da coleção da Figura A.2, por exemplo, a query \{morena, bobagem\} é composta por um termo muito frequente e outro muito raro. Coincidentemente, os documentos (3) e (5), contém apenas um dos dois elementos da consulta, porém ambos apresentam $t f_{t, d}=1$ para os respectivos termos. Todavia, ao passo que esta frequência se repete entre os documentos da coleção múltiplas vezes para o termo morena, ela é única para o termo bobagem, o que de fato diferencia o documento (5) dos demais.

$\mathrm{O} i d f_{t}$ (inverse document frequency) foi então introduzido para atenuar o efeito de termos muito comuns no cálculo de relevância, diminuindo o peso relacionado a um termo por um fator que cresce com sua frequência em documentos na coleção [Manning et al. 2009]. A equação A.10 apresenta a forma clássica do idf, na qual $N$ representa o número de documentos da coleção e $d f_{t}$ (document frequency) é o número de documentos que contém o termo $t$. É comum que o universo da busca seja uma coleção de documentos de altíssima dimensão, resultando em valores de $d f_{t}$ muito discrepantes. O uso do log diminui a escala de valores, permitindo que frequências muito grandes e muito pequenas sejam comparadas sem problemas.

$$
i d f_{t}=\log \frac{N}{d f_{t}}
$$

Valores de $i d f_{t}$ para a coleção da Figura A.2 são apresentados na tabela A.3. Novamente os radicais dos termos são considerados: $i d f_{\text {morena }}=i d f_{\text {moren }}=\log \frac{8}{6}=0.12$, enquanto $i d f_{\text {bobagem }}=i d f_{\text {bob }}=\log \frac{8}{1}=0.9$.

\begin{tabular}{|l|c|c|c|c|c|c|c|c|}
\hline Termo & moren & roup & don & crav & canel & olh & ros & bob \\
\hline idf $_{\boldsymbol{t}}$ & 0.12 & 0.9 & 0.6 & 0.6 & 0.42 & 0.6 & 0.42 & 0.9 \\
\hline
\end{tabular}

Tabela A.3: Valores de $i d f_{t}$ para termos do dicionário

A medida $t f_{-} i d f_{t, d}$ combina as definições de $t f$ e $i d f$, de acordo com a equação A.11.

$$
t f_{-} i d f_{t, d}=t f_{t, d} \cdot i d f_{t}
$$

O peso composto resultante apresenta as seguintes propriedades:

1. É alto quando $t$ ocorre muitas vezes em $d$ e em poucos documentos da coleção (ambos tf e idf são altos);

2. Diminui quando ocorre menos vezes em $d$ ( $t f$ mais baixo) ou em muitos documentos da coleção (idf mais baixo);

3. É muito baixa quando o termo ocorre em quase todos os documentos (mesmo para valores altos de $t f$, para termos muito comuns o peso idf domina a fórmula, em decorrência do uso do $\log$ ).

A medida de relevância apresentada na equação A.9 pode ser refinada para somar os pesos $t f_{-} i d f$ do documento $d$ com relação aos termos da query $q$, resultando na media $R_{d, q}$ apresentada na equação A.12 [Manning et al. 2009].

$$
R_{d, q}=\sum_{t \in q} t f_{-} i d f_{t, d}
$$

A tabela A.4 apresenta a ordenação dos documentos da coleção como resultado do cálculo de relevância por $t f \_i d f$ para as consultas $q_{1}=\{$ morena $\}, q_{2}=\{$ morena, bobagem $\}$ e $q_{3}=\{$ morena, dona,rosa $\}$. Os valores $t f_{-} i d f_{t, d}$ foram obtidos a partir da equação A.11, 
com os pesos das tabelas A.2 e A.3. Por exemplo, $t f_{-} i d f_{\text {morena, } 1}=t f_{\text {morena }, 1} \cdot i d f_{\text {morena }}=$ $2 \cdot 0.12=0.24$.

\begin{tabular}{|c|c|c|}
\hline \multirow{2}{*}{ doc } & $\boldsymbol{q}_{\mathbf{1}}$ & \multirow{2}{*}{$\boldsymbol{R}_{\boldsymbol{d}, \boldsymbol{q}}$} \\
\cline { 2 - 3 } & morena & \\
\hline$(1)$ & 0.24 & 0.24 \\
\hline$(2)$ & 0.12 & 0.12 \\
\hline$(4)$ & 0.12 & 0.12 \\
\hline$(6)$ & 0.12 & 0.12 \\
\hline$(7)$ & 0.12 & 0.12 \\
\hline$(8)$ & 0.12 & 0.12 \\
\hline$(3)$ & 0 & 0 \\
\hline$(5)$ & 0 & 0 \\
\hline
\end{tabular}

\begin{tabular}{|c|c|c|c|}
\hline \multirow{2}{*}{ doc } & \multicolumn{2}{|c|}{$\boldsymbol{q}_{\mathbf{2}}$} & \multirow{2}{*}{$\boldsymbol{R}_{\boldsymbol{d , \boldsymbol { }}}$} \\
\cline { 2 - 3 } & morena & bobagem & \\
\hline$(5)$ & 0 & 0.9 & 0.9 \\
\hline$(1)$ & 0.24 & 0 & 0.24 \\
\hline$(2)$ & 0.12 & 0 & 0.12 \\
\hline$(4)$ & 0.12 & 0 & 0.12 \\
\hline$(6)$ & 0.12 & 0 & 0.12 \\
\hline$(7)$ & 0.12 & 0 & 0.12 \\
\hline$(8)$ & 0.12 & 0 & 0.12 \\
\hline$(3)$ & 0 & 0 & 0 \\
\hline
\end{tabular}

\begin{tabular}{|c|c|c|c|c|}
\hline \multirow{2}{*}{ doc } & \multicolumn{3}{|c|}{$\boldsymbol{q}_{\mathbf{3}}$} & \multirow{2}{*}{$\boldsymbol{R}_{\boldsymbol{d}, \boldsymbol{q}}$} \\
\cline { 2 - 4 } & morena & dona & rosa & \\
\hline$(1)$ & 0.24 & 1.2 & 0 & 1.44 \\
\hline$(8)$ & 0.12 & 1.2 & 0 & 1.32 \\
\hline$(7)$ & 0.12 & 0 & 0.84 & 0.96 \\
\hline$(5)$ & 0 & 0 & 0.84 & 0.84 \\
\hline$(3)$ & 0 & 0 & 0.42 & 0.42 \\
\hline$(2)$ & 0.12 & 0 & 0 & 0.12 \\
\hline$(4)$ & 0.12 & 0 & 0 & 0.12 \\
\hline$(6)$ & 0.12 & 0 & 0 & 0.12 \\
\hline
\end{tabular}

Tabela A.4: Ordenação dos documentos como resultado das consultas $\boldsymbol{q}_{\mathbf{1}}, \boldsymbol{q}_{\mathbf{2}}$ e $\boldsymbol{q}_{\mathbf{3}}$

Existem diversas variantes para o cálculo dos pesos $t f_{t, d}$ e $i d f_{t}$, propostas com o intuito de aperfeiçoar o processo de busca. Por exemplo, geralmente a presença de uma palavra 20 vezes num documento não tem de fato 20 vezes mais representatividade do que uma ocorrência única. Documentos distintos podem referenciar o mesmo conceito de forma concisa ou prolixa, e esse fato por si só não deve ser motivo para pesos muito discrepantes com relação a uma query, visto que o teor do texto é o mesmo. A variante denominada tf sub-linear incorpora o logaritmo ao cálculo do $t f$ para atenuar o crescimento do peso para valores crescentes de frequência (equação A.13).

$$
t f-s u b_{t, d}= \begin{cases}1+\log t f_{t, d} & , \text { se } t f_{t, d}>0 \\ 0 & , \text { caso contrário }\end{cases}
$$

Outras abordagens alternativas utilizam normalizações por diversas medidas: comprimento do documento, comprimento médio dos documentos da coleção, $t f$ máximo ou médio entre os $t f \mathrm{~s}$ de todos os termos do documento, entre outros.

\section{A.4.1 Modelo de espaço vetorial}

Uma coleção de documentos pode ser representada por um conjunto de vetores, sendo cada documento descrito como um vetor de termos do dicionário e os respectivos pesos tf_idf do documento. Tem-se como resultado uma visão da coleção como uma matriz de dimensões $M \times N$, na qual as linhas representam os $M$ termos do dicionário e as colunas os $N$ documentos da coleção. Esta representação da coleção, conhecida como modelo de espaço vetorial, é amplamente utilizada em soluções para recuperação da informação.

Assumindo que o vocabulário se restringe apenas aos termos para os quais os valores de $t f$ e idf foram calculados (tabelas A.2 e A.3), a coleção de documentos da Figura A.2 pode ser representada no modelo de espaço vetorial pela matriz da tabela A.5.

\begin{tabular}{|l|c|c|c|c|c|c|c|c|}
\hline \multicolumn{9}{|c|}{ tf $_{\text {_idf }} \boldsymbol{t , \boldsymbol { d }}$} \\
\hline Termo & $\mathbf{1} \boldsymbol{( 1 )}$ & $\mathbf{( 2 )}$ & $\mathbf{( 3 )}$ & $\mathbf{( 4 )}$ & $\mathbf{( 5 )}$ & $\mathbf{( 6 )}$ & $\mathbf{( 7 )}$ & $\mathbf{( 8 )}$ \\
\hline moren & 0.24 & 0.12 & 0 & 0.12 & 0 & 0.12 & 0.12 & 0.12 \\
\hline roup & 1.8 & 0 & 0 & 0 & 0 & 0 & 0 & 0 \\
\hline don & 1.2 & 0 & 0 & 0 & 0 & 0 & 0 & 0.6 \\
\hline crav & 0 & 0 & 1.2 & 0 & 0 & 0 & 0 & 0.6 \\
\hline canel & 0 & 0.42 & 0 & 0 & 0 & 0.42 & 0 & 0.42 \\
\hline olh & 0 & 1.8 & 0 & 1.2 & 0 & 0 & 0 & 0 \\
\hline ros & 0 & 0 & 0.42 & 0 & 0.84 & 0 & 0.84 & 0 \\
\hline bob & 0 & 0 & 0 & 0 & 0.9 & 0 & 0 & 0 \\
\hline
\end{tabular}

Tabela A.5: Representação da coleção no modelo de espaço vetorial 


\section{A.4.2 Similaridade de cosseno}

Medir a similaridade entre dois documentos pode ser útil, por exemplo, para disponibilizar o recurso "mais do mesmo", onde o usuário pede indicações de itens semelhantes a um que ele já conhece. Porém, se a diferença entre os vetores de pesos de dois documentos for usada como medida para avaliação de similaridade entre os mesmos, pode acontecer de documentos com conteúdo similar serem considerados diferentes simplesmente porque um é muito maior que o outro. Para compensar o efeito do comprimento dos documentos utiliza-se como medida de similaridade o cosseno do ângulo entre os vetores que os representam $(\theta)$, apresentada na equação A.14. O numerador representa o produto escalar dos dois vetores e o denominador a distância euclidiana entre os mesmos.

$$
\operatorname{sim}\left(d_{1}, d_{2}\right)=\cos (\theta)=\frac{V\left(\vec{d}_{1}\right) \cdot V\left(\vec{d}_{2}\right)}{\left|V\left(\vec{d}_{1}\right)\right|\left|V\left(\vec{d}_{2}\right)\right|}
$$

Dado um documento $d$, para encontrar os documentos de uma coleção que mais se assemelham a esse, basta encontrar aqueles com maior similaridade de cosseno com $d$. Para tanto, pode-se calcular os valores $\operatorname{sim}\left(d, d_{i}\right)$ entre $d$ e os demais $d_{i}$ documentos da coleção e os maiores valores indicarão os documentos mais semelhantes.

Considerando o fato de que queries, assim como documentos, são um conjunto de palavras, elas também podem ser representadas como vetores no modelo de espaço vetorial. A tabela A.6 apresenta as consultas $q_{1}, q_{2}$ e $q_{3}$ neste espaço. Logo, a similaridade de cosseno também pode ser utilizada em buscas, considerando que os documentos mais similares a determinada query são os mais relevantes para a mesma (equação A.15).

$$
R_{d, q}=\operatorname{sim}(d, q)
$$

\begin{tabular}{|l|c|c|c|}
\hline \multicolumn{4}{|c|}{$t f_{-} i d f_{\boldsymbol{t}, \boldsymbol{d}}$} \\
\hline Termo Query & $\boldsymbol{q}_{\mathbf{1}}$ & $\boldsymbol{q}_{\mathbf{2}}$ & $\boldsymbol{q}_{\mathbf{3}}$ \\
\hline moren & 0.12 & 0.12 & 0.12 \\
\hline roup & 0 & 0 & 0 \\
\hline don & 0 & 0 & 0.6 \\
\hline crav & 0 & 0 & 0 \\
\hline canel & 0 & 0 & 0 \\
\hline olh & 0 & 0 & 0 \\
\hline ros & 0 & 0 & 0.42 \\
\hline bob & 0 & 0.9 & 0 \\
\hline
\end{tabular}

Tabela A.6: Representação das queries no modelo de espaço vetorial

\section{A.5 Okapi BM25}

Okapi BM25 é o modelo probabilístico considerado estado da arte em recuperação da informação [Pérez-Iglesias et al. 2009]. É amplamente utilizado no desenvolvimento de ferramentas de busca para os mais diversos domínios de aplicação. Tornou-se bastante popular em virtude de seu destaque nas avaliações do TREC ${ }^{2}$, sendo apontado como o melhor entre os esquemas de peso probabilísticos conhecidos [Betts 2007]. A título de ilustração, Xapian $^{3}$ e Lucene ${ }^{4}$, bibliotecas livres para construção de motores de busca, são projetos de

\footnotetext{
${ }^{2} \mathrm{O}$ Text Retrieval Conference (TREC) é uma conferência anual realizada pelo U.S. National Institute of Standards and Technology (NIST) que promove uma ampla competição em recuperação da informação de grandes coleções de texto com o intuito de incentivar pesquisas na área.

${ }^{3}$ http://xapian.org/

${ }^{4}$ http://lucene.apache.org/
} 
grande destaque na comunidade que utilizam o BM25 como medida de pesos. O nome Okapi advém do primeiro sistema no qual foi implementado, denominado City Okapi, enquanto BM se refere à família de esquemas Best Match.

Embora seja comumente apresentado num contexto de busca em texto, o esquema não é específico para este domínio e pode ser usado na estimativa de relevância para qualquer tipo de recuperação de informação. A realização de consultas depende da descrição de itens e necessidades dos usuários, no entanto o modelo em princípio é compatível com inúmeras possibilidades de unidades descritivas [Jones et al. 2000]. Todavia, formalmente o modelo se refere a descrições de documentos como $D$ e de consultas como $Q$, ambas podendo ser decompostas em unidades menores. Cada componente é um atributo $A_{i}$, que pode assumir valores do domínio \{presente, ausente\} ou valores inteiros não negativos, representando o número de ocorrências do termo no documento ou na query.

A busca no modelo probabilístico fundamenta-se no Princípio de Ordenação por Probabilidade, segundo o qual a maior eficácia de uma consulta num conjunto de dados é obtida quando os documentos recuperados são ordenados de maneira decrescente pela probabilidade de relevância em tal base de dados. [Robertson 1977]. No entanto, o ponto chave do Princípio é que a probabilidade de relevância não é o fim em si mesma, mas um meio de ordenar os documentos para apresentação ao usuário. Portanto, qualquer transformação dessa probabilidade pode ser usada, desde que preserve a ordenação pela relevância [Jones et al. 2000].

\section{A.5.1 Modelo formal}

Dado um documento descrito por $D$ e uma query $Q$, o modelo considera a ocorrência de dois eventos: $L=\{D$ é relevante para $Q\}$ e $\bar{L}=\{D$ não é relevante para $Q\}$. Para que a ordenação por relevância seja possível, calcula-se para cada documento a probabilidade $P(L \mid D)$. A aplicação do teorema de Bayes permite que $P(L \mid D)$ seja expressa em função de $P(D \mid L)$ (equação A.16).

$$
P(L \mid D)=\frac{P(D \mid L) P(L)}{P(D)}
$$

Para evitar a expansão de $P(D)$, a chance de $(L \mid D)$ é utilizada em vez da probabilidade. Na verdade, o logaritmo da chance é aplicado (equação A.17), considerando que esta é uma transformação que satisfaz o Princípio de Ordenação [Jones et al. 2000]. Ademais, dado que o último termo da fórmula é igual para todos os documentos, ele pode ser desconsiderado sem que isso altere a ordenação dos documentos. Desta forma, a equação A.18 descreve uma pontuação por relevância referenciada como primária $\left(R-P R I M_{D}\right)$.

$$
\begin{aligned}
\log \frac{P(L \mid D)}{P(\bar{L} \mid D)} & =\log \frac{P(D \mid L) P(L)}{P(D \mid \bar{L}) P(\bar{L})} \\
& =\log \frac{P(D \mid L)}{P(D \mid \bar{L})}+\log \frac{P(L)}{P(\bar{L})} \\
\text { R-PRIM } & =\log \frac{P(D \mid L)}{P(D \mid \bar{L})}
\end{aligned}
$$

Assim como o modelo de classificação Bayes ingênuo, o BM25 assume que os atributos dos documentos são estatisticamente independentes de todos os outros. [Jones et al. 2000] justifica a suposição de independência de atributos pelos seguintes argumentos:

1. Facilita o desenvolvimento formal e expressão do modelo;

2. Torna a instanciação do modelo tratável computacionalmente; 
3. Ainda assim permite estratégias de indexação e busca com melhor performance do que estratégias rudimentares, como o simples casamento de padrões aplicados a termos da query no documento.

De acordo com a suposição de independência, a probabilidade de um documento pode ser trivialmente derivada a partir das probabilidades de seus atributos. Logo, $R$ - $P R I M_{D}$ poderia ser estimado como um somatório de probabilidades, cada uma relacionada a cada atributo da descrição $D$ (equação A.19).

$$
\begin{aligned}
R-P R I M_{D} & =\log \prod_{i} \frac{P\left(A_{i}=a_{i} \mid L\right)}{P\left(A_{1}=a_{1} \mid \bar{L}\right)} \\
& =\sum_{i} \log \frac{P\left(A_{i}=a_{i} \mid L\right)}{P\left(A_{1}=a_{1} \mid \bar{L}\right)}
\end{aligned}
$$

No entanto, a fórmula A.19 pressupõe a consideração de um componente para cada valor do atributo, por exemplo, para presença de um termo assim como para sua ausência. Uma alternativa mais natural seria considerar apenas valores para a presença, contabilizando a ausência como um zero natural. Desta forma, é subtraído da pontuação de cada documento o componente relativo a cada valor de atributo zerado (fórmula A.20).

$$
\begin{aligned}
R-B A S I C_{D} & =R-P R I M_{D}-\sum_{i} \log \frac{P\left(A_{i}=0 \mid L\right)}{P\left(A_{1}=0 \mid \bar{L}\right)} \\
& =\sum_{i}\left(\log \frac{P\left(A_{i}=a_{i} \mid L\right)}{P\left(A_{1}=a_{1} \mid \bar{L}\right)}-\log \frac{P\left(A_{i}=0 \mid L\right)}{P\left(A_{1}=0 \mid \bar{L}\right)}\right) \\
& =\sum_{i} \log \frac{P\left(A_{i}=a_{i} \mid L\right) P\left(A_{1}=0 \mid \bar{L}\right)}{P\left(A_{1}=a_{1} \mid \bar{L}\right) P\left(A_{i}=0 \mid L\right)}
\end{aligned}
$$

Considerando $W_{i}$ como um peso para cada termo $t_{i}$ do documento (equação A.21), $R-B A S I C_{D}$ pode ser então reescrito em função deste peso, como na equação A.22.

$$
\begin{aligned}
& W_{i}=\log \frac{P\left(A_{i}=a_{i} \mid L\right) P\left(A_{1}=0 \mid \bar{L}\right)}{P\left(A_{1}=a_{1} \mid \bar{L}\right) P\left(A_{i}=0 \mid L\right)} \\
& R-B A S I C_{D}=\sum_{i} W_{i}
\end{aligned}
$$

No caso em que os atributos $A_{i}$ restringem-se a exprimir a presença ou ausência do termo $t_{i}$ (atributos binários), pode-se dizer que $P\left(A_{1}=0 \mid L\right)=1-P\left(A_{i}=1 \mid L\right)$, o mesmo vale para $\bar{L}$. Portanto, considerando que $p_{i}=P\left(t_{i}\right.$ ocorre $\left.\mid L\right)$ e $\bar{p}_{i}=P\left(t_{i}\right.$ ocorre $\left.\mid \bar{L}\right)$, a fórmula A.21 pode ser usada como um peso para presença de termos. A pontuação de relevância para um documento seria então a soma dos pesos $w_{i}$ dos termos da query presentes no documento.

$$
w_{i}=\log \frac{p_{i}\left(1-\overline{p_{i}}\right)}{\overline{p_{i}}(1-p)}
$$

A seguir será apresentada a interpretação do modelo formal a partir de informações disponíveis sobre a coleção de documentos, com o intuito de definir funções de peso eficazes para a ordenação por relevância. 


\section{A.5.2 Incidência dos termos e atestação de relevância}

A incidência dos termos nos documentos da coleção é uma informação que pode ser facilmente coletada e pode ser utilizada como parâmetro no cálculo da probabilidade de relevância. $\mathrm{O}$ popular $i d f_{t}$ (equação A.10) é uma medida plausível e, apesar de ter sido proposta baseada apenas na frequência de incidência dos termos, também pode ser derivada da equação A.23 [Jones et al. 2000].

No entanto, apenas a incidência dos termos é uma base fraca para a estimativa de probabilidades de relevância. As estimativas podem ser refinadas com a consideração de dados acerca da real relevância ou irrelevância de documentos, obtidos por meio de mecanismos denominados atestação de relevância (relevance feedback). Ao receber o resultado de uma consulta, o usuário avalia a lista de itens retornados, indicando quais deles são de fato relevantes, para que uma nova consulta seja realizada.

A tabela de contingência da incidência dos termos é apresentada na tabela A.7. $N$ representa o número total de documentos da coleção, enquanto $n$ representa o número de documentos nos quais o termo $t$ da query ocorre. Analogamente, $R$ é a quantidade de documentos relevantes para a consulta e $r$ a quantidade de documentos relevantes nos quais o termo ocorre.

\begin{tabular}{|l|c|c|c|}
\hline & Relevante & Irrelevante & Incidência na coleção \\
\hline$t$ ocorre & $r$ & $n-r$ & $n$ \\
\hline$t$ não ocorre & $R-r$ & $N-n-R+r$ & $N-n$ \\
\hline total de documentos & $R$ & $N-R$ & $N$ \\
\hline
\end{tabular}

Tabela A.7: Tabela de contingência da incidência dos termos

Portanto, a probabilidade de um termo $t$ ocorrer num documento, dado que esse é relevante para a query, é $p=\frac{r}{R}$. Analogamente, dado que o documento não é relevante, $\bar{p}=\frac{n-r}{N-R}$. Sendo assim, a equação A.23 pode ser redefinida como a fórmula A.24, que exprime o logaritmo da razão de chances de um termo ocorrer em documentos relevantes e irrelevantes.

$$
w=\log \frac{r(N-n-R+r)}{(R-r)(n-r)}
$$

Por fim, o fator de correção 0.5 é acrescido a cada termo central da fórmula para evitar que o peso seja zerado quando algum destes termos for zero.

$$
R W_{t}=\log \frac{(r+0.5)(N-n-R+r+0.5)}{(R-r+0.5)(n-r+0.5)}
$$

Se não houver informações provenientes da atestação de relevância, o $i d f_{t}$ clássico pode ser utilizado (equação A.10), ou ainda, uma variação de $R W_{t}$ a partir do estabelecimento de que $R=r=0$ (equação A.26).

$$
R W_{t}=\log \frac{N-n+0.5}{n+0.5}
$$

\section{A.5.3 Distribuição dos termos nos documentos}

A incidência dos termos na coleção distingue os documentos com relação aos termos da query no que diz respeito apenas à ocorrência ou ausência dos mesmos. Usando apenas essa medida não é possível portanto diferenciar dois documentos em relação a um termo se o mesmo ocorre em ambos. No caso em que dados de frequência dos termos são providos nas descrições dos documentos, tal informação pode contribuir para a estimativa de relevância de um documento.

Assume-se que cada termo é associado a um conceito, ao qual um determinado documento pode estar relacionado ou não. Logo, para cada conceito existe um conjunto de documentos 
que dizem respeito a ele e outro conjunto que não (complementar ao primeiro). A frequência de um termo em um documento caracteriza sua ocorrência quantitativamente, porém, uma frequência maior que zero não significa que o documento esteja necessariamente relacionado com o conceito do termo. Diante da impossibilidade de se prever esta relação conceitual, considera-se a distribuição de frequências dos termos nos documentos como uma mistura de duas distribuições, uma para cada um dos conjuntos [Jones et al. 2000].

Essa distribuição pode ser entendida como originada num modelo de geração de texto: o autor se depara com as posições de palavras nos documentos e escolhe termos para ocupar tais posições. Se a probabilidade de escolha de cada termo for fixa e todos os documentos forem de igual comprimento, caracteriza-se uma distribuição de Poisson para frequências dos termos nos documentos. Assume-se probabilidades diferentes para o conjunto de documentos relacionados ao conceito do termo e para o conjunto dos que não são - esta é a razão para a mistura de duas distribuições [Jones et al. 2000].

A derivação deste componente do peso é mais extensa e por esta razão foi omitida neste texto. A fórmula resultante é complexa, no entanto [Robertson and Walker 1994] examina o comportamento da mesma e propõe uma aproximação que apresenta comportamento similar à original, expressa pela equação A.27.

$$
R D_{t, D}=\frac{t f_{t, D}\left(k_{1}+1\right)}{k_{1}+t f_{t, D}}
$$

A constante $k_{1}$ determina o quanto o peso do documento em relação ao termo deve ser afetado por um acréscimo no valor de $t f_{t, D}$. Se $k_{1}=0$, então $R D_{t, D}=1$, e $t f_{t, D}$ não interfere no peso final. Para valores altos de $k_{1}$, o peso passa a ter um crescimento linear com relação a $t f_{t, D}$. De acordo com experimentos do TREC, valores entre 1.2 e 2 são os mais indicados, visto que implicam numa interferência altamente não linear de $t f_{t, D}$, ou seja, após 3 ou 4 ocorrências o impacto de uma ocorrência adicional é mínimo [Jones et al. 2000].

No entanto, a modelagem por meio de distribuições de Poisson assume que todos os documentos têm mesmo comprimento, o que não acontece na prática. Porém, uma interpretação ligeiramente estendida do modelo permite a consideração de documentos com comprimentos distintos.

Os comprimentos dos documentos da coleção podem variar por inúmeros motivos. Todavia, nesta nova interpretação assume-se que quando dois documentos acerca do mesmo conceito têm tamanhos distintos, a razão é simplesmente que um é mais verboso que o outro. Em outras palavras, considera-se que a recorrência de palavras deve-se sempre à repetição em vez de, por exemplo, melhor elaboração do tema. Partindo desta suposição, é apropriado estender o modelo normalizando o valor de $t f_{t, D}$ em função do comprimento do documento (equação A.28).

$$
R D_{t, D}=\frac{\frac{t f_{t, D}}{N L}\left(k_{1}+1\right)}{k_{1}+\frac{t f_{t, D}}{N L}}=\frac{t f_{t, D}\left(k_{1}+1\right)}{k_{1} * N L+t f_{t, D}}
$$

Dado que o comprimento dos documentos pode ser medido de diversas formas (quantidade de palavras, caracteres e bytes, considerando ou não stop words), considera-se a medida uniformizada para normalização, obtida pela razão entre o comprimento dos documentos e o comprimento médio dos documentos $\left(\frac{l_{d}}{l_{\text {avg }}}\right)$. Ademais, uma normalização simples resultaria na mesma pontuação para um documento de comprimento $l$ no qual o termo ocorre $t f$ vezes e para outro de comprimento $2 l$ que contém $2 t f$ ocorrências do termo. Este comportamento pode ser indesejável por exemplo quando se considera que a recorrência de palavras está geralmente associada ao aprofundamento do conceito, em vez de mera repetição.

A fórmula proposta (A.29) permite que a normalização ocorra em diferentes graus, de acordo com o ajuste do parâmetro constante $b$ que assume valores no intervalo $[0,1]$. Se a configuração for $b=1$, a normalização tem efeito completo (equivalente ao esquema BM11). 
Valores menores reduzem esse efeito, e se $b=0$ o comprimento do documento não afeta a pontuação final, (como no modelo BM15).

$$
\begin{gathered}
N L=\left((1-b)+b \frac{l_{d}}{l_{\text {avg }}}\right) \\
R D_{t, D}=\frac{t f_{t, D}\left(k_{1}+1\right)}{k_{1}\left((1-b)+b \frac{l_{d}}{l_{\text {avg }}}\right)+t f_{t, D}}
\end{gathered}
$$

\section{A.5.4 Consultas longas}

Em situações onde as consultas podem ser descritas por queries longas, por exemplo, o caso em que um documento pode ser utilizado como base para a consulta, a consideração da frequência do termo na query pode ser mais um fator contribuinte para a estimativa de relevância. O componente $R Q_{t, Q}$ também é derivado a partir da modelagem em distribuições de Poisson, porém aplicadas ao conjunto de queries em vez do conjunto de documentos. $\mathrm{O}$ resultado é um peso semelhante ao $R D_{t, D}$, porém com parâmetros constantes próprios (equação A.31). Todavia, para o caso de queries com poucos termos, este componente do peso deve ser desconsiderado.

$$
R Q_{t, Q}=\frac{\left(k_{3}+1\right) q t f_{t, Q}}{k_{3}+q t f_{t, Q}}
$$

\section{A.5.5 Estimativa de relevância}

Finalmente, a relevância de um documento $D$ para uma consulta $Q$ pode ser obtida pelo somatório dos pesos dos termos da query com relação a $D$. O peso de cada termo é obtido pelo produto dos componentes apresentados anteriormente, como indica a equação A.32.

$$
R_{D, Q}=\sum_{t \in Q} R W_{t} \cdot R D_{t, D} \cdot R Q_{t, Q}
$$

\section{A.6 Apriori}

A mineração de Dados, também referenciada como descoberta de conhecimento em bases de dados, é a área da ciência da computação destinada à descoberta de correlações e padrões frequentes num conjunto de dados. Informações extraídas de uma base de dados de transações de venda, por exemplo, têm alto valor para organizações que pretendem realizar processos de marketing guiados por informação - modelo denominado análise de carrinho de compras (market basket analysis). Outros domínios de aplicação que também utilizam técnicas de mineração são: detecção de intrusão por meio da análise de logs de sistemas computacionais, pesquisas na área de saúde sobre a correlação entre doenças, sequenciamento de DNA etc [Hegland 2003].

Os padrões frequentes podem ser descritos por conjuntos de itens que ocorrem simultaneamente ou por implicações na forma $X \Rightarrow Y$, denominadas de regras de associação, sendo $X$ e $Y$ conjuntos de itens disjuntos $(X \cap Y=\emptyset)$. Suporte e confiança são duas métricas para quantificar a força dos padrões de acordo com a sua representatividade no banco de dados de transações. O suporte de um conjunto de itens é a frequência com a qual ele ocorre numa base de dados. Para uma regra de associação $X \Rightarrow Y$, mede-se o suporte do conjunto de itens $X \cup Y$. A confiança de uma regra é medida pela frequência de $Y$ nos registros que contém $X$, representando o grau de co-ocorrência de $X$ e $Y$. 
O Apriori é um algoritmo clássico para mineração de regras de associação sustentadas por medidas mínimas de suporte e confiança numa base de dados. O problema computacional é comumente decomposto em dois sub-problemas:

(1) Identificação de todos os conjuntos de itens que extrapolam um valor de suporte mínimo na base de dados (denominados de conjuntos frequentes).

(2) Produção de regras de associação a partir dos conjuntos frequentes, selecionando apenas as que satisfazem à condição de confiança mínima. Visto que as regras são partições binárias de conjuntos de itens, uma solução trivial para esse problema pode ser a seguinte: para cada subconjunto $S$ de um conjunto frequente $F$, gerar a regra $S \Rightarrow F-S$ e testar seu valor de confiança.

O Apriori foi o primeiro algoritmo a tratar do sub-problema (1), que de fato é o mais desafiador, de forma mais eficiente. Uma solução ingênua para tal problema seria: listar todos os conjuntos candidatos (conjunto das partes do universo de itens) e selecionar os conjuntos frequentes a partir do cálculo de suporte para cada um. No entanto, esta é uma estratégia extremamente custosa visto que o conjunto das partes de um conjunto com $n$ elementos contém $2^{n}$ subconjuntos, inviabilizando o cálculo para domínios de aplicação com um universo de itens grande [Hegland 2003]. A Figura A.3 ilustra um diagrama de Hasse que representa o conjunto das partes do universo de itens $U=\{a, b, c\}$.

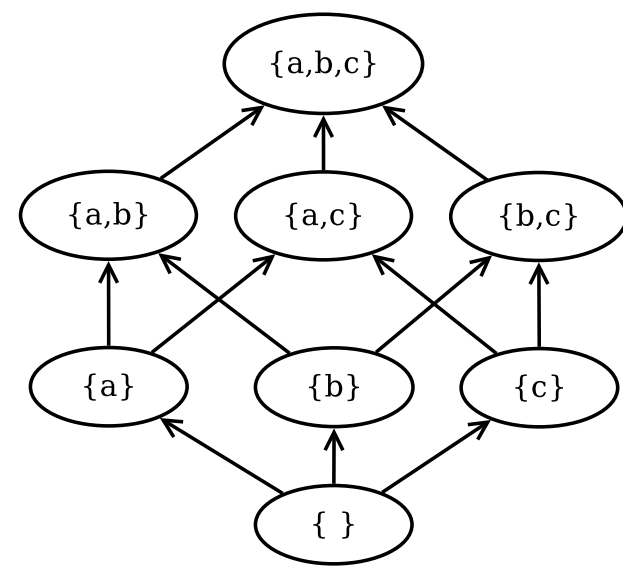

Figura A.3: Conjunto das partes ilustrado por um diagrama de Hasse

A inovação do Apriori sobre a abordagem ingênua é a redução da quantidade de conjuntos candidatos pelo descarte de certos conjuntos que comprovadamente não são conjuntos frequentes. Desta maneira o algoritmo consegue detectar todos os conjuntos frequentes sem a necessidade de calcular o suporte para todos os $2^{n}$ subconjuntos possíveis.

A descoberta de conjuntos frequentes acontece por níveis, como uma busca em largura no diagrama de Hasse começando pelos conjuntos unitários. Em vez de gerar os conjuntos candidatos a partir da base de dados, a cada nível da busca é feita uma combinação dos elementos para gerar os candidatos do nível seguinte. Nesse ponto a solução se beneficia do seguinte princípio: qualquer subconjunto de um conjunto frequente também é um conjunto frequente. Portanto, só devem participar da nova combinação os elementos que apresentarem um suporte superior ao limite, pois um conjunto que não é frequente não será jamais subconjunto de um conjunto frequente [Agrawal and Srikant 1994].

A Figura A.4 ilustra a descoberta dos conjuntos frequentes em contraposição com o conjunto das partes do conjunto $U=\{a, b, c, d, e\}$. Neste exemplo, os subconjuntos $\{e\},\{a, b\}$ e $\{b, d\}$ estão destacados por apresentarem suporte inferior ao limite. Consequentemente, todos os conjuntos dos quais estes são subconjuntos foram desconsiderados como conjuntos 
candidatos (nós com fundo cinza na Figura). Portanto, apenas os nós com fundo branco teriam o suporte calculado.

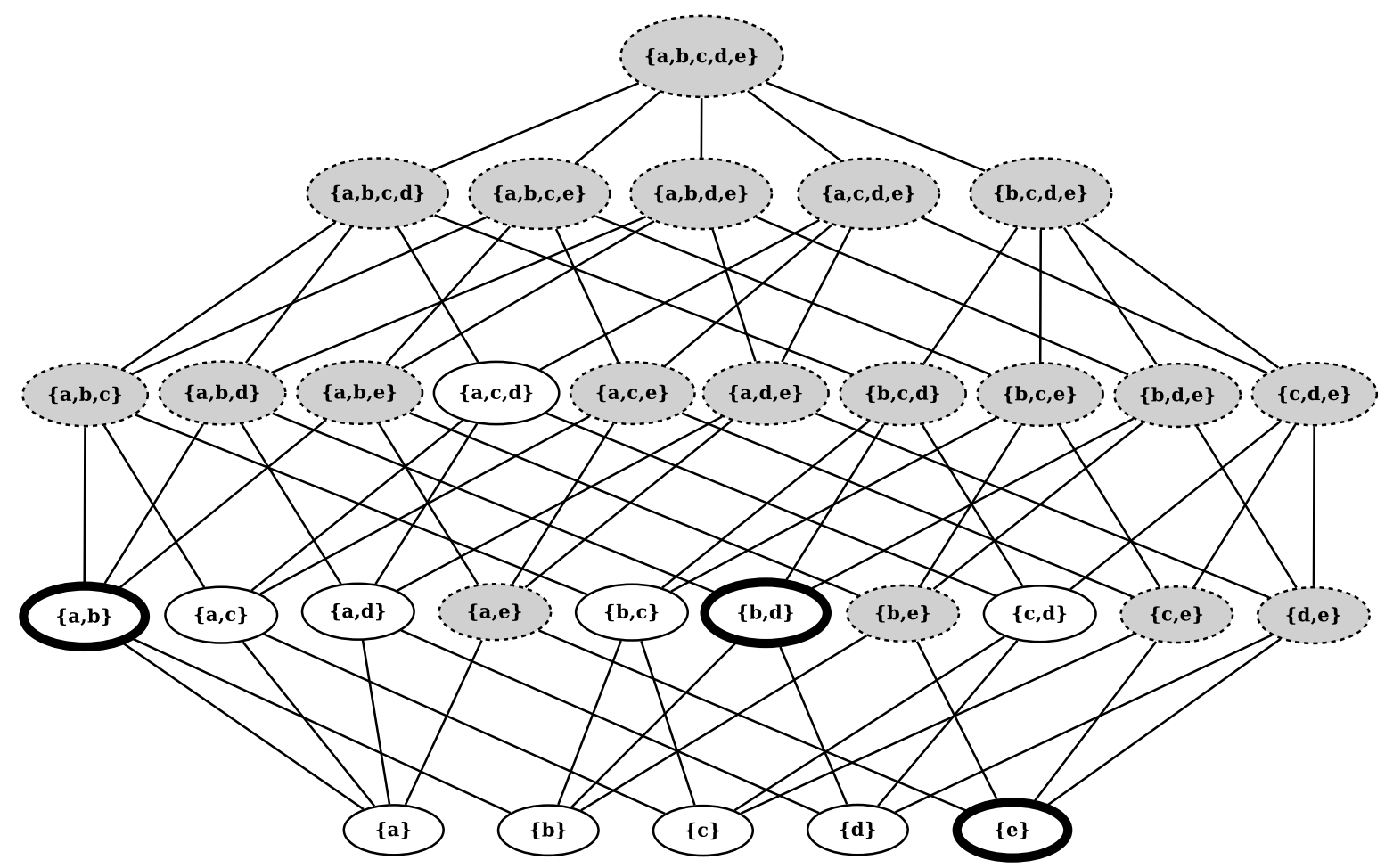

Figura A.4: Geração de conjuntos candidatos pelo algoritmo Apriori

A introdução do Apriori representou um marco para o desenvolvimento de soluções para mineração de dados, motivando o surgimento de inúmeras variantes baseadas no mesmo princípio. Entre elas, surgiram algumas propostas específicas para situações onde os dados têm características adicionais conhecidas como, por exemplo, base de dados particionada, dados que satisfazem a determinadas restrições ou que fazem parte de uma taxonomia conhecida [Hegland 2003].

Apesar de apresentar um processo inovador para geração de regras de associação, o Apriori também apresenta fraquezas, sendo a principal delas a necessidade de percorrer a base de dados múltiplas vezes para cálculo de suporte e confiança dos conjuntos de itens. Algumas soluções alternativas fazem uso de estruturas de dados auxiliares para armazenar informações extraídas da base de dados numa única passagem, evitando assim repetidos acessos à mesma. Árvores de prefixos, árvores lexicográficas e matrizes binárias são algumas dessas estruturas [Kotsiantis and Kanellopoulos 2006]. 



\section{Índice Remissivo}

Advanced Packaging Tool (APT), 9, 40

Agrupamento, 72

Amazon, 19

Anapop, 27

AppCenter, 9

AppRecommender, 31

Avaliação

consulta pública, 59

experimentos offline, 49

métricas, 50, 57, 61

resultados, 52, 57, 62

código-fonte, acesso ao, 45, 46

codificação, 46

desenvolvimento, 38

estratégias de recomendação, 43

exemplo de uso, 45

funcionamento básico, 2

motivação, 2

parâmetros de entrada, 46

perfis demográficos, 41

privacidade, 43

protótipo, 45

trabalhos correlatos, 27

AppStream, 28, 41

Apriori, 19, 34, 39, 83-85

Apt-xapian-index, 34

Atestação de relevância, 81

Bayes ingênuo, 72, 79

Bernoulli, modelo de, 73

Multinomial, modelo, 73

BM11, 82

BM15, 82

BM25, 78, 79

Busca

espaço vetorial, modelo de, 77

inverse document frequency, 76

Okapi BM25, 78

stemming e lematização, 74 stop words, 74

term frequency, 74

sub-linear, 77

tf_idf, medida, 74

Canonical, 28

CentOS, 32

Classificador bayesiano, 72

Clustering, 72

Cross-distribution Meeting on Application Installer, 28

Curva ROC, 56

Debian

Advanced Packaging Tool (APT), 9, 40

apt-xapian-index, 34

Bug Tracking System (BTS), 37

DebConf, 27, 28, 33

Debian Data Export (DDE), 36, 39

Debian Developer (DD), 7

Debian Maintainer (DM), 7

Debtags, 32, 33, 40

dependências e conflitos entre pacotes, 9

estrutura de um pacote, 6

gerenciadores de pacotes, 8

manutenção de pacotes, 6,7

Missing in Action (MIA), 35

números do projeto, 32

Popularity Contest (Popcon), 29, 32, 35

relação entre pacotes, 7,8

screenshots.debian.net, 37, 39

sistema de empacotamento, 6

Ultimate Debian Database (UDD), 36, 39

Debommender, 27

F score, medida, 23

FreeDesktop.org, 29 
Github, 45, 46

GNU, projeto, 5

GNU/Linux, distribuições, 5

Hasse, diagrama de, 84

Internet Movie Database (IMDb), 16

k-Means, 72

k-Medoids, 39, 72

k-Nearest Neighbors (k-NN), 17, 71

vizinhança, 71

Linux, kernel, 5

Lucene, 78

Market basket analysis, 83

Mineração de dados, 28

Netflix, 13

Open Collaboration Service (OCS), 28

Open Source Initiave, 1

Poisson, distribuição de, 82

Popcon, 32, 35, 38, 41, 43

Popsuggest, 27

Python, 46

Receiver Operating Characteristic (ROC), 23,56

Relevance feedback, 81

Similaridade de cosseno, 78

Sistemas de recomendação

Avaliação, 21

métricas, 22

validação cruzada, 25, 49

desafios, 14

Estratégias, 16

baseadas em conhecimento, 18

baseadas em conteúdo, 17

baseadas em dados demográficos, 19

colaborativa, 17

híbridas, 19

reputação, 16

histórico, 13

segurança da informação, 26

técnicas, 20

Software Center, 9, 28

SourceForge, 1

Synaptic, 9

Text Retrieval Conference (TREC), 78

Trip Advisor, 16
Ubuntu, 28, 32

Ratings and Reviews Server, 29

Xapian, 34, 39, 78 